Florida International University FIU Digital Commons

7-7-2011

\title{
Understanding China's Climate Change Mitigation Policy Development: Structures, Processes and Outcomes
}

Liguang Liu

Florida International University, 1liu003@fiu.edu

DOI: $10.25148 /$ etd.FI1 1072516

Follow this and additional works at: https://digitalcommons.fiu.edu/etd

\section{Recommended Citation}

Liu, Liguang, "Understanding China’s Climate Change Mitigation Policy Development: Structures, Processes and Outcomes" (2011). FIU Electronic Theses and Dissertations. 429.

https://digitalcommons.fiu.edu/etd/429 


\title{
FLORIDA INTERNATIONAL UNIVERSITY
}

Miami, Florida

\section{UNDERSTANDING CHINA'S CLIMATE CHANGE MITIGATION POLICY DEVELOPMENT: STUCTURES, PROCESSES AND OUTCOMES}

\author{
A dissertation submitted in partial fulfillment of the \\ requirements for the degree of \\ DOCTOR OF PHILOSOPHY \\ in \\ PUBLIC AFFAIRS \\ by \\ Liguang Liu
}

2011 
To: Dean Kenneth Furton

College of Arts and Sciences

This dissertation, written by Liguang Liu, and entitled Understanding China's Climate Change Mitigation Policy Development: Structures, Processes and Outcomes, having been approved in respect to style and intellectual content, is referred to you for judgment.

We have read this dissertation and recommend that it be approved.

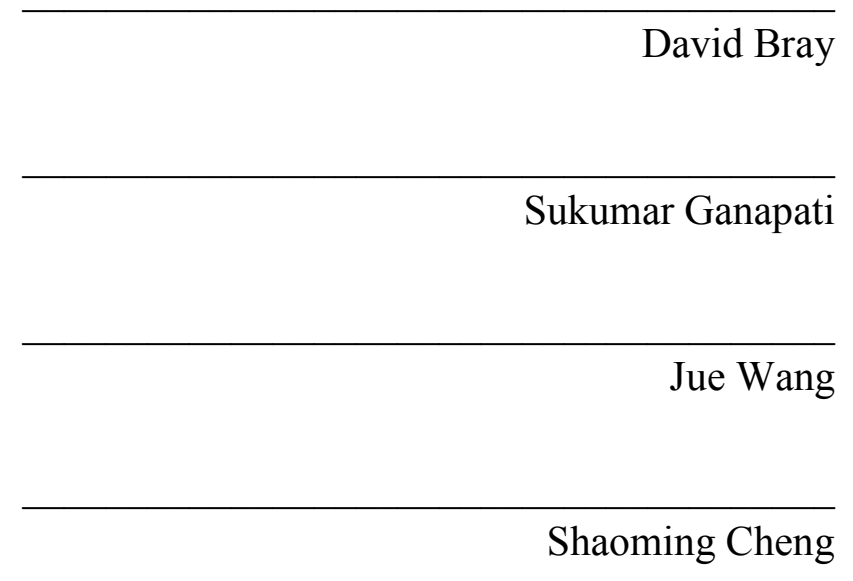

Allan Rosenbaum, Major Professor

Date of Defense: July 7, 2011

The dissertation of Liguang Liu is approved.

$\begin{array}{r}\begin{array}{r}\text { Dean Kenneth Furton } \\ \text { College of Arts and Sciences }\end{array} \\ \hline \begin{array}{r}\text { Dean Lakshmi N. Reddi } \\ \text { University Graduate School }\end{array}\end{array}$

Florida International University, 2011 
C Copyright 2011 by Liguang Liu All rights reserved. 


\section{DEDICATION}

I dedicate this dissertation to my wife, my daughter and my parents. Without

their patience, support, dedication, and most of all love, the completion of this dissertation would not have been possible. 


\section{ACKNOWLEDGMENTS}

I am indebted to a number of people who have played critical roles in bringing this project to fruition. My deepest gratitude goes to my major professor Dr. Allan Rosenbaum for his persistent support, encouragement and guidance during my doctoral studies and for his patience and advice throughout the writing of this dissertation. I am also grateful to other committee members Dr. Sukumar Ganapati, Dr. Jue Wang, Dr. Shaoming Cheng, and Dr. David Bray for their valuable comments, which have greatly helped me refine my thoughts and arguments.

I would also like to express my gratitude to my former colleagues and interviewees during my trip to China in the winter of 2009. They provided helpful information and comments which helped me improve my work and test preliminary findings. Furthermore, since the study allows me to present three separate cases in a number of international conferences and submit to journals for publication, I have received a large amount of helpful comments and suggestions. I would like to thank these panel participants, reviewers and editors. While the list of those to thank is too numerous to include here, some names should be noted. They are Wu Jisheng, Zhu Yong, Cao Zhanying, Zhang Baozhi, Liu Yong, Qin Dahe, Wang Wuyi, Amanda Shum, Fu Qiang, David Creedy, Jiang Daichang, Song Zheng, Yang Hongwei, David Davis, Amir Bashir Bazaz, Jeffrey Broadbent, Lorraine Elliott, Zhong Ma, Ruben Zondervan, Wanxin Li, Xin Tian, David Tyfield, and many others.

A special note of appreciation is given to the University Graduate School of Florida International University, which generously supported my dissertation work through Doctoral Evidence Acquisition (DEA) Fellowship and Doctoral Dissertation 
Year (DY) Fellowship. Also, I would like to thank the Department Chair, Dr. Meredith Newman, and many doctoral students at the Department of Public Administration for their encouragement and moral support.

Lastly, I own much to my family for their understanding and love over the years of my study. 


ABSTRACT OF THE DISSERTATION
UNDERSTANDING CHINA'S CLIMATE CHANGE MITIGATION POLICY
DEVELOPMENT: STRUCTURES, PROCESSES AND OUTCOMES
by
Liguang Liu

Florida International University, 2011

Miami, Florida

Professor Allan Rosenbaum, Major Professor

Climate change is one of the most important and urgent issues of our time. Since 2006, China has overtaken the United States as the world's largest greenhouse gas (GHG) emitter. China's role in an international climate change solution has gained increased attention. Although much literature has addressed the functioning, performance, and implications of existing climate change mitigation policies and actions in China, there is insufficient literature that illuminates how the national climate change mitigation policies have been formulated and shaped. This research utilizes the policy network approach to explore China's climate change mitigation policy making by examining how a variety of government, business, and civil society actors have formed networks to address environmental contexts and influence the policy outcomes and changes.

The study is qualitative in nature. Three cases are selected to illustrate structural and interactive features of the specific policy network settings in shaping different policy arrangements and influencing the outcomes in the Chinese context. The three cases include the regulatory evolution of China's climate change policy making; the country's involvement in the Clean Development Mechanism (CDM) activity, and China's 
exploration of voluntary agreement through adopting the Top-1000 Industrial Energy Conservation Program. The historical analysis of the policy process uses both primary data from interviews and fieldwork, and secondary data from relevant literature.

The study finds that the Chinese central government dominates domestic climate change policy making; however, expanded action networks that involve actors at all levels have emerged in correspondence to diverse climate mitigation policy arrangements. The improved openness and accessibility of climate change policy network have contributed to its proactive engagement in promoting mitigation outcomes.

In conclusion, the research suggests that the policy network approach provides a useful tool for studying China's climate change policy making process. The involvement of various types of state and non-state actors has shaped new relations and affected the policy outcomes and changes. In addition, through the cross-case analysis, the study challenges the "fragmented authoritarianism" model and argues that this once-influential model is not appropriate in explaining new development and changes of policy making processes in contemporary China. 


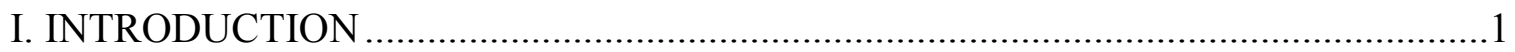

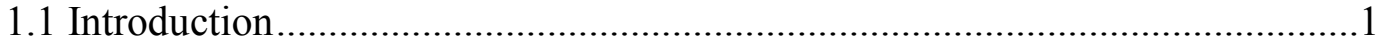

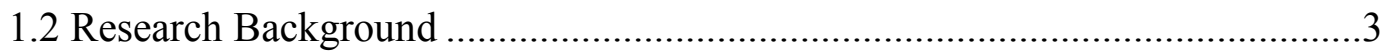

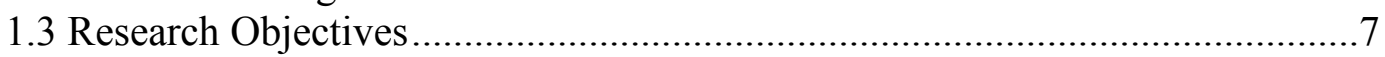

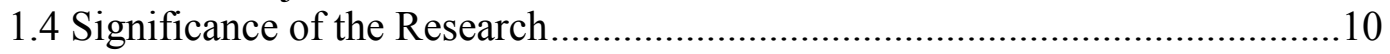

1.5 Overview of Methodology ......................................................................11

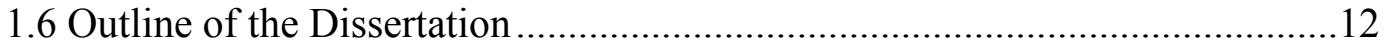

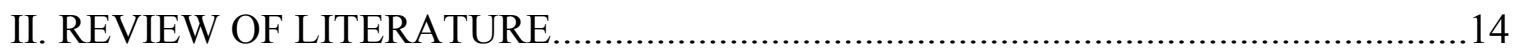

2.1 Theories of Public Policy Process.................................................................15

2.2 Research on China's Policy Process ............................................................21

2.3 Global Climate Change Governance and China's Response .............................29

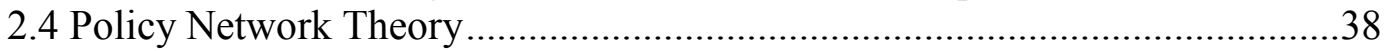

2.5 Policy Network as Analytic Framework ………….........................................42

2.6 Hypotheses of the Research ...................................................................49

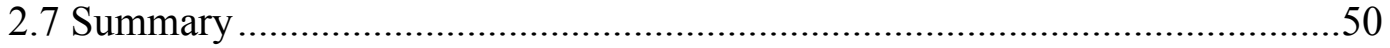

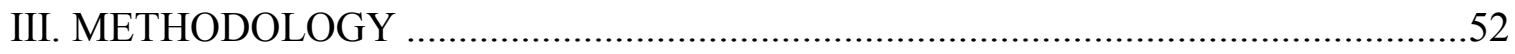

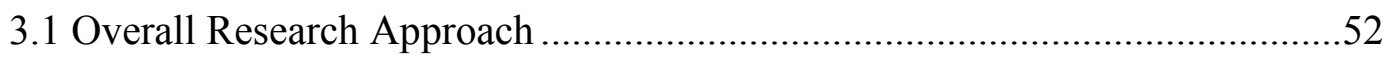

3.2 Case Study Approach...............................................................................54

3.3 Dimensions to Measure the Policy Network ……………..............................62

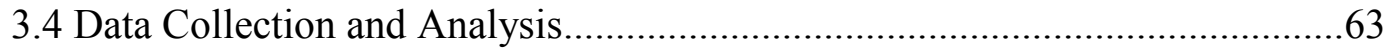

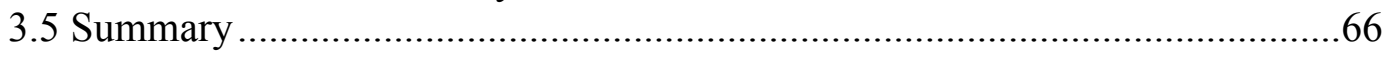

IV. HISTORICAL DEVELOPMENT OF CHINA'S CLIMATE CHANGE ACTION ...68

4.1 Formulating Climate Institutions, 1988- 1992 ……………………............68

4.2 Pre-Kyoto Preparations, 1992-1997 ...............................................................73

4.3 Piloting for the Kyoto Protocol, 1997-2005 ………......................................76

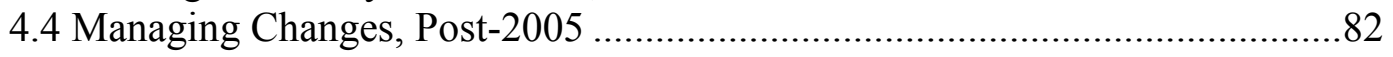

V. CASE 1: CHINA'S CLIMATE CHANGE MITIGATION INITIATIVE …………......88

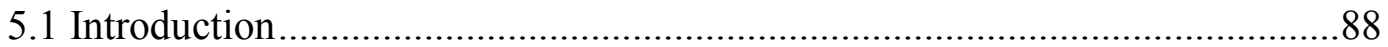

5.2 Network Actors, Structures, and Interactions …………..................................

5.3 Climate Change Policy Outcomes .............................................................100

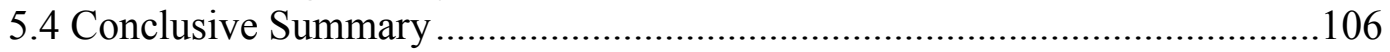




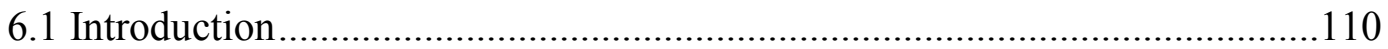

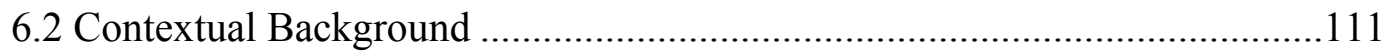

6.3 Developing CDM Institutions and Actor Network....................................117

6.4 CDM Project Development and Policy Adaptation....................................129

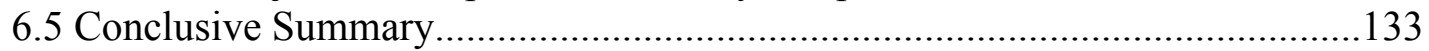

VII. CASE 3: TOP-1000 INDUSTIRAL ENERGY CONSERVATION PROGRAM...136

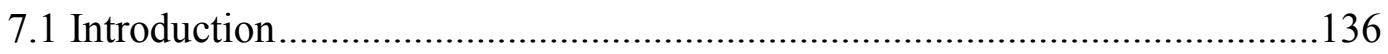

7.2 Contextual Background of the Program .....................................................137

7.3 Network Development of the Top-1000 Program ......................................143

7.4 Results of the Program..............................................................................151

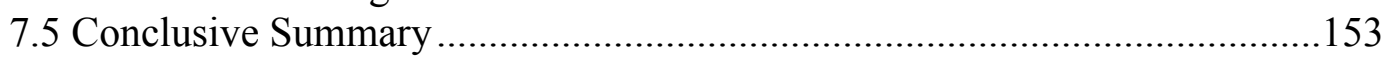

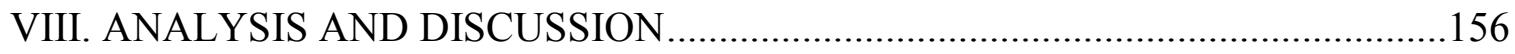

8.1 Hypothesis Testing through Within-case Analysis....................................156

8.2 Results of the Cross-case Analysis .............................................................158

8.3 Reflections on the Fragmented Authoritarianism Model..............................168

IX. CONCLUSIONS AND FUTURE RESEARCH .............................................. 174

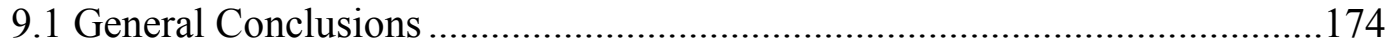

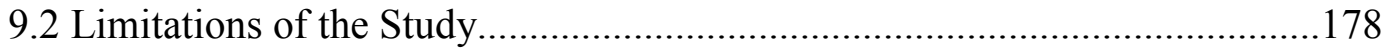

9.3 Suggestions for Future Research ..................................................... 180

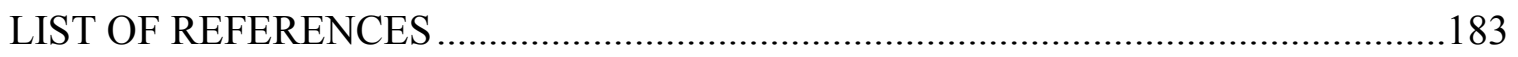

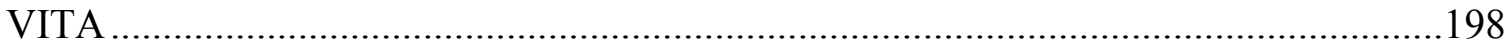




\section{LIST OF TABLES}

TABLE

PAGE

Table 2.1 Concern Issues, Research Questions and Hypotheses ................................ 50

Table 3.1 Main Features of the Three Identified Cases ............................................ 59

Table 5.1 Evolution of China's Climate Change Coordination Committee.................... 90

Table 5.2 Division within the Inter-ministerial Coordination Committee.................... 91

Table 5.3 Research Institutes Involved in China's Climate Change Discussion ............ 94

Table 5.4 Composition and Focused Issues of China's Climate Policy Network........... 98

Table 5.5 Major Climate Change Policies and Measures Adopted in China................ 102

Table 6.1 Major CDM Capacity Building Projects in China................................... 115

Table 6.2 Comparison of the CDM Measures of Two Versions ................................ 119

Table 6.3 Features of China's CDM Institutions ................................................. 121

Table 6.4 Supplementary CDM Policy Regulations in China ................................. 131

Table 7.1 The Growth Rates of Selected Energy-related Indicators (2000-2005) ....... 142

Table 7.2 Actors and Their Functions in the Top-1000 Program .............................. 147

Table 7.3 Follow-up Activities of the Top-1000 Program ..................................... 151

Table 7.4 Progress of the Top-1000 Program and the National Program.................... 152

Table 8.1 Empirical Support for the Hypotheses................................................ 157

Table 8.2 Key Factors in the Three Cases ..................................................... 160

Table 8.3 Levels of Actor Involvement in Climate Policy Making in Three Cases ..... 162

Table 8.4 Effectiveness of Policy Arrangements in Three Cases .............................. 165 


\section{LIST OF FIGURES}

FIGURE

PAGE

Figure 2.1 Policy Network Analytical Framework .............................................. 43

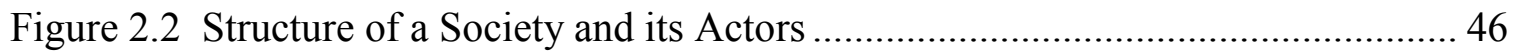

Figure 5.1 Growth of China's Carbon Dioxide Emissions....................................... 104

Figure 5.2 Annual Growth Rate Changes of GDP and Carbon Emissions in China.... 104

Figure 6.1 Processes and Parties Involved in a CDM Project ................................. 113

Figure 6.2 Flowchart of CDM Approval Procedures............................................... 126

Figure 7.1 Framework of Actors in China's Industrial Management ......................... 141

Figure 7.2 Framework of Actors in Shandong Pilot Voluntary Program ................... 144

Figure 7.3 Top-1000 Program Actor Network and its Extension............................... 149

Figure 8.1 New Relationships among Policy Actors that Deserve Research .............. 172 


\section{LIST OF ABBREVIATIONS AND ACRONYMS}

ADB

AIJ

AP 6

CAS

$\mathrm{CCP}$

CCX

CDM

CECA

CER

COD

COP

DOE

DNA

EB

EIA

ERI

ETS

EU

FCCC

FDI

GAQSIQ

GDP
Asian Development Bank

Activities Implemented Jointly

Asia-Pacific Partnership for Clean Development and Climate

Chinese Academy of Sciences

Chinese Communist Party

Chicago Climate Exchange

Clean Development Mechanism

China Energy Conservation Association

Certified Emission Reduction

Chemical Oxygen Demand

Conference of the Parties (to the UNFCCC)

Designated Operational Entity

Designated National Agency

Executive Board

Energy Information Administration

Energy Research Institute

(EU) Emission Trading Scheme

European Union

Framework Convention on Climate Change

Foreign Domestic Investment

General Administration of Quality Supervision, Inspection and Quarantine

Gross Domestic Product 


\begin{tabular}{|c|c|}
\hline GEF & Global Environmental Facility \\
\hline GHG & Greenhouse Gas \\
\hline GONGO & Government Organized Non-governmental Organization \\
\hline HCFC & Hydro-chlorofluorocarbon \\
\hline $\mathrm{HFC}$ & Hydro-fluorocarbon \\
\hline IEA & International Energy Agency \\
\hline IET & International Emission Trading \\
\hline $\mathrm{INC}$ & Intergovernmental Negotiating Committee \\
\hline IPCC & Intergovernmental Panel on Climate Change \\
\hline JI & Joint Implementation \\
\hline MEP & Ministry of Environmental Protection \\
\hline MOA & Ministry of Agriculture \\
\hline MOE & Ministry of Energy \\
\hline MOF & Ministry of Finance \\
\hline MOFA & Ministry of Foreign Affairs \\
\hline MOP & Meeting of the Parties (to the Kyoto Protocol) \\
\hline NBS & National Bureau of Statistics \\
\hline NCB & National CDM Board \\
\hline $\mathrm{NCCCC}$ & National Coordination Committee on Climate Change \\
\hline NCCCG & National Climate Change Coordination Group \\
\hline NCCLG & National Climate Change Leading Group \\
\hline NDRC & National Development and Reform Commission \\
\hline NECERLG & $\begin{array}{l}\text { National Energy Conservation and Emission Reduction Leading } \\
\text { Group }\end{array}$ \\
\hline NELG & National Energy Leading Group \\
\hline
\end{tabular}




\begin{tabular}{ll} 
NEPA & National Environmental Protection Agency \\
NGO & Non-government Organization \\
NPC & National People's Congress \\
PDCD & Organization for Economic and Cooperation and Development \\
PP & Project Design Document \\
RGGI & Project Proponent \\
SASAC & Regional Greenhouse Gas Initiative \\
SDPC & State-owned Assets Supervision ad Administration Commission \\
SEPA & State Development and Planning Commission \\
SETC & State Environmental Protection Administration \\
SMA & State Economic and Trade Commission \\
SPC & State Meteorological Administration \\
SSTC & State Planning Commission \\
TCE & State Science and Technology Commission \\
UNCED & Tons of Coal Equivalent \\
UNDP & UN Conference on Environment and Development \\
UNEP & United Nations Development Program \\
UNFCCC & United Nations Environmental Program \\
WMO & World Trade Organization \\
WTO & World Meteorological Organization \\
\hline
\end{tabular}




\section{CHAPTER I}

\section{INTRODUCTION}

\subsection{Introduction}

Climate change has risen to dominate environmental and development agendas. As a result of its rapid economic development and high dependency on carbon-intensive energy sources, China has surpassed the United States as the largest greenhouse gas (GHG) emitter in the world. Since China is still in the process of industrialization and urbanization, given the country's current technological capacity and energy supply mode, there is no indication that its GHG emissions will decrease in the near future. Consequently, China's role in a climate change solution has gained increased international attention.

The international community has established the United Nations Framework Convention on Climate Change (UNFCCC) and created the Kyoto Protocol during the 1990s to coordinate international actions and meet the long-term GHG emission reduction targets. As a developing country, China has no legally-binding commitments to reduce GHG emissions for the first commitment period of the Kyoto Protocol from 2008 to 2012. However, the country is facing more domestic and international pressures than ever before to address climate change issues. Domestically, China is vulnerable to climate change which will pose great negative impacts on China's development pattern (NDRC 2004; 2007), and the rapid domestic economic growth has been confronting serious environment and resource constraints. Internationally, China's commitment in 
mitigation has become more important because of its increased share in the world's GHG emissions and its growing economic influence around the world.

What lies behind the international climate change regime negotiation is the less eye-catching fact that China has made remarkable and continuous progress in combating climate change. The efforts include establishing and restructuring an inter-ministerial coordination committee, developing relevant climate change policies, and initiating mitigation and adaptation activities. Dozens of policies at the national level have been adopted to implement international climate change mitigation agreements, improve energy efficiency, diversify its energy sources and reduce polluting emissions. In the following, these policies are categorized as climate change mitigation policies. Examples of climate change mitigation policies at national level include China's National Climate Change Program developed in mid-2007 and a number of policy instruments, measures, and programs having been developed since 2004 (IEA 2010; Leggett et al. 2008). With the institutional development and policy implementation, a variety of state, business, and civil society actors have formed networks to develop stable relationships between actors and contribute to the mitigation of carbon emissions.

Whereas it remains a question what commitment China will accept in the future climate regime, the understanding of the working mechanism of how China has formulated and processed these current climate change mitigation policies can definitely provide some useful indications of what the future will bring. Employing the policy network approach, this study investigates the forces that drive China's climate change policy development and the impacts of the actor networks on the policy outcomes. 
This chapter introduces the background, research objectives, research significance, and the methods that have been adopted in the study. Section 1.2 provides background information about China's climate change policy development and action. This leads to a presentation of the objectives and significance of the research in sections of 1.3 and 1.4. Following a brief description of research methodology in Section 1.5, the structure of this dissertation is introduced in Section 1.6.

\subsection{Research Background}

Global climate change threatens the sustainability of human civilization, and remains one of the most important and urgent issues of our time. Internationally, the United Nations Framework Convention on Climate Change (UNFCCC) was established in 1992 to form policy architecture to address the issue. In 1997, the Kyoto Protocol, initiated at the Third Conference of the Parties to the UNFCCC (COP 3), was signed to mandate developed countries to achieve quantified emission reduction targets during the first commitment period of 2008-2012. The Protocol also allows for three market-based mechanisms, in which industrialized countries can cooperate with other counterparts, including developing countries, to trade surplus emission reduction credits and achieve their commitment targets with lower costs. These three flexibility mechanisms include the International Emission Trading (IET), the Joint Implementation (JI), and the Clean Development Mechanism (CDM). Although currently there has been no quantified emission reduction commitment for developing countries, many developing countries have initiated policies and taken actions to mitigate their carbon emissions and adapt to future climate impacts. The international community is working intensely to negotiate a 
new climate change regime, which would be more comprehensive than the Kyoto Protocol and with stronger commitments for more countries.

Over the past three decades, China's market-oriented reform has brought remarkable economic growth. The rapid economic growth not only gives China a heavy burden to restructure its energy supply and protect the environment, but also exerts an increasing share of responsibility in mitigating greenhouse gas (GHG) emissions. China's share in the global energy-related $\mathrm{CO}_{2}$ emissions increased from $10.6 \%$ in 1990 to $20.6 \%$ in 2006 (EIA 2009). Since 2006, China has overtaken the United States as the world's largest GHG emitter (EIA 2008; Heggelund 2007; Gallagher 2007) and it is estimated the growing trend will continue in the coming decades (Levine and Aden 2008). In addition, China has played a major and influential role in forming the developing countries' position in the international climate change negotiations (Bjørkum 2005).

China's political regime has also experienced significant changes with the economic reform. On the one hand, the policy making is still highly state-led, in which most issues are considered and discussed among elites within party and government organizations (Peng 2003; Brown 2010); on the other hand, there has been a progressive decline of the state control over economy, with powers devolved towards "groups, new or reformed institutions, households and perhaps even individuals" (Saich 2004, 223), and meanwhile lower levels of the state in general enjoy greater financial freedom from higher levels for decision-making within their jurisdictions. Over time, greater social mobility and interaction among these actors affect outcomes and changes of public policy development. With the transition from planned economy to market economy, the role of 
government in China has been experiencing continued transformations. How has the policy been shaped and evolved in China to address the climate change challenges?

In climate change policy discussions, "mitigation" and "adaptation" are two important terms. Mitigation is defined as "an anthropogenic intervention to reduce the sources or enhance the sinks of greenhouse gases" (IPCC TAR 2001). Examples include promoting the use of renewable energies, enhancing industrial energy efficiencies, and expanding forest to remove carbon dioxide from the atmosphere. Adaptation refers to the "adjustment in natural or human systems in response to actual or expected climatic stimuli or their effects, which moderates harm or exploits beneficial opportunities" (Op cit.). Adaptation aims at reducing vulnerability to climate change. Examples include defending against sea level rise, changing patterns of land use, and developing drought tolerant crop varieties. Mitigation tackles the causes of climate change, while adaptation deals with the effects of the phenomenon. Both have extensive economic, social and environmental implications. For many years, mitigation options have dominated the international climate policy discussions, but in recent years, adaptation has become an equally important topic. Although experts believe mitigation and adaptation strategies can and should be pursued simultaneously and in coordination, most of the current international cooperation and negotiations are oriented towards mitigation policy development and implementation. This study concentrates on the mitigation approach of China's climate change policy.

As a matter of fact, the importance of climate change mitigation action has been echoed by a series of climate-specific and climate-related policies endorsed and implemented by the Chinese central government (Gallagher 2008; NDRC 2007; 
Richerzhagen and Scholz 2008). Since 1996, under the umbrella of climate change mitigation policy, China has adopted 27 policies and measures to address climate change impacts, as shown by the International Energy Agency data (IEA 2010). These policies and measures are taken in various forms. Some are regulatory instruments promulgated by the State Council or its affiliated ministries; some are formulated and approved by the National People's Congress as laws. Furthermore, the voluntary agreement, which involves some agreements between government and industry to achieve environmental objectives beyond compliance to regulated obligations, has emerged as a pragmatic and flexible approach to encourage energy-saving and emission reduction actions in industrial sectors. A large amount of literature has dealt with the evaluation of these mitigation policies and tried to predict the policy trends; however, the conclusions and suggestions of these studies often differ significantly, mainly because there is no consensus regarding the country's mitigative capacity, and a realistic, agreed-upon baseline of carbon emissions China does not seem to exist. Simultaneously, China's arguments of its status as a developing country and its refusal to implement a quantified GHG emission reduction commitment in climate negotiations have intensified the concerns.

Given that the existing literature on China's climate change mitigation policy primarily focuses on the assessment of domestic mitigation policy performance and the analysis of policy potentials and prospects, there is a paucity of publications on how the existing mitigation policies have been formulated and developed, and why they are processed in such manners. This study will attempt to fill in this gap by analyzing China's climate change mitigation policy making process through case studies. Three 
representative cases are selected from the population of mitigation policies or programs that have been adopted by the Chinese central government and implemented nationwide.

Policy development can be convoluted process and frequently exists in a constantly changing and specific political environment. Within this process, a range of actors from government, business and civil society shape relations and organize their interactions toward achieving collective goals. The policy network approach captures such main features by conceptualizing policy making as a process through which a variety of independent and interdependent actors form networks to address the environmental context and determine the policy outcomes and change.

Given that an expanded network of actors has emerged in China's climate change policy process, this study employs the Adam and Kriesi's policy network framework (Adam and Kriesi, 2007) as an analytic toolbox to examine the country's climate change policy development and investigate the influences of actor networks to policy outcomes and change. Such an arrangement is consistent in logic with some most important literature that focuses on the roles of the structures and interactions of public and private actors in explaining Chinese economic and energy policy processes (Lieberthal and Oksenberg 1988; Saich 2004).

\subsection{Research Objectives}

The central research objectives of this study are to gain a better understanding

of the nature of the process of China's climate change mitigation policy making and implementation, and of the role and influence of the state and non-state actor networks 
involved in the process. To achieve these objectives, the answers to the following research questions are sought.

Q1. How do the policy networks influence the proactiveness of developing climate change mitigation policies in China?

Q2. How does the political reform influence the choices of innovative mitigation policy tools, such as market-based measures and voluntary agreements?

Q3. How are the non-state actors involved in China's climate change policy making process?

Q4. Under the rapidly changing international and domestic contexts, how does China arrange its institutions to organize and coordinate climate change mitigation actions?

On the basis of insights from the initial field study and the understanding of policy network theory, four hypotheses were suggested to predict the possible outcomes of the research questions.

Hypothesis 1: Increasing interaction between government, business, and civil society actors will increase the likelihood of China's taking a more proactive approach to develop climate change mitigation policy.

Hypothesis 2: More fragmentation in the distribution of regulative power will increase the likelihood of China's utilizing more innovative policy instruments and measures.

Hypothesis 3: Decreasing political control in policy development and implementation will encourage other actors, in particular non-state actors, to exert greater effort in shaping mitigation policy. 
Hypothesis 4: Increasing demand for shared responsibilities among ministries and provincial governments will increase the likelihood of stronger coordination by the central government.

Exploring dynamics of China's climate change mitigation policy development opens a window to a better understanding of the policy making process in contemporary China. Among many models that have been used to analyze the Chinese policy process, the fragmented authoritarianism model is the most influential and frequently referred one. The model, developed by Lieberthal and Oksenberg (1988) and through cases studies of China's energy policy development, argues that the Chinese political system, though no longer totalitarian, is still authoritarian; and the authority has been fragmented both horizontally and vertically to the lower-level administrative units, making the policy process "disjointed, protracted and incremental" (Lieberthal and Oksenberg 1988; Lieberthal 1992). The fragmented authoritarian model is taken as the most influential model through which to understand Chinese politics and policy process; however, recent studies show that the fragmented authoritarianism model cannot well explain the fundamental changes in Chinese policy development that has happened over the past decade (Lema and Ruby 2007; Wang 2006; Yu 2008; Mertha 2008). Does the generic fragmented authoritarianism model still capture the main features of China's climate change mitigation policy development? By generalizing empirical findings from the three cases of different climate change mitigation policy arrangements and through a historical and institutional tracing of some large scale shifts in China's climate change mitigation policy development, this study also tests the validity of the fragmented authoritarianism 
model in contemporary China and, through the use of the policy network approach, provides an improved understanding of the policy making process in contemporary China.

\subsection{Significance of the Research}

The study has much academic and practical significance. First, this study will improve our understanding of China's climate change policy making process under its unique political and institutional circumstances. Due to lack of study on the domestic climate policy process issues, debates and disputes have not been mitigated with regard to the evaluation of Chinese climate change policy performance. The study on China's policy making process will provide useful insights for domestic policy innovation and international climate regime negotiations.

Second, although the policy network approach has become one of promising theoretical frameworks to simplify the complexity of the policy process, much remains to be done to enhance its explanatory power and move from a general, relatively simple framework to a denser, more logically interconnected framework or theory (Borzel 1998; Sabatier 2007b). This study will contribute to the development of the approach by generating a set of logically interrelated propositions and empirically testing the validity of these propositions.

Third, the study will provide an empirical application of the policy network approach in the Chinese context. The applications of the policy network theory and approach have largely been limited to the liberal democracies for which it was originally

developed. However, the exploration of applying this approach to study Chinese policy 
process has begun, as shown in the journal papers by Li et al. (2003) and Zheng et al. (2010). This study will continue the discussion on the usefulness of such application.

Last but not least, with the transition towards market-based economy and the rise to the position of a major economy on the global stage, the political system and governance in China are under continuous changes. The study will promote theoretical discussions and gain a better understanding of dynamics of policy making process in contemporary China, thus providing useful indications of future policy trends.

\subsection{Overview of Methodology}

The study is qualitative and inductive in nature. The historical development of China's climate change mitigation policy and action will be analyzed, as well as its relevance with policy outcomes. The case study approach is used to illuminate structural and interactive features of the specific policy network settings in shaping different policy arrangements and influencing the outcomes in the Chinese context. Three cases, from the pool of adopted climate mitigation policies, are selected to interpret the features of the policy processes. The three cases include the development of China's national climate change strategy; China's involvement in the Clean Development Mechanism (CDM) regime; and the initiation of a voluntary industrial efficiency program, i.e., the Top-1000 Industrial Energy Conservation Program.

The policy network analytical framework is adopted to guide the empirical data collection and analysis, and the subsequent interpretation. Informative data are gained from literature, interviews and field study. The detailed description of research design and methods will be provided in Chapter 3 . 


\subsection{Outline of the Dissertation}

This research consists of nine chapters. Following this introductory chapter, Chapter 2 reviews the literature on global climate change politics, China's political regime and policy process, policy process theories, in particular the policy network approach to be employed in the study. Chapter 3 describes the design of the research and methodologies used for data collection, measurement and analysis. Three cases, including one generic case and two nested cases about specific mitigation policy arrangements have been selected to address the research questions and to test the relevant hypotheses. The data come from governmental documents, scholarly journals and books, site visits, observations, and interviews. The fieldwork and some related interviews were taken in two Chinese cities of Beijing and Shenyang from November 2009 to February 2010.

Chapter 4 provides a historical overview of China's climate change mitigation policy development. It provides a timeline for the first generic case and sets a boarder context for the other two nested cases. Chapters 5 to 7 contain the findings from the three cases. The first case in Chapter 5 focuses on the regulatory evolution and network development in China's climate change mitigation policy making. The time period ranges from 1988 to the present and will be divided into four phases. The second case in Chapter 6 focuses on China's involvement in the Clean Development Mechanism (CDM) regime, a market scheme under the Kyoto Protocol that allows China to initiate carbon reduction projects and trade certified credits in the global carbon market. The formal rule for initiating the scheme in China was issued in June 2004 and revised in October 2005. Chapter 7 presents the third case, which highlights China's initiation of a voluntary public-private agreement: the Top-1000 Industrial Energy Conservation Program. The 
program, modeled on international sectoral target-setting programs, is a voluntary, mitigation-related program implemented since March 2006. The industries included in the program are large-scaled enterprises from nine energy-intensive sectors. The program requires provincial governments to sign contracts with local enterprises and oversee the enterprises to reach the energy efficiency goals. Chapters 5 to 7 describe the formation and implementation of mitigation policies in the areas of concern, and examine the interrelations between policy environmental context, actor networks and policy outcomes and changes. The three cases are framed by the policy network approach introduced in Chapter 2.

Chapters 8 and 9 analyze the results and present the conclusions. Chapter 8 draws together findings of the review studies and the three case studies to verify the raised hypotheses and examine the appropriateness of the fragmented authoritarianism model in depicting China's policy process. The final chapter, Chapter 9, lists the overall conclusions, the limitations of the research, and the recommendations for future research. 


\section{CHAPTER II}

\section{REVIEW OF LITERATURE}

This literature review covers the topics of public policy process, global climate change governance, China's political regime change, and relevant theories of the policy network approach. It is divided into two main parts. Sections 2.1 to 2.3 constitute the first part. Section 2.1 presents selected research on the policy process and the relevant theories. It also explains when the policy network approach is taken in this study to guide the investigation. Section 2.2 focuses on the literature of China's policy process and political regime change because of reforms it has experienced, as well as reviews of the fragmented authoritarianism model. Section 2.3 addresses the topic of climate change regime and governance, highlighting the impacts of international climate change governance and China's efforts in taking climate change mitigation actions.

The second part reviews literature related to policy network concept and theory. Section 2.4 reviews literature of policy network theory, as well as the progress on enhancing its explanatory functions. Subsequently, an explanatory framework built on discussions of policy network is developed in Section 2.5. Building connections between contextual factors, policy networks and policy outcomes, this framework will be applied to guide the empirical study and interpret the related results. Next, in Section 2.6, several hypotheses are suggested and will be tested through case studies. Finally, Section 2.7 summarizes the chapter. 


\subsection{Theories of Public Policy Process}

\subsubsection{Public Policy and Policy Process}

There are various definitions of "public policy". The term always refers to "the actions of government and the intentions that determine those actions" (Cochran et al. $1999,1)$. Thomas Dye $(2005,1)$ defines public policy as "whatever the government chooses to do or not to do" and policy analysis is to describe and explain causes and consequences of government activity (Op. cit., 4). Cochran et al. (1999, 1-2) characterize public policy as "an intentional course of action followed by a government institution or official for resolving an issue of public concern." It consists of "political decisions for implementing programs to achieve societal goals" (Cochran and Malone 1995, 1). Peters $(1999,4)$ adds that public policy is the "sum of government activities, whether acting directly or through agents, as it has an influence on the life of citizens." Seeking to emphasize the dynamic, interdependent relationship between government and citizens, Gerston $(2004,7)$ defines public policy as "the combination of basic decisions, commitments, and actions made by those who hold or affect government positions of authority." Although there is no consensus on the precise definition of public policy, all the variants of definition imply that public policy is the output of the government and firmly grounded in politics. Birkland (2001) suggests in studying policy issues, the researchers should "look at the broader sweep of politics, not simply the written laws and rules themselves."

Policy process is "the process through which the policy is formed" (Gupta 2001). It has a "perpetual, dynamic, and evolutionary quality" (Gerston 2004, 6). In this process of policy making, "problems are conceptualized and brought to government for 
solution" and "governmental institutions formulate alternatives and select policy solutions; and those solutions get implemented, evaluated and revised" (Sabatier 2007a, 3). The policy cycle model provides a similar understanding. Under this approach, the policy making process is segmented into series of continuous stages, such as agenda setting, policy formulation, policy adaptation, policy implementation, policy evaluation, and policy change (Gupta 2001). However, most of the time, the process is not as neatly segmented as the policy cycle model suggests.

Other scholars also explain the complexity of understanding the policy process. According to Sabatier (2007a, 3-4), an extremely complex set of elements interacts over time in the process of public policy making. These complicating factors include: hundreds of state and non-state actors involved, time span of a decade or more, interrelationship of different policy arrangements, and possible technical and legal involvement. Birkland (2001) points out that structural and historical factors influence the policy making and constitute the environment in which public policy is made. These environmental factors are not fixed in time, but the change in environment is rather slow. Mol et al. (2001) use the term "policy culture" to describe politico-institutional factors that influence policy making and implementation. Further, accepting the irrational nature of policy process, Gerston (2004, 7-15) argues the interaction of key ingredients of policy process, such as institutions, actor, issues, resources and political regime, has made policy making a challenging process.

\subsubsection{Models of Public Policy Process}

In explaining the policy making process, "the emphasis is much more on the unfolding than on the authoritative decision, with attention devoted to the structure, 
context, constraints and dynamics of the process, as well as to the actual decisions and events that occur" (Schlarger 2007). To simplify the situation and develop general concepts that apply to more than one case or problem, policy analysts have developed a number of theories and models to study the policy process. Easton (1965) provides a model that views policy process as the product of a system, influenced by and influencing the environment in which it operates. The policy environment contains the features of structural, social, political and economic systems. As the input of the policy making system, societal demands involve public opinion, interest groups, mass media, political parties, and community elites. It is the political system within government that translates the societal demands into specific policy outcomes, consisting of laws, regulations and other policy arrangements. However, the major criticism of the Easton's model is that it treats the internal workings of political system as a black box and does not provide further explanation (Birkland 2001, 221).

Related to Easton's system model is the most commonly-used policy cycle model, also termed as stages heuristic (Jones 1970). The model represents the policy process as a cycle, or series, of linearly connected stages, i.e., agenda setting, policy formulation, decision-making, policy implementation, and policy evaluation. According to Sabatier (2007a, 6-7), the policy cycle approach served a useful purpose in the 1970s and early 1980s and stimulated some excellent research within specific stages, particularly, agenda setting and policy implementation. However, the model is subject to some criticisms, such as lack of causal drivers, oversimplification of practical interacting process, and possible inaccurate description of the stages. 
Over the past three decades, more sophisticated and useful models and frameworks have been developed or extensively modified by political scientists to study the policy process. Some representative models include Kingdon's multiple streams metaphor (Kingdon 1995), Ostrom and her colleagues' institutional analysis and development (IAD) model (Ostrom 1990), Sabatier's advocacy coalition framework (Sabatier 1988), Baumgartner and Jones' punctuated equilibrium model (Baumgartner and Jones 1993), and the policy network approach (e.g., Knoke 1990; Adam and Kriesi 2007). According to Sabatier (2007b, 321), although all these frameworks are relatively promising general frameworks, they "need to be developed into more logically coherent and 'denser' theoretical frameworks and, eventually, into fully developed theories".

These models, derived from the practice of Western democracies and developed by Western academics, provide diversified ways to order and simplify reality. Dye (2002, 45) claims that models have strengths and limitations; however, a good model should keep congruence with the reality, direct inquiry and research, and suggest causes and consequences of public policy. Sabatier (2007b) further clarifies the criteria of a more robust theory or framework, such as logical coherence, clear causal process, empirical falsifiability, and broad coverage in scope.

\subsubsection{Application of the Policy Network Approach in the Research}

Among a set of models and approaches to analyze policy processes, in this study, the policy network approach is chosen as the analytic tool to historically and institutionally examine China's climate change mitigation policy making process. This choice was made primarily due to the following four considerations. 
First, policy network theory takes into account various types of actors that affect the development of public policy. Although government, as the key state agency, is often the leading institution in steering non-state action in the political process; businesses and social institutions also affect preferences and actions of state actors. By treating public policy as the product of interdependent interactions between state and society, the researcher can characterize the roles of actors in policy processes from a broad spectrum, ranging from a closed, access-restricted structure to an open, loosely-organized, and unstable issue networks (Rhode and March 1992; Mol et al. 2000). In the case of China, although the decision making may still be characterized as centralized and top-down, it is by no means monolithic (Saich 2004; Li 2005). With the rapid socio-economic change under the reform, there has been more bargaining, negotiation and collaboration among state actors, private actors and civil society actors in the policy process (Saich 2004).

Second, policies are generated under specific political-institutional contexts. These contexts influence the actors and ideas in most policy making processes. Among a number of approaches to using the network concept (to be described in detail in Section 2.3), this study takes Adam and Kriesi's approach (2007) of proposing a casual model to conceptualize the policy process. Under this approach, a variety of interdependent actors form networks to address environmental contexts and determine policy outcomes and changes. Such a causal model of policy network is helpful in generating logicallycoherent propositions which will be tested empirically (Sabatier 2007b).

Third, the complexity of the policy process calls for an examination of historical development of the networks and relationship between networks and policy outcomes. By identifying the dimensions of policy networks (introduced in Section 3.3), 
development of structures, functions, and changes of networks over time can be studied. Further, more general features of policy style and policy outcomes can be connected with the specific structures and interactions of actor networks. The present research treats policy process as a dynamic cycle that involves various actors and is consistent with the development of actor networks.

Fourth, although the institutional development and analysis (IAD) framework and the advocacy coalition framework are the most impressive models having been empirically tested in many different settings, no study has applied these frameworks to study Chinese policy processes. However, there have been growing academic endeavors in recent years that employ the policy network approach to study Chinese policy issues. Li et al. (2003) applies Rhodes' typology to analyze Chinese housing and real estate policy. Tang (2004) uses conflict of interest among actors to analyze tax reforms in the countryside. A recent study by Zheng and her Dutch colleagues (Zheng et al. 2010) argues that the policy network theory is generally "useful to describe and explain policymaking in the Chinese context," and "most, if not all, the theoretical notions developed around policy networks proved fruitful when applied to the fragmentation, interdependencies, stalemates and breakthroughs in decision-making processes in China" (Op cit., 17).

Eichhorst and Bongardt (2009) suggest some adaptations be made in order to analyze a specific policy arrangement in China. It is worth noting that policy networks develop in the course of time through frequent interactions between mutually dependent actors in the whole process of policy cycle, not only in decision-making phase, but also in other phases such as agenda setting, policy implementation. The emphasis of the action 
network development is important because the decision-making normally takes a topdown approach in China and this process is rarely documented in detail, but this topdown approach incorporates bargaining and negotiation among diverse state and nonstate actors at all levels in the policy making process. As Saich (2004) argues, "China's size and diversity makes it especially important that policy remains flexible to account and that policy makers receive accurate information for policy design and on feedback once policy begins to be implemented". Therefore, the examination of the features and evolutions of the implementation networks should be included in analyzing the policy process and understanding policy outcomes and changes.

Before reviewing the literature of policy network theory in Section 2.4, Sections 2.2 and 2.3 will review the literature related to China's policy process and China's response to the global climate change governance.

\subsection{Research on China's Policy Process}

\subsubsection{Formal Policy Process in China}

With China's reform and opening up, its policy making process has been evolving, and decision-making has been more institutionalized at the top-level. The country has established an integrated, multilevel nationwide bureaucratic system to accommodate the requirements of economic reforms.

Most literature addresses the issue by identifying the actors, and examining their

functions and interactions. The National People's Congress (NPC) and the State Council are the two key institutions in policy making at the national level. The NPC holds the power to make national laws, while the State Council drafts implementing rules, 
regulations, decrees and orders. Commissions and ministers affiliated to the State Council can issue orders, directives and regulations, which shall be consistent with laws passed the NPC and with regulations of the State Council. At the local level, the local congress and government may draft separately additional regulations for local implementation.

In reality, the State Council, which receives substantial input from ministries and commissions, holds the power in policy formulation and development, especially in the economic sector. The National People's Congress, plays a marginal role in the drafting and consultation process, though its role for policy advisory and supervision has been growing (Andrews-Speed 2004). In most cases, the agencies responsible for the policy implementation in a specific sector may also take responsibility in drafting the policies for that sector (Andrews-Speed 2004). Pang and Zou (2008) show a general process of developing a policy in China. First, relevant experts and government officials work on preparing policy drafts. The drafts will then be circulated among different governmental departments to obtain comments and revisions. Next, the competent departments submit a finalized draft to the State Council for approval. Some of the policies will be promulgated in the form of laws that require the approval by the National People's Congress. Once approved, either the State Council or the relevant departments is charged with implementing and refining regulations and measures.

China has tried to decentralize its decision making. The decentralization, characterized by local governments and officials assuming more power and responsibility in stimulating local economic growth, to some extent, weakens the authority of the central government, which results in inconsistency, conflict and ambiguity of the policies. To achieve compromise between competing agencies, China normally makes special 
organizational arrangements by forming leadership groups or committees that bring together the functionally-related bureaucracies (Lieberthal 2004, 217).

The major stakeholders in China's policy process include the government, industrial sectors, academic institutions, media, the public and non-government organizations (NGOs). The government in China is the dominant player in policy making, while the NGOs have the weakest roles (Pang and Zou 2008). Although, in China, the NGOs have been expanding and becoming more active, especially in environmental issues; comparatively speaking, NGOs and the public voices are not loud and clear enough in the policy making process (Op cit.).

Within the government system, the State Council, supported by its affiliated ministries and local governmental administration, leads the policy making, puts into effect the national economic plan, and oversees policy implementation and enforcement. However, the implementation of policies in China runs into a series of obstacles, such as insufficient institutional capacity, shortage of human resources, conflict and ambiguity of policies, influence of informal rules, and personal relations (Chen 2003). Some researchers point out that in China, there are other approaches to facilitate the policy implementation led by the administrative agencies: one is the utilization of the power of the Communist Party to set guidelines for policy making (Peng 2003, 45; Constantin 2007); the other is a trend towards greater legislative involvement in policy making and implementation instead of political command, as the NPC has strengthened its institution and improved its professionalization (Peng 2003; Saich 2004). 


\subsubsection{Models of Analyzing China's Policy Making Process}

Several models have been developed and used to analyze the policy making process in China. The first one is the broad rationality model. The model postulates that decision makers attempt to pursue strategies that can maximize the expected outcomes of the choices they could make (Howlett et al. 2009). When used to analyze China's policy process, it views China's central state as a rational, unitary and coherent actor and assumes that top-level leaders can exert considerable power over the political system and can choose the most efficient means in achieving policy goals and advancing the national interest (Lieberthal and Oksenberg 1988, 9-12; Constantin 2007; Lieberthal 1992).

The pure rationality model is regarded as nonrealistic and has serious limitations, thus Herbert Simon (1955) puts forward an alternate notion of "bounded rationality." In general, the rationality model could not well capture the realistic complex dimensions of the system. For example, the decision makers may have limited information and time available; the policy might not be a direct response to the underlying problem; and the efficiency of policy options is dependent on changing circumstances. In addition, the closed nature of the Chinese political regime limits the study of the degree to which the rationality of decisions is limited or bounded. Therefore, the rationality model cannot "provide sufficiently powerful explanatory value to be used in isolation from other approaches" (Lieberthal and Oksenberg 1988, 14).

The second model is the power model, which assumes the policy outcomes are the result of "struggles among the top leaders who are sensitive to the implications of alternative policy choices upon their stature and power" (Lieberthal and Oksenberg 1988, 14). This model has been used extensively to analyze the complex dynamics of China, 
especially before its economic reforms when little information is available outside China. The power model assumes that "Chinese political behavior is the result of interorganizational bargaining for budgets, status, and power" (Dreyer 2006, 17). The power model holds that to study the bureaucratic politics, the crucial question is to identify the most powerful bureaucratic organizations or alliances that denominate the policy process. However, the model considers only the organizational constraints that have formed the actors' behavior, while ignoring ideological and cultural constraints, as well as the issues at stake (Lieberthal and Oksenberg 1988, 17).

Arguably, the most impressive and influential model of understanding China's institutional setting and policy process is called the fragmented authoritarianism model, developed by Lieberthal and Oksenberg (1988) in the late 1980s with their study of policy process of large-scale energy projects. The next section presents a brief overview of the fragmented authoritarianism model.

\subsubsection{Fragmented Authoritarianism Model}

The fragmented authoritarianism model was first developed by Lieberthal and Oksenberg (1988) to label the bargaining features of Chinese bureaucracy through their case studies of China's energy policy process. The model acknowledges the insights from the rationality and the power approaches and integrates more available information to study the impacts of decentralization of decision-making authority brought by China's economic reform in the late 1970s.

The fragmented authoritarianism model focuses on two dimensions of centralization and decentralization to reflect the bureaucratic practice: one is the structural distribution of resources and authority; the other is the process of decision 
making and policy implementation. The authors argues that the bureaucratic activity of shaping and implementing policy in China takes place under a structurally "fragmented, segmented and stratified" environment, and the affected institutions negotiate, bargain, and seek consensus to pursue their own interests in the process. Correspondingly, policy outcomes are shaped by the incorporation of interests of diverse actors, especially the implementation agencies, into the policy itself. As a result, the policy making process in China is governed by the "disjointed, protracted and incremental" changes.

With the term of "fragmented authoritarianism", Lieberthal (1992) further developed the idea of bureaucratic fragmentation and argues that bargaining and negotiation are crucial elements of the political process in China, thus it is difficult to predict accurately the policy outcome with one particular approach. Because of the decentralization of decision making, the local levels have gained power to block upward flows of information and frustrate the policies of the upper-level authorities. He suggests the policy analysis should focus on the relationship of administrative hierarchies, in particular between line agencies at the central level and the provinces and localities. Lieberthal (1992) admits that one of the limitations of the fragmented authoritarianism model is that it emphasizes the structural dimensions of authority and policy process and gives less concern on value integration which can potentially affect policy process under the complex political system and lacks focus on role of party.

Although the fragmented authoritarianism is regarded as one of the most influential models of understanding the policy process in contemporary China (e.g., Dreyer 2006; Constantin 2007; Chen 2003), it has been frequently challenged by researchers, because this static model of labeling Chinese policy making as "protracted, 
disjointed and incremental" fails in capturing the characteristics of current policy making process in China (Wang 2006; Mertha 2008; Yu 2008; Lema and Ruby 2007; Constantin 2007). For example, Lema and Ruby (2007), through the study of wind project development, argue that policy reforms in China have changed largely from a state of fragmented authoritarianism towards policy coordination. Mertha (2008) claims that the policy process in China has become increasingly pluralized and more non-state actors are involved in the policy process. Yu (2008) argues that China's policy making in the area of climate change diplomacy is highly coordinated, instead of fragmented.

\subsubsection{State-Society Relationship in China}

The actors involved in the policy process can be divided into two groups: state actor, the one directly participates in the state policy making (Zhao 2002), and the civil society actor, the one endowed with human agency (Long and Long 1992). The relationship between the state and society is the relationship between two types of actors. In China, economic reforms induce the changes of state-society relations. Literature has given substantial attention to China's transition of the relations between state and society, especially since the collapse of the Soviet system in the early 1990s.

In general, China's state-society relations have been undergoing a massive change under the reforms. As Saich $(2004,223)$ notes, "The economic changes (in China) have redefined the social structure and are changing the distribution of power between state and society, have altered the principles on which society is organized and the ways in which it interacts with the state apparatus." However, debates continue on whether the civil society or alternatively the state corporatism better describes China's circumstances. 
Some scholars view the Chinese citizens' more assertive behavior and the emergence of more associations as contributing to civil society. Adherents of this view argue that although there have been some setbacks, China is marching towards a vigorous civil society (e.g., Dean 1993; Watson 2008). However, Lieberthal $(2004,300)$ claims that evidence overall shows that in China, basic levels of the state and non-state organizations are lack of powers and resources in limiting the ability of higher levels of the state to penetrate influences, therefore the Western civil-society model does not apply to China's situation to date. Frolic (1997, according to Saich 2004, 228) uses the term of "state-led civil society" to describe the situation that in China: "the civil society is created by the state to help it govern, co-opt and socialize potentially politically active elements in the population”. In studying the policy making process, Andrews-Speed $(2004,191)$ claims that China still gives little emphasis "on protecting voluntary economic agreements or on controlling the power of the state."

State corporatism is a commonly applied model to describe state-society relations. Given the limitations that in China, each non-state organization must register with a government body and receive approval as a legal entity, and that only one organization is allowed to represent each sectoral constituency, the state's domination over social organizations is clear. However, the applications of the state corporatism model have come in various forms. Unger and Chan $(2008,48-68)$ view most of China's major associations and groups as state corporatist, especially at the national level, because most of these organizations were founded by the state and firmly under the control of a state or Party agency. However, at the periphery, the emergence of more 
small local organizations shows the possibility of shifts in the future toward societal corporatism and even civil society.

Another scholar, Walder (1986) adopts the term of "Communist NeoTraditionalism" to draw distinctions with pluralism and authoritarian paradigm. It argues that the political loyalty is rewarded systematically with career opportunities and other rewards, and the evolution of the Chinese communism will create a highly institutionalized clientelism network.

Although state corporatism model captures well the top-down nature of control in the system, some scholars question its ability in explaining the complexity of dynamics of the interaction between state and civil society (Foster 2008, 116; Kennedy 2008, 153174). Perry and Selden (2000) highlight the roles of local state institutions in controlling social protests and opposition that happened frequently in China. They argue that "while local officials frequently crack down on popular resistance, in numerous cases their leadership is instrumental in shaping, legitimating and articulating the demands of social movements, and in some cases in networking with state officials on behalf of local interests" (Op cit., 11). As Kennedy $(2008,174)$ puts it, "no one label - civil society, corporatism, or any other - adequately reflects the nature of government-business relations in China."

\subsection{Global Climate Change Governance and China's Response}

\subsubsection{History of Global Climate Change Regime}

The development of scientific knowledge regarding causes and potential consequences of global climate change has led to the increased concern of global 
warming issue. The nature of the climate change problem has made it clear that no country can solve this issue by itself and global scientific and political cooperation would be necessary to find solutions and create an effective response.

The creation of Intergovernmental Panel on Climate Change (IPCC) by the United Nations Environmental Program (UNEP) and the World Meteorological Organization (WMO) in 1988 marks one of the most important steps to transform the climate change issue from a scientific issue into a policy issue. The IPCC issued its first report in 1990 and reported an observed temperature increase of $0.3-0.6{ }^{\circ} \mathrm{C}$ (degree Celsius) over the past century and predicted a $1-3{ }^{\circ} \mathrm{C}$ during the 21 st century. Soon after the publication of the IPCC report, the United Nations General Assembly authorized formal negotiations on a global climate agreement. At the 1992 Earth Summit held in Rio de Janeiro, the United Nations Framework Convention on Climate Change (UNFCCC), which aims to form international climate policy architecture, was signed by 154 nations. The four key elements contained in the agreement include a general long-term objective to stabilize GHG concentrations, a near-term quantitative emission reduction goal for industrialized countries; the principle of "common but differentiated responsibilities" as the guidance of burden sharing; and the preference for the market-based measures. The four elements have largely defined the international climate change policy regime since 1992 (Aldy and Stavins 2007).

The UNFCCC commitments were voluntary and did little to establish firm governmental targets. In 1997, the Third Conference of the Parties to the UNFCCC (COP 3) met in Kyoto and adopted the Kyoto Protocol, which creates a comprehensive yet flexible international GHG emission reduction regime. The industrialized countries 
agreed to reduce the GHG emissions by $5.2 \%$ below the 1990 level during the first commitment period from 2008 to 2012. Besides, three market-based mechanisms were designed to facilitate the compliance of legally-binding targets with lower costs. However, because the United States refused to ratify the treaty, it was not until February 2005 that the Kyoto Protocol gained enough ratification and finally entered into force.

The Kyoto Protocol has been both lauded and criticized (Wiener 2007; Victor 2004; Aldy and Stavins 2007). On the one side, it is the first step to create marketoriented rules to comply with quantified emission reduction targets set for developed countries. On the other side, the implementation of the Kyoto Protocol is criticized because it bypasses several key GHG emitters, such as the United States, China, India, and has specific deficiencies in the design that make it ineffective and relatively costly to implement. However, both sides agree that it is imperative to negotiate a successor regime for the post-Kyoto period. The Thirteenth UNFCCC Conference of the Parties (COP 13) held in Bali 2007 set four thematic building blocks for future actions: mitigation, adaptation, technology, and finance. Parties agreed to establish an Adaptation Fund to assist developing countries to adapt to the climate change impacts. The Bali Roadmap also outlined a new negotiating process to be concluded in the COP 15 in Copenhagen to feed into post-Kyoto international agreement on climate change. However, in the COP 15 Copenhagen and the COP 16 Cancun climate change conferences, although all parties have agreed to an accord that sets a goal of limiting global warming to below $2{ }^{\circ} \mathrm{C}$ above pre-industrial levels by 2100 , no legally-binding agreement has been signed due to vast differences among countries. 
Notably, there are other forms of international climate negotiations, such as the Asia-Pacific Partnership for Clean Development and Climate (AP 6), the G8 Gleneagles Plan of Action, the GLOBE G8+5 Climate Change Dialogue (Williams 2007). These negotiations complement the Kyoto Protocol regime and are undertaken between key economies, which are also major carbon emitters. Besides, domestic climate change actions are taken in various forms worldwide. For example, in the United States, voluntary mitigation programs include the Regional Greenhouse Gas Initiative (RGGI), the Chicago Climate Exchange (CCX), and other regional and sectoral programs. However, the persistence of some voluntary programs could not be guaranteed. For example, the emission trading in the Chicago Climate Change has been closed since November 2010 because of the market uncertainties.

\subsubsection{Structural Features of Global Climate Change Regime}

The emergence and development of the international climate change regime has gradually gained attention among researchers. The structure of the international climate change regime has shown three features. First, not only governments, but also the other non-state actors, such as businesses, NGOs, scientific community, and the public, are involved in policy discussion and implementation, seeking to reduce the emissions of GHGs. Although the national states still dominate the regime negotiations, and the role of

non-state actors remain limited to influence the action of governments, the non-state actors have contributed to influencing human behavior more directly, which would result in an improved performance in GHG emission reductions (Raustiala 2001).

Second, vast differences exist between developing countries and developed countries; and within the two groups, coordinated actions could not be taken. The sources 
of differences are complex and include "levels of development, sources of GHG emissions, national energy policies, key economic sectors, and expected impacts of climate change" (Downie et al. 2009, 122). In developed countries, only the EU member countries have committed to meeting emission reduction targets set by Kyoto Protocol. The US refuses to participate unless other emerging economies, such as China, India, Brazil, would accept quantified GHG emission reduction targets. On the other hand, the developing countries argue that the priority for these countries is economic development, and the developed countries should take on historical, legal and moral responsibilities to reduce their emissions first, and provide financial and technical assistance to developing countries.

Third, governance of climate change across all levels of government and relevant stakeholders has emerged. According to Corfee-Morlot et al. (2009), the multilevel governance encompasses two dimensions of action: vertical dimension and horizontal dimension. Under the vertical dimension, government at the national level cannot effectively deal with the climate change challenges alone without cooperation with the international community and participation of lower levels of government; while under the horizontal dimension, climate change issues and solutions overlap with other global environmental and development issues, thus calling for policy integration and coordination between departments and institutions when developing relevant policies.

\subsubsection{The Adoption of Climate Change Mitigation Policy}

The climate change mitigation policy arrangement is a portfolio of policies and measures that fit specific national circumstances and aim to reduce or limit GHG emissions across all sectors. Different policies and measures could have induced different 
outcomes, and the impacts may last for a long time. These policies can be broadly divided into the climate-specific and the climate-related. Such a division has been widely employed in discussing climate change issues and their connections with energy and environmental issues (Willems and Baumert 2003; Burtraw and Toman 2001; Gallagher 2008; NDRC 2007; Richerzhagen and Scholz 2008).

Climate-specific policies refer to GHG emission reduction oriented policies. The United Nations (UN)-sponsored climate mitigation mechanisms, i.e., the three mechanisms under the Kyoto Protocol, fall into this category. Much literature has addressed China's policies and actions that respond to the UN-sponsored mechanism, in particular its performance in taking the CDM activities. Other climate-specific mitigation actions include China's participation in China-EU Climate Change Partnership, AsiaPacific Partnership for Clean Development and Climate (AP 6), and some bilateral cooperative agreements (Pew 2007; IEA 2010).

The climate-related mitigation policies refer to the policies, regulations, and measures that, though not directly driven by climate change concerns, treat GHG emission reduction as a by-product activity of economic development. Compared with climate-specific policies, these policies are much more inclusive (Burtraw and Toman 2001). They are broadly adopted in areas of energy production and transformation, energy efficiency improvement and conservation, transportation, industrial processes, forestry, and other sectors (NDRC 2007). Other policies, such as those affecting trade, foreign investment, social development, can also affect emissions, but their relations with mitigation are not direct, thus not taken as mitigation policies (IPCC 2007). 
Since the 1990s, and especially over the past decade, China has begun adopting a number of policies and taking various measures to address GHG emissions. These policies and measures come in response to concerns about several interrelated issues, including climate change, energy efficiency, air pollution, long-range planning, and international opinion (Downie et al. 2009, 105). The International Energy Agency (IEA 2010) lists the climate change mitigation policies and measures that China has adopted and that are in force. Of the 27 domestic mitigation policies, 6 were implemented during 1996-2004 period; 11 were taken during 2005-2006; 10 were taken after 2007. These policies are taken in various forms: regulations and standards, taxes and charges, subsidies, financial incentives, voluntary agreements, etc. Many of the policies and measures have been laid out and reemphasized in the Renewable Energy Law of 2005, the Energy Conservation Law of 2008, the Medium- and Long-Term Development Plan for Renewable Energy of 2007, and the 11th Five-Year Program (2006-2010).

The most important climate change policy adopted is the National Climate Change Program released by the Chinese government in July 2007. The Program outlined activities that China has been planning to undertake in mitigating GHG emissions and adapting to the consequences of potential climate change. However, some critics note that it has only a symbolic role, because China does not set emission reduction goals and/or a timeline. One year later, China issued a white paper titled China's Policies and Actions for Addressing Climate Change, indicating that China will actively participate in worldwide efforts to address climate mitigation and adaptation, earnestly observe the UNFCCC and the Kyoto Protocol, and play a constructive role in international cooperation (State Council 2008). 


\subsubsection{China's Climate Mitigation Performance}

There have been many debates and controversies about China's performance in mitigating climate change impacts. Regarding the impacts of climate change on China, some hold that there are potential net gains to China from a warmer world (Nordhaus and Boyer 2000; Weiner 2007), while other studies show that China will be one of the worstimpacted countries in the world if the climate changes as predicted (NDRC 2007; IPCC 2007).

Concerning how China has made contributions to the climate change mitigation, based on Weiner (2007), some researchers claim that China would not limit its GHG emissions, because, under the current Kyoto Protocol, it has no binding obligations and politically, reducing GHG emissions will harm its economic development and influence social stability. The only solution, therefore, is to promote international cooperation, and provide incentives to China for mitigation actions. In contrast to that, others claim that China has been more proactive on climate change actions and has made great efforts in reducing carbon. A Pew report shows that the energy intensity and GHG intensity (GHG emissions per unit of GDP) in China have fallen significantly over the past few decades, largely through energy efficiency plan development and institutional effort. Weber et al. (2008) show that with China becoming world's manufacturing center, up to one third of Chinese emissions were actually due to production of exports, rising from $12 \%$ in 1987 . This means that the importer countries, primarily industrialized countries, have exported their emissions with large scale movement of manufacturing to China. In fact, there have been a lot of debates that between exporters and importers, who should be responsible for carbon dioxide emissions of the Chinese-made goods (Wang 2008; BBC 2009; Johnson 
2009). By comparing China's involvement in three UN environmental programs, Heggelund and Beacker (2007) claim that, although China is currently providing no leadership, it has emerged as an active participant and stakeholder in the international environmental arena.

Various scholars hold different opinions about the level of China's climate mitigative capacity. Gallagher (2007) argues that China still lacks many of the institutions, policies and enforcement mechanisms, especially at provincial and local levels; while Richerzhagen and Scholz (2008) argue that China's climate mitigative capacity has been considerably improved in areas of climate science and policy coordination, but the main problem is that China's climate-related mitigation actions are not driven by climate consideration, but based on the desire to maintain economic growth.

It is almost impossible to generalize about China's climate mitigation performance from evaluating a single policy or program. Much literature has addressed China's participation in the UN-sponsored CDM scheme, in which the Chinese entities can develop carbon emission reduction projects and trade the accredited emission reduction credits with industrialized countries for funds and technology. The studies cover a variety of aspects, such as sustainable development, institutional capacity building, technology transfer, carbon market and finance (Saner 2005; Heggelund 2007; Ganapati and Liu 2008; WWF 2008; Seres 2007; Hall 2007). Since 2007, China has surpassed India and Brazil as the largest CDM credit supplier in the world, with $42 \%$ of the issued CDM credits coming from China, almost twice the number in India (CD4CDM 2010). Researchers have identified some reasons that can explain China's success, such as lower abatement costs, more effective administrative arrangements, governmental 
manipulation, large emission reduction potential, as well as the flaws of this scheme (Michaelowa 2007; Wiener 2008; Duan 2008; Lloyd and Subbarao 2009; Ganapati and Liu 2009).

\subsection{Policy Network Theory}

Policy making takes place in policy domain-specific subsystems, which "consists of a large number of state and non-state actors dealing with specific policy issues" (Adam and Kriesi 2007). To have a closer examination of the emergence, development and change of climate change mitigation policy in China's political system, an analytical framework is needed to build links between various factors and investigate the relations between actors in China's climate change mitigation policy process. In this research, the policy network approach is employed to guide empirical inquiry, analyze the development of China's climate change mitigation policy, and explain the mechanisms of policy making process. Relevant literature on the policy network approach is reviewed in this section.

\subsubsection{Concept of Policy Network}

The concept of policy network has its roots in organizational studies, economics, sociology, anthropology, public policy, political science, etc. (Hudson and Lowe 2004; Berry et al. 2004). The term has been used in the study of political processes since 1970s, and refers to "the set of political actors inside and outside government who are involved in, or take an interest in, the making of public policy, and/or or relations between these actors" (Compston 2009). Policy network theory holds that a large number of actors (individuals and organizations) are dealing with specific policy issues. The political 
process is not controlled by state actors alone, but rather by the interactions of state and non-state actors at all levels (Adam and Kriesi 2007; Marsh and Smith 2000; Hudson and Lowe 2004). As an open and flexible system of relationships of actors, the policy network integrates both macro-level trends and the impact of the implementation of policy at the micro-level (Adam and Kriesi 2007).

There are different understandings and applications of the policy network concept. In general, three major approaches exist (Borzel 1988; Adam and Kriesi 2007). The first approach treats the policy networks as a specific form of governance that is different from the conventional market and hierarchy. Networks, characterized by the predominance of informal, decentralized, and horizontal relations, are autonomous and self-governing in that they resist government manipulation.

The second approach analyzes the network structure through formalized and quantitative procedures and often uses software. The quantitative analysis results in images of network structures and summary indexes; however, this approach gives little concern for actors' characteristics, nor on the origins of the dynamic change of networks.

The third approach applies the network concept to different types of interactions among actors in a policy subsystem. This approach interprets policy networks as a type of interest intermediation between public and private actors in which resources are exchanged. The basic assumption of this approach is that "the existence of policy networks, which reflect the relative status or power of particular interests in a policy area, influences (though thus not determine) policy outcomes" (Borzel 1998). Adam and Kriesi $(2007,130)$ note that "These typologies often rely on the classic distinction between pluralist and corporatist systems of interest intermediation." and "Whereas pluralist 
concepts stress the wide range of actors involved in policy making and the resulting competition among them, corporatist concepts point to the cooperation between a few central actors."

On the basis of the degree of integration, the restriction to the memberships and distribution level of resources, Marsh and Rhodes $(1992,249)$ place policy network in a specific sector on a continuum with two ending points: policy community and issue networks. Policy community is a tightly integrated, well organized and access restricted structure, which is often linked to the corporatist arrangements and characterized by cooperation between a few dominant actors; while issue network is a loosely-organized, more open and less coherent structure, which is associated with pluralist arrangements. Thus the study of policy network on a policy community- issue network continuum has been linked with the discussion of state-society relations. From the discussion on contemporary China's state-society relationship in Section 2.2.3, it is more appropriate to broadly categorize China's policy network as a form more prone to policy community; however, the number and types of actors involved in the policy process have been expanded under the reform and vary with the specific policy domains.

Policy network can also be defined by other classified dimensions. For example, Van Waarden (1992) indentifies seven major dimensions, including the number and type of actors involved, their functions, structures, degree of institutionalization, rules of conduct, power relations, and strategies. Lieffererink et al. (2001) characterize policy network with three dimensions: the distribution, mobilization and exchange of resources, policy issues and actors, and interactions in the network. 


\subsubsection{Network Approach in Analyzing Policy Process}

The use of the policy network concept has been doubted by some scholars because of its shaky theoretical basis (Dowding 1995, 2001; Richardson 2000). However, some important progress has been made to strengthen the ability to explain policy processes, especially over the past decade. Marsh and Rhode $(1992,262)$ argue that the policy community is associated with policy continuity, and "the existence of a policy network, or more particularly a policy community, constrains the policy agenda and shapes the policy outcomes". They also claim policy networks are central to understanding the policy change and the ways in which political institutions and practices adapt (Op cit., 267).

Marsh and Smith (2000) further develop a dialectical model to explain the role of the policy network in the policy process. They point out that the relationship between the network and outcomes is not simple and unidimensional, but interactive that "each affects the other in a continuing iterative process" (Op cit., 5). They accordingly identify three dialectical relationships: between the network and the context within which it operates; between the structure of the network and the actors operating within them; and between the network and the policy outcome.

Adam and Kriesi $(2007,129-149)$ treat the policy network approach more as an analytical toolbox than a theory. In their model, a complete policy process is separated into two causal events linked by the policy network: as dependent variables, the structures of policy networks are determined by the external factors, namely the transnational context, national context and policy-domain specific context; as independent variables, the structures of policy networks, which capture two basic 
elements of networks - actors and their relations, affect policy outcomes. In particular, the distribution of power determines the potential for policy change and the type of interactions between actors influence the types of policy change.

The causal links of policy network features and policy change have been used by some scholars to explain policy process and analyze the impacts of actor networks. For example, Lynn et al. (2000) present a causal model of governance, where the governance outcomes are explained by a set of "network" factors, such as environmental contexts, actors, structures, treatments, and managerial roles and action. Mol et al. (2001) use the policy network approach to examine the driving forces behind the emergence of joint-environmental policy making through three case studies across three EU countries. In addition, there have been a growing number of empirical case studies that adopt the policy network approach to explain the policy outcomes and changes in specific policy sectors (Jost and Jacob 2004; Zhou and Mori 2008; Compston 2009).

\subsection{Policy Network as Analytic Framework}

The aim of the present study is to gain a better understanding of how a set of state and non-state actors in China have engaged in climate change policy making and development. An analytic framework is adapted from the policy network model by Adam and Kriesi (2007) to guide the empirical inquiry. The analytic framework frames the key variables and is used to explain the dynamics of China's climate change mitigation policy

process. In this framework, three components are highlighted. The first component incorporates contextual factors that will lead to the focused issues and shape the specific climate change policy network. The second focuses on structural and interactive features 
of the policy network as intervening variable. The third is the policy outcomes and possible changes influenced by the policy network. Figure 2.1 presents a schematic overview of the model.

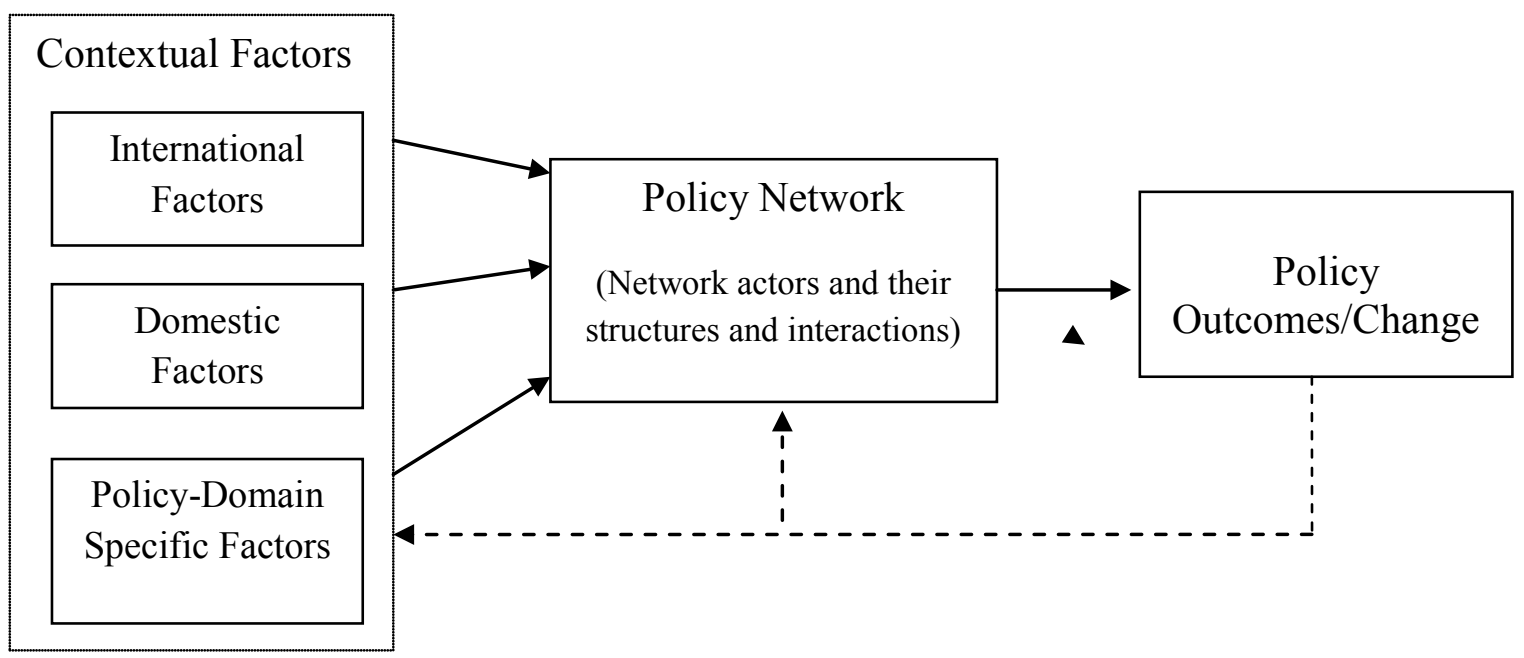

Figure 2.1 Policy Network Analytical Framework

Source: adapted from Adam and Kriesi (2007)

\subsubsection{Contextual Factors of the Policy Network}

A variety of factors influences the emergence and form of a policy network. These environmental factors "vary with the territorial and functional specificities of the policy network under study" (Adam and Kriesi 2007, 137). Adam and Kriesi (Op cit.) suggest three contextual factors based on macro-political and domain-specific scope: international, domestic, and the policy-domain specific contexts.

- International Contexts

Whereas international contexts alone are not sufficient to explain the features of policy networks (Cowles et al. 2001), the "internationalized policy environments" have become important factors that influence the formation of policy networks and the shaping 
of domestic policies (Coleman and Perl 1999; Adam and Kriesi 2007). In the study of climate change policy making process, global climate change regime forms the main and direct internationalized policy environments, and should be given considerations when analyzing of specific mitigation policy process. Section 2.3 has reviewed relevant literature on historical development of global climate change regime and its main characteristics.

\section{- Domestic Contexts}

According to Adam and Kriesi (2007), the structural and interactive features of policy network are influenced by the formal national institutional structure. Two perspectives, namely corporatism and pluralism, are commonly used to analyze the domestic institutional regime (Mol et al. 2001, 16). Katzenstein (1978) argues that the level of centralization in state-society relations, and the degree of differentiation of between the state and society are two critical variables in the establishment of policy networks. In addition, some studies show the importance of informal domestic structures for explaining the development of policy networks (e.g., Kenis 1991; Knoke et al. 1996). Again, as regards climate change, the domestic institutional contexts are not sufficient factors for the emergence and development of policies (Mol et al. 2001). Literature on China's policy process, including its institutional structures and ongoing changes under the economic reform, has been reviewed in Section 2.2.

\section{- $\quad$ Policy-Specific Contexts}

Even within the same country, the structure and function of policy networks differ from sector to sector and from policy to policy (Atkinson and Coleman 1995). Therefore, it is important to take a closer look at the policy-specific influences to the 
policy networks in different sectors and at different times. Researchers (Adam and Kriesi 2007, 141; Thacher 1998; Colman et al. 1997) claim that there are general and situational policy-specific variables that need to be considered. General policy-specific variables include policy incentives, the expectation, visibility/salience and traceability of the effects; while situational variables focus on the reasons for change within policy network, such as economic and technological development, and changes in ideas, values and knowledge.

It should be noted that complex interactions of three contextual factors affect the development of policy networks, and the influences of these contexts cannot be distinctly separated. Furthermore, not all factors have the same weight, and some factors are conditional upon others (Kenis 1991). Adam and Kriesi (2007, 143) suggest the research should "look at the combined impact of different types of determinants". In this study of China's climate change mitigation policy process, the development of the international climate change regime and the development of Chinese political economy are treated as independent contextual variables that occur before other variables and impact the policy process; while policy-specific factor is treated as a "moderator" variable that set conditions or modify basic relationships under which an independent variable (policy network) exerts effects on a dependent variable (policy outcomes).

\subsubsection{Network of Actors}

The policy making process involves many actors. The actors come from three key institutional sectors: government, market and civil society (Metz et al. 2007). However, their roles, responsibilities and powers have changed in relation to social and economic changes over the past two decades. Whereas the government, defined strictly 
by the nation state, remains the central actor in policy making, businesses and civil society actors are playing more prominent roles, although the specific level of involvement remains a hotly contested subject. In addition, the concept of government has become more inclusive and thus recognizes the contributions of various levels of government. Figure 2.2 shows the three components that constitutes the entirety of a society (state, market and civil society) and their actor compositions. Market and civil society actors form the non-state group.

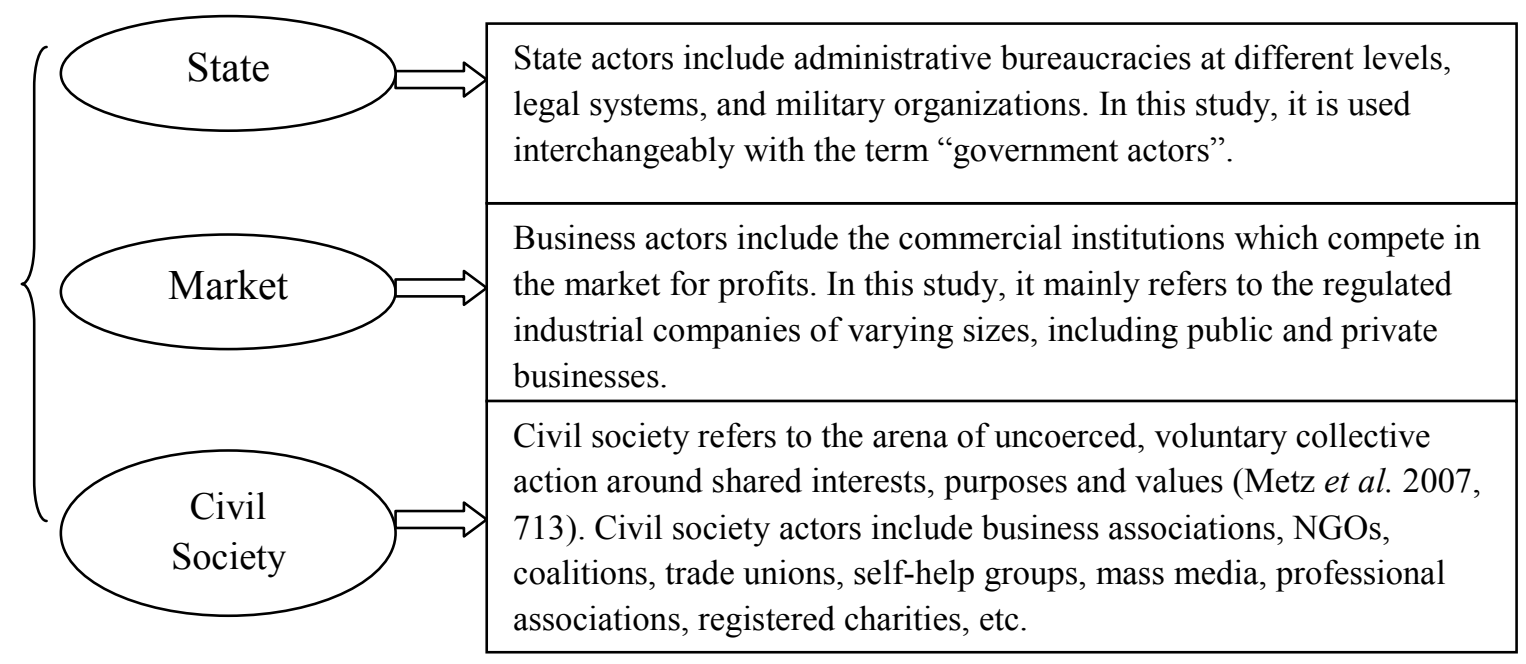

Figure 2.2 Structure of a Society and its Actors

Source: Metz et al. 2007; Howlett et al. 2007

In practice, the boundaries between state, market and civil society are often complex, blurred and negotiated, reflecting the changing environmental contexts and the actors' changing roles and functions. In addition, the definitions often run into difficulty when they are applied universally. For example, mass media play an important indirect influence on public policy making and are taken as crucial links between the state and society (Howlett et al. 2007). Unlike most other liberal-domestic countries, in China, the 
mass media are mostly created by the state; therefore, the media are most often led by government officials and sometimes neglect their positions and voices. Another example is the widespread existence of the GONGOs (Government Organized Non-Governmental Organizations). In the Chinese context, they include trade unions, women's organizations and some registered charities. They also include industrial associations, some of which are closely tied to industrial ministries, as well as public research institutes, which may be finically independent but organizationally are still attached to ministries (Wu 2003).

The international system is increasingly influencing domestic political and policy processes and consequently changing the nature and style of the civil society actors involved in policy developments. For example, the IPCC is an international organization that assesses the human-induced impacts of climate change. It also facilitates discussions of domestic climate change polices and the development of important epistemic or knowledge communities (Metz et al. 2007). However, to put epistemic community as civil society actors is not without controversy. Biagiotti (2002) views epistemic community as a separate non-state group, as opposed to civil society actors and corporate actors.

\subsubsection{Impacts of Policy Network}

The policy network plays a crucial role in shaping and constructing responses to external factors and creating policy outcomes (Adam and Kriesi 2007). In the empirical study, researchers identify various dimensions for depicting policy networks and link them with policy outcomes. For example, in Mol and his colleagues' model (Mol et al. 2001, 26), network dimensions include resource dependence, boundaries of the network, and interaction. In Compston's (2009) model, policy changes are caused by network 
changes in dimensions of resources, preferences and strategies of network members, perceived problems and solutions, as well as formal and informal rules. Adam and Kriesi (2007) suggest the structural and interactive features within a network determine the form of policy change. The present study follows Adam and Kriesi's approach and takes the actor identification, structure, and interaction as key dimensions in measuring features of policy networks.

Policy outcomes, as the third component of the model, are measured with different indicators. Mol and his colleagues (2001) use effectiveness and legitimacy to evaluate the policy outcomes. Effectiveness is to evaluate the extent in which policy arrangements reflect more general policy goals and the extent to which these objectives are actually achieved. Legitimacy refers to the analysis of the fairness and communicative qualities of participation. Policy change can also be classified into different types. For example, Hall (1993) differentiates three orders of policy change: the maintenance of status quo, incremental change, and the dramatic shift in policy goals and arrangements.

Climate change mitigation policy development is a continued and evolutionary process. The eventual effectiveness of policy design also depends on the implementation of policy instruments, and policy outcomes induce impacts on the future policy change. This study will incorporate the policy implementation into account and treat policy making as a cyclical process. Such "dialectical" policy network - policy outcome relations, as depicted by Marsh and Smith (2000), is diagramed with dotted arrow lines in Figure 2.1. 
Notably, although such a model has not been used in the name of "policy networks" to analyze China's climate change policy process, scholars have given the similar focus on the roles of the structures and interactions of public and private actors in studying China's energy and climate change policies (Lieberthal and Oksenberg 1988; Richerzhagen and Scholz 2008; Downs 2008; Zhou and Mori 2008; Bjørkum 2005; Constantin 2007).

\subsection{Hypotheses of the Research}

As mentioned above, this research will employ the policy network analytic framework illustrated in Figure 2.1 as a toolbox to guide empirical evidence acquisition and interpret relevant findings of China's climate mitigation policy making process. In addition, the causal framework also provides insights on formulating research questions and working hypotheses, leading to in-depth investigation and verification.

The policy network analytic framework, as shown in Figure 2.1 highlights three components of policy networks in conducting analysis of policy processes: the environmental context, the composition and features of policy networks, and the corresponding policy outcomes. The research questions and working hypotheses are drawn from some fundamental understanding of the interrelationships of these three component factors on the basis of previous observations, experience and understanding of China's policy making process in general. Table 2.1 illustrates how the concern issues are translated into research questions, and what hypotheses are generated to address these questions. 
Table 2.1 Concern Issues, Research Questions and Hypotheses

\begin{tabular}{|c|c|c|c|}
\hline No. & Concern Issues & Research Questions & Working Hypotheses \\
\hline 1 & $\begin{array}{l}\text { The functioning of the } \\
\text { climate mitigation policy } \\
\text { network }\end{array}$ & $\begin{array}{l}\text { How do the policy networks } \\
\text { influence the proactiveness of } \\
\text { developing climate change } \\
\text { mitigation policies in China? }\end{array}$ & $\begin{array}{l}\text { Increasing interaction between } \\
\text { government, business, and civil } \\
\text { society actors will increase the } \\
\text { likelihood of China's taking a } \\
\text { more proactive approach to } \\
\text { develop effective climate } \\
\text { change mitigation policy. }\end{array}$ \\
\hline 2 & $\begin{array}{l}\text { The contextual factors of the } \\
\text { policy network }\end{array}$ & $\begin{array}{l}\text { How does the political reform } \\
\text { influence the choices of } \\
\text { innovative mitigation policy } \\
\text { tools, such as market-based } \\
\text { measures and voluntary } \\
\text { agreements? }\end{array}$ & $\begin{array}{l}\text { More fragmentation in the } \\
\text { distribution of regulative power } \\
\text { will increase the likelihood of } \\
\text { China's utilizing more } \\
\text { innovative policy instruments } \\
\text { and measures. }\end{array}$ \\
\hline 3 & $\begin{array}{l}\text { The involvement of non- } \\
\text { state actors in the policy } \\
\text { network }\end{array}$ & $\begin{array}{l}\text { How are the non-state actors } \\
\text { involved in China's climate } \\
\text { change policy making } \\
\text { process? }\end{array}$ & $\begin{array}{l}\text { Decreasing political control in } \\
\text { policy development and } \\
\text { implementation will encourage } \\
\text { other actors, in particular non- } \\
\text { state actors, to exert greater } \\
\text { effort in shaping mitigation } \\
\text { policy. }\end{array}$ \\
\hline 4 & $\begin{array}{l}\text { The operation of the policy } \\
\text { network }\end{array}$ & $\begin{array}{l}\text { Under the rapidly changing } \\
\text { international and domestic } \\
\text { context, how does China } \\
\text { arrange its institutions to } \\
\text { organize and coordinate } \\
\text { climate change mitigation } \\
\text { actions? }\end{array}$ & $\begin{array}{l}\text { Increasing demand for shared } \\
\text { responsibilities } \\
\text { ministries among } \\
\text { governments will increase the } \\
\text { likelihood of stronger } \\
\text { coordination by the central } \\
\text { government. }\end{array}$ \\
\hline
\end{tabular}

\subsection{Summary}

In the first part of this chapter, literature of policy process theory, global climate change regime, and China's climate change policy development has been reviewed. To better understand the dynamics of China's policy process in general and climate change mitigation policy process in particular, it is important to accept the fact that China has experienced significant changes under the reforms in aspects of the center-locality relationship and the state-society relationship. With regard to the study of climate change policy process, the actors involved in the policy process are not exclusively limited to the government regulators and decision-makers; rather, since climate change initiative is a 
dynamic and ongoing process, the more appropriate approach is to incorporate other key state and non-state actors who participate in policy implementation and may have influences in policy making. These actors, including government actors at central and local levels, business actors (e.g., regulated businesses, in particular large-scale energy companies), and civil society actors (e.g., industrial associations, NGOs, academic institutions, mass media), get involved in network due to the specific policy needs and may later influence the policy process through their interactions with others.

On the basis of the relevant theories of policy network, in particular the causal policy network model proposed by Adam and Kriesi (2007), an analytic framework is developed in Section 2.5. The framework conceptualized the policy making as a process involving a wide range of actors who are mutually interdependent, and they form networks to address the external factors and determine policy outcomes and changes. This causal model is used to guide the empirical investigation and explain the working mechanism of China's climate change mitigation policy making process. Before conducting the empirical inquiry of the mitigation policy process, the next chapter outlines the research design and methodology that have been adopted in the research. 


\section{CHAPTER III}

\section{METHODOLOGY}

Chapter 1 has identified the area of study as the dynamic process in China's climate change mitigation policy making and implementation. In Chapter 2, an analytic framework built on policy network concept and theory has been developed to guide the empirical data collection and analysis. Chapter 3 describes the methodology issue used in my research. In general, the methodology employed is a combination of grounded theory and case study approach, which is qualitative and inductive in nature and evidenced by data from interviews, observations and relevant literature.

The chapter proceeds as follows. Section 3.1 describes the overall research design of this qualitative study. Section 3.2 presents the case study approach, including the purpose, the case selection criteria, and a brief description of the three cases. Section 3.3 addresses the variable measurement issues and explains the dimensions in measuring the concept of policy network. Section 3.4 outlines how the data are collected and used for the research. Finally, Section 3.5 summarizes this chapter.

\subsection{Overall Research Approach}

To simplify understanding, Creswell (2007) has identified five approaches to qualitative research, including narrative research, phenomenology, grounded theory, case study, and ethnography. However, in real research, it is "possible to find two or more variations or combinations of these approaches within a single study" (Fraenkel and Wallen 2009, 427). 
The overall research approach can be categorized as combinations of grounded theory and case study approach. Since few studies have addressed China's climate change mitigation policy process; therefore, one of the purposes of this study is to generate grounded theories inductively from the collected data of China's climate policy development as a part of the study. Under grounded theory approach, the "substantive and formal" theories are built and grounded in data of social inquiry through inductive and exploratory process. Grounded theory approach relies on a set of clearly formulated procedures for developing theory (Crotty 1998). According to Glaser and Strauss (1967, $3-5)$, grounded theory is the best way of generating "initial, systematic discovery of the theory from the data of social research", which helps to forestall the opportunistic use of logic-deductive theories that have dubious fit and working capacity. In this study, the propositions that reflect climate change mitigation policy making process in China will be explored by testing the hypotheses through empirical inquiry. The results will be referred and compared with the fragmented authoritarianism model, which has been widely taken as the most important model in studying Chinese policy process. Case study approach will be presented in detail in Section 3.2.

To enhance explanatory functions of the policy network approach, researchers have tried to establish causal models to study relations between policy networks and policy outcomes. This study follows this logic to conduct the empirical work. Through inductive reasoning applied to three cases and guided by research questions, the research tries to generalize some essential features of China's climate change policy network and understand how these features have influenced the outcomes of mitigation policies or 
programs. Such an exploratory approach aims to conceptualize the similarities of an aggregate of individual cases and develop a set of logically-interrelated propositions.

Three cases have been selected to facilitate elaboration of the mitigation policy arrangements under the Chinese specific circumstances. They are the national climate change mitigation policy in general, the CDM management rules adopted in 2004; and the Top-1000 Industrial Energy Conservation Program initiated in 2006. All three policy arrangements experience some changes, but remain in force till now. The next section addresses case selection issues in more detail.

\subsection{Case Study Approach}

The aim of this research is to examine China's climate change mitigation policy making process and explain its working mechanisms. Employing the policy network approach, it will study the features of the policy actor networks and explain how the networks contribute to policy development. This section discusses the case study design and the appropriateness of this approach.

\subsubsection{Reasons for Case Study}

There are several reasons why the case study method has been chosen for the study. First, as discussed in the previous chapter, China has experienced rapid change in the past three decades due to reforms, and its state-society relationship has experienced profound changes accordingly. Despite substantial research on China-related issues, there are few studies that have focused on the policy process, and none on the climate change policy making process. Therefore, this study is largely exploratory in nature, and consequently, a case study approach is more appropriate for this inquiry. 
Second, studying the policy process is a highly complex matter that requires tracing the process of policy development to understand the interactions of various factors. A quantitative approach based on statistics cannot cope with complex causal patterns and is limited by the number of homogenous cases; while case study method is sensitive to contextual factors and allows examining the multiple causes and interaction effects of the complex social world in detail (Ragin 2005).

Third, on the basis of the International Energy Agency (IEA) information (IEA 2010), the adopted climate change mitigation policies in China are still relatively small in number. Although all these policies aggregately contribute to the reduction of carbon emissions, each of them is unique in nature and difficult to compare. From the network perspective, each policy arrangement is matched with unique structures and interactions of state and non-state actors. According to George and Bennett $(2005,19)$, the case study method is generally strong to "closely examine the hypothesized role of causal mechanisms in the context of individual cases".

Finally, although the policy network analytic framework mentioned above has reflected causal mechanism among contextual factors, policy networks and policy outcomes in policy making process, it is still challenging to measure the indicators that best represent these components. Instead of using statistical methods that lump together dissimilar cases and rigidly require quantifiable variables, a case study approach "allows for conceptual refinement with a higher level of validity over a smaller number of cases" (Op cit., 19). 


\subsubsection{Case Selection}

In a country as large and diverse as China, the design of case study research in climate change mitigation policy process presents special challenges. These challenges come from the following four aspects. First, although China established the interministerial committee to address climate policy coordination issues as early as the 1980 s, the great majority of the climate mitigation policies had not been formulated in the form of laws, regulations and guidelines until around 2005, the year when the Kyoto Protocol entered into force. Most of the policy statements are in forms of speeches or articles, presented by government officials, especially by those working with the inter-ministerial committee (Qi et al. 2007).

Second, climate change-related policies overlap with other policies relating to economic development, environment protection and energy development. These policies are not climate oriented, but they treat the limitation and reduction of GHG effects as accessory benefits. Evidence shows that with the increased concerns on climate mitigation issues, governments at the central level and at the local level have paid more attention on the improvement of policy coordination and integration. Third, in China, the central government weighs much higher in initiating climate mitigation activities than local governments. Finally, there is a geographical mismatch in mitigation capacity and obligations among the regions. Provinces and regions in the western part of China that suffer from climate change negative impacts most have weaker capacities and resources to reduce GHG emissions compared with the coastal provinces and municipalities.

The sample case/cases shall be the subset of the population, which are the climate change mitigation policies that have been adopted by the Chinese national 
government. As a reference, IEA (2010) has identified dozens of climate mitigation policies, measures, and programs. These policies, in different forms, have mobilized a wide variety of actors to interact in taking mitigation actions.

Stake (1995) claims that the case study should maximize what we can learn. This means to ensure the sample case/cases be more representative of the population and achieve maximum variability. Since the adopted climate mitigation policies, measures and program are unique and involve diverse actors, multiple case study design is preferable to a single case study. Each single case should be instrumental to learning about particular effects of the policy networks, and generalization will be refined through collective case studies.

Due to the time and resource constraints for this research, it is only feasible to conduct a limited number of case studies. Criteria to select cases are important, especially given the inherent complexities associated with the policy types, scales, involved actors and time period under which mitigation policies take place. Given that many government programs cover interrelated subjects and involve multiple levels of government, market and civil society actors in operation, policy subsystem or domain is suggested as an appropriate unit of analysis (Sabatier 2007a, 4). Accordingly, the study will take the general national climate change mitigation policy development as a single case. The other cases will be nested within this broad case, and aim to provide unique evidence linking policy networks and outcomes. This arrangement generally belongs to the "hierarchical time-series and comparative-historical" type of case research design developed by Gerring (2004). 
Two nested cases for in-depth empirical inquiry within the research were selected. The selection criteria are as follow:

- Independence of the case. Independence is an important criterion of case selection (George and Bennett 2005). To this end, it is more feasible and appropriate to select a mitigation program, which is a focused arrangement aiming to realize specific policy goals and normally has a clear starting and ending points.

- Involvement of actors. To maximize the independence, the cases with the "high degree of automaticity" (Salamon and Lund 1989) will be ruled out. These cases normally do not require detailed administrative action. For example, tax incentives are largely self-executing because individuals or entities will seek them out and make corresponding changes. In this study, the better cases are the ones that attract actor involvement, and incorporate relatively independent decision makings and a substantial degree of management efforts.

- Representativeness of policy types. Since climate change mitigation policy can be broadly divided into two types: the one taking carbon emissions reduction as key objective (climate-specific) and the one taking it as accessory action (climate-related), the case selection thus will follow this typology.

- Geographical and sector coverage. It is preferable that the nested cases are programs that are comprehensive and involves actions from more than one sector. In addition, the case policies are preferably policies that are formulated by the national government and implemented nationwide. 
- Site and data accessibility. The selected cases should have achieved observable and measurable mitigation results. The secondary data sources are accessible and individuals knowledgeable about the cases are willing to be interviewed.

After the screening of China's climate mitigation activities taken in the past few years, three cases have been selected: China's national climate change mitigation action, China's involvement in the Clean Development Mechanism (CDM) regime and the Top1000 Industrial Energy Conservation Program. The main features of the three cases are summarized in Table 3.1.

Table 3.1 Main Features of the Three Identified Cases

\begin{tabular}{|c|c|c|c|c|c|c|}
\hline $\begin{array}{c}\text { Policy/Progra } \\
\mathrm{m}\end{array}$ & $\begin{array}{l}\text { Category/ } \\
\text { Sector }\end{array}$ & $\begin{array}{c}\text { Domestic } \\
\text { Governmental } \\
\text { Actors }\end{array}$ & Types & $\begin{array}{l}\text { Time } \\
\text { Period }\end{array}$ & $\begin{array}{l}\text { Level of } \\
\text { Actor } \\
\text { Participation }\end{array}$ & $\begin{array}{c}\text { Policy } \\
\text { Linkage } \\
\text { (Scales of } \\
\text { Action) }\end{array}$ \\
\hline $\begin{array}{l}\text { Case 1: } \\
\text { National } \\
\text { Climate } \\
\text { Change } \\
\text { Mitigation } \\
\text { Action } \\
\end{array}$ & $\begin{array}{l}\text { Frame } \\
\text { policy }\end{array}$ & $\begin{array}{l}\text { State Council, } \\
\text { NDRC, MOST, } \\
\text { MOFA and } \\
\text { other ministries, } \\
\text { provincial } \\
\text { governments }\end{array}$ & $\begin{array}{l}\text { Domestic } \\
\text { mitigation } \\
\text { policies, } \\
\text { and } \\
\text { measures }\end{array}$ & $\begin{array}{l}\text { From } \\
1988 \text { to } \\
\text { present }\end{array}$ & $\begin{array}{l}\text { From low } \\
\text { actor } \\
\text { involvement } \\
\text { to high actor } \\
\text { involvement }\end{array}$ & $\begin{array}{l}\text { International } \\
\text {-national- } \\
\text { subnational- } \\
\text { local }\end{array}$ \\
\hline $\begin{array}{l}\text { Case2: Clean } \\
\text { Development } \\
\text { Mechanism } \\
\text { (CDM) } \\
\text { Project } \\
\text { Management } \\
\text { (in force) }\end{array}$ & $\begin{array}{l}\text { Climate } \\
\text { specific } \\
\text { policy/ } \\
\text { variety }\end{array}$ & $\begin{array}{l}\text { NDRC, MOST, } \\
\text { MOFA, and } \\
\text { other } \\
\text { ministries; } \\
\text { (limited local } \\
\text { government } \\
\text { involvement) }\end{array}$ & $\begin{array}{l}\text { Market- } \\
\text { based } \\
\text { approach }\end{array}$ & $\begin{array}{l}\text { From } \\
2004 \text { to } \\
\text { present }\end{array}$ & $\begin{array}{l}\text { From low } \\
\text { actor } \\
\text { involvement } \\
\text { to high actor } \\
\text { involvement }\end{array}$ & $\begin{array}{l}\text { International } \\
\text {-national- } \\
\text { subnational }\end{array}$ \\
\hline \multirow{2}{*}{$\begin{array}{l}\text { Case3: Top- } \\
1000 \\
\text { Industrial } \\
\text { Energy } \\
\text { Conservation } \\
\text { Program (in } \\
\text { force) }\end{array}$} & \multirow{2}{*}{$\begin{array}{l}\text { Climate- } \\
\text { related } \\
\text { policy/ } \\
\text { variety } \\
\text { (industry) }\end{array}$} & \multirow{2}{*}{$\begin{array}{l}\text { State Council, } \\
\text { NDRC, NBS, } \\
\text { Provincial } \\
\text { government, } \\
\text { associations } \\
\text { (high local } \\
\text { government } \\
\text { involvement) }\end{array}$} & $\begin{array}{l}\text { Voluntary } \\
\text { agreement }\end{array}$ & $\begin{array}{l}03 / 2006 \\
- \\
10 / 2008\end{array}$ & \multirow{2}{*}{$\begin{array}{l}\text { From low } \\
\text { actor } \\
\text { involvement } \\
\text { to high actor } \\
\text { involvement }\end{array}$} & \multirow{2}{*}{$\begin{array}{l}\text { National- } \\
\text { subnational- } \\
\text { local }\end{array}$} \\
\hline & & & $\begin{array}{l}\text { Voluntary } \\
\text { agreement } \\
\text { with strong } \\
\text { regulations }\end{array}$ & $\begin{array}{l}10 / 2008 \\
- \\
\text { present }\end{array}$ & & \\
\hline
\end{tabular}

According to Sabatier $(2007 \mathrm{a}, 3)$, the policy process usually "involves time spans of a decade or more, as that is the minimum duration of most policy cycles." For the climate change mitigation policy development in China, although the history is not 
long (almost two decades if counted from the time that China approved the UNFCCC in 1992), there have been substantial evolution with regard to policy development. Since this study focuses on the evolutionary process of policy development and network formation, the timeframe of each case can be broadly divided into several phases, instead of only a static analysis on network actors and their interactions. Next section briefly describes three cases.

\subsubsection{Description of the Cases}

Of three selected cases, Case 1 provides a holistic perspective of the development of climate change mitigation policy and action in China. It focuses on the regulatory evolution and the current advocacy for market-based instruments of China's climate change mitigation policy making. The case is also characterized by the rapid growth of policy networks, in which a wide variety of government, business and civil society actors have closely linked and interacted. The time period, ranging from 1988 to the present, is divided into four phases, corresponding with the most important development in the international climate change regime (The establishment of the UNFCCC in 1992, the creation of the Kyoto Protocol in 1997, and its entry into force in 2005, are set as demarcation lines). The first case also sets a broader context in which the two other cases are nested.

Case 2 of the CDM management policy development is a case of a policy subsystem, in which China is joining the international climate governance network and developing market-based approach to mitigate domestic emissions. The Clean Development Mechanism (CDM) is a project-based climate mitigation scheme under the Kyoto Protocol, which entered into force in 2005. The dual goals of the CDM are to 
promote sustainable development in host developing countries and to allow industrialized countries to trade the emissions credits from their investments in emission-reducing projects in developing countries. The CDM allows China to develop emission reduction projects and trade credits in international carbon market. The future development of the CDM scheme depends on the international climate change regime after 2012. After several years' capacity building experience, in 2004, Chinese government promulgated interim CDM management rules, established administrative institutions, and formally initiated CDM project development. One year later, the interim rules was rescinded and replaced by an updated one, which specifies new rules for actors involved in the project activities.

The third case of the Top-1000 Industrial Energy Conservation Program deals with joint development of climate-related program in industrial sectors. Under this program, governments at provincial level sign contracts with local enterprises and oversee the enterprises to reach the contracted energy efficiency goals. Modeled on international target-setting programs, the Program has been implemented since March 2006 and is frequently referred to as a voluntary program. The industries included in the program are large-scale, financially independent enterprises widely dispersed in the country, representing more than $33 \%$ of China's total energy demand and $47 \%$ of the total industrial energy consumption in 2004 (Price and Wang 2007). Notably, this is the first time that the central government has incorporated provincial governments to supervise and monitor program implementation. Initially, only limited policies and incentives were provided to the involved enterprises. However, realizing the goal of reducing energy intensity by $4 \%$ per year was difficult to meet, from September 2008, China has adopted 
new financial and administrative measure to strengthen the enforcement, and expand the program to a larger scale.

\subsection{Dimensions to Measure the Policy Network}

As shown in the analytic framework in Figure 2.1 of Chapter 2, the policy network is shaped by the environmental contexts and will determine the policy outputs and outcomes. Considering there are different approaches to use the policy network concept and in order to guide data collection in three case studies, it is of importance to define dimensions that can characterize the main features of policy networks.

Three dimensions are distinguished to identify the features of policy networks. Since policy networks are a collection of mutually dependent actors, the first dimension often refers to specifying the boundaries of the system, which include the membership of the network and the attributes of these actors. The members are those actors that take part in the exchange of resources (Liefferink et al. 2000). They can be institutional actors, as well as the individual actors. The attributes of actors may include the goals, perceptions of the issues, and the strategies the actors employed (Zheng et al. 2010; Adam and Kriesi 2007).

The second dimension of policy network deals with structural features, which characterize the distribution and mobilization of power among the set of actors within a policy subsystem (Adam and Kriesi 2007, 134). The dimension is "concerned with whether power is concentrated in the hands of one dominant actor or coalition of actors or whether it is shared between actors or coalitions of actors" (Op cit., 134). The relations of power and resources inside the network are the core element of the policy network; however, the policy process may also be affected by links with networks around adjacent 
policy issues, which are labeled by some scholars as "horizontal" element of the network structure (Liefferink et al. 2000). In the case of studying national climate change policy, not only the structural features of key state and non-state actors will be studied, but also network structural links with other related policy issues will be included, such as issues of economic development, environmental protection and energy management.

The interactions in policy networks, which are presented by the degree of cooperation among actors, constitute the third dimension. Adam and Kriesi $(2007,134)$ define three forms of interactions between network actors and put them into a continuum: conflict/competition, bargaining/negotiation, and cooperation, in which "bargaining constitutes an intermediate or ambivalent type characterized by both conflict/competition and cooperation". The interaction dimension allows a better connection of “configurations of policy networks to policy dynamics" (Op cit. 134).

With the help of these three dimensions, the shape and functioning of China's climate change mitigation policy networks will be empirically investigated in the coming chapters. At the same time, the features of the policy networks will be linked to the analysis the policy contexts and policy outcomes.

\subsection{Data Collection and Analysis}

\subsubsection{Data Collection Methods}

The data collection and analysis are to provide sufficient and reliable information to support project study. On the basis of the analytic framework, the empirical data have been collected focusing on the three aspects of the policy processes: policy contexts (international, domestic and policy-related), policy networks, and policy 
outcomes. Both primary data and secondary data have been used. They are from archival records, documental research, in-depth interviews, and field research.

The major source of information for this study is from different kinds of literature: books, newspaper, journal papers, articles, government documents about the climate change regime, Chinese politics, and Chinese climate change policy. The reason of taking literature as major source of information is because of its advantages in accessibility and coverage. On the other hand, in China, interviewing relevant officials inside the system has been proven hard, and governmental officials are reluctant to be interviewed. However, some of the sources from literature should be used with caution, given the fact that information is sometimes subject to governmental control in China, and the reliability of Chinese data has frequently been questioned. It is not possible to avoid these problems when doing research about China, therefore, in this study, information from multiple resources has been triangulated to improve the reliability of data.

In addition to literature, a series of semi-structured interviews have been taken to collect primary data and deepen the understanding of empirical inquiry. The interviews were conducted from November 2009 to February 2010 during the course of three-month of fieldwork in two Chinese cities: Beijing and Shenyang. Beijing was selected because of its position as the political center where key government agencies are located, as well as the place where a variety of international and domestic society and organizational actors are found. Shenyang is the capital city of Liaoning province, which is the home of many of the heavy industries and has high stakes in implementing climate change policies. The visited sites included regulatory agencies and participatory (or regulated) 
units related to the key climate mitigation policy making and implementation. The interviewees were government officials, research scholars, business consultants, and other practitioners from relevant governmental agencies, international organizations, research institutions, and businesses. Interviews conducted in the two cities have provided very useful background information about how the national climate change mitigation policy is oriented to fit into local interests.

\subsubsection{Within-case Analysis and Cross-case Analysis}

In reality, it is almost impossible to apply experimental methods or make perfectly controlled comparison to analyze processes and outcomes of policies, which weakens the rigorous application of comparative method (George and Bennett 2005, 151153). However, within-case analysis provides an alternative approach that "compensates for the limits of both statistical and comparative case analyses" (Op cit., 178).

To examine the institutional and historical development of China's climate change mitigation policy process in individual cases, the central task is to link numerous observations within a case in particular ways to make them possible for casual inferences. The policy network analytical framework developed in previous chapter provides a causal linkage of some key factors to guide for empirical evidence acquisition. The employment of the within case approach is thus to trace key policy changes in each of the three cases, test hypotheses concerning roles and functions of policy networks, and uncover a causal mechanism posited by the analytic framework.

On the other hand, since there is a paucity of research on the process of China's climate change mitigation policy making and implementation, it is expected that the study can generalize some commonalities from the three cases through the cross-case 
analysis. The cross-case approach is taken as an alternative approach of within-case analysis which focuses on examining individual causal links (Eisenhardt 1989). Although the multiple case study design may implicitly enhance the representativeness of the study, making case studies more generalizable, the cross-case analysis also suggests a weakness of comparability. As Gerring (2004) claims, the tradeoff between comparability and representativeness is intrinsic to the case study choice of research design. Given that three selected cases are different but mutually related mitigation arrangements, it should be noted that in the study, the cross-case analysis is used to comparatively generalize some commonalities of key features in processing climate mitigation policies in China.

In a word, when analyzing empirical evidence, the within-case analysis is in conjunction with cross-case analysis, in order to generate and verify some propositions at the abstract level for theory testing and development. The within-case and cross-case analyses will be taken in Chapter 8 .

\subsection{Summary}

This chapter has presented the methodology to be used in conducting the research. In general, the study is exploratory and inductive in nature. To study China's climate change mitigation policy process from the perspective of policy network development, the multiple case study method has been employed.

Three cases have been selected from a pool of the climate change mitigation policies that have been implemented and are still in force. These cases were used to illuminate the main features of the specific policy network settings in shaping different policy arrangements and influencing the outcomes in the Chinese context. The first case 
examines the regulatory evolution of China's climate change mitigation policy making since the late 1980s. The second and the third cases deal with sub-policies. Case 2 focuses on China's involvement in the Clean Development Mechanism (CDM) regime, and Case 3 studies China's attempt to initiate industrial voluntary-agreement program: the Top-1000 Industrial Energy Conservation Program.

The main data source was documentary literature published in English and/or Chinese, including government documents, books, journals, newsletters, newspapers, research reports, and other materials on the internet. Fieldwork and interviews were taken as supplementary sources of information. Important data are checked to improve the reliability of information for analysis. In addition, within-case analysis is taken to test relevant hypotheses; while cross-case analysis is taken to generalize some findings to verify the prevailing understanding of policy process.

Before presenting the findings from the three cases, next chapter provides a historical overview of China's climate change policy development. Considering that Case 1 deals with generic evolution of China's climate change mitigation policy making, and Case 2 and 3 are nested within it, the presentation of overall policy development not only traces substantive information for Case 1, but also provides contextual background for the discussion of the other two cases. 


\section{CHAPTER IV}

\section{HISTORICAL DEVELOPMENT OF CHINA'S CLIMATE CHANGE ACTION}

This chapter presents historical development of China's national climate change mitigation policy making and action, which is also taken as contextual background of the three cases. The historical development is usefully divided into four phases: (1) the Institutional Preparation Period, from 1988-1992, when climate change had been transformed into a policy issue, and the Chinese central government began to establish its first inter-ministerial committee to prepare for international climate negotiations and cooperation; (2) the Pre-Kyoto Period, from 1993-1997, when international community centered on negotiating a legally binding commitment that can be more broadly accepted by involved parties; (3) the Kyoto Ratification Period, from 1997 to 2005, when the Kyoto Protocol was stalled from its signing in 1997 and finally entered into force, and when China had been hesitatively involved in pilot mitigation project cooperation; (4) the New Development Period since 2005, when China began to adjust its strategies to be more proactive in promoting mitigation policies and participating in international negotiations.

\subsection{Formulating Climate Institutions, 1988- 1992}

In the late 1980 s, climate change entered into the international political agenda. As an intergovernmental scientific group to provide authoritative assessment of the potential risks of climate change caused by human activity, the Intergovernmental Panel on Climate Change (IPCC) was created in August 1988 by the World Meteorological Organization (WMO) and the United Nations Environmental Program (UNEP). In 
response to the international scientific effort, at the same year, the Chinese government established its first research group to coordinate participation in the IPCC-related work. The Environmental Protection Commission of the State Council brought together four agencies: the State Meteorological Administration (SMA), the State Science and Technology Commission (SSTC), the National Environmental Protection Agency (NEPA), and the Ministry of Foreign Affairs (MOFA). Among the four agencies, the SMA played the leading role in directing the studies on the science of climate change; the SSTC was in charge of the development of relevant response strategies; the NEPA was responsible for the assessment of the climate impacts; and finally, the MOFA coordinated the international climate negotiations. At this early stage, the climate change issue was taken more as a scientific and international relations issue, rather than an economic development issue (Economy 1997, 24).

Substantial administrative reforms also were undertaken in 1988. The Ministry of Energy (MOE) was reestablished, and the National Environmental Protection Agency (NEPA) was separated from the Ministry of Urban-Rural Construction, forming as a vice-ministerial agency. However, during this period, economic growth in China experienced a big fluctuation under unstable political conditions. The serious inflation in 1988 was followed by a program of economic retrenchment imposed in late 1988 and tightened after the Tiananmen event in June 1989, which led to serious economic recession and subsequent social dislocation (Saich 2004, 74). Chinese decision makers had to reconsider development strategies for economic growth, and at the same time, deal with greater challenges of international relations with the end of the Cold War. In late 
June of 1989, Jiang Zemin was appointed to replace Zhao Ziyang as the General Secretary of the Chinese Communist Party.

In 1990, the IPCC released its First Assessment Report, reporting that global temperatures having increased by 0.3 to $0.6 \mathrm{C}$ over the previous century. The scientific discussions concerning climate change began and proceeded with more political negotiations. In 1991, Intergovernmental Negotiating Committee (INC) for Framework Convention on Climate Change (INC/FCCC) was established by the UN General Assembly, with the aim of negotiating a convention containing commitments before the UN Conference on Environment and Development (UNCED), scheduled for June 1992. At the same time, Global Environmental Facility (GEF) was established to help developing countries fund projects and programs in the areas of climate change, biodiversity, international waters, and stratospheric ozone protection.

Correspondingly, in China, the National Climate Change Coordination Group (NCCCG) was established under the Environmental Protection Commission of the State Council. The coordination group was chaired by Song Jian, then State Councilor, as well as the Minister of the SSTC. The core member agencies included the four initiallyappointed agencies working for IPCC tasks, and two newly added ministerial agencies, namely the MOE and the State Planning Commission (SPC). The Secretariat of the NCCCG was placed within the State Meteorological Administration (SMA).

The functioning of the NCCCG was greatly driven by the international climate scientific discussions and political negotiations. Three issues emerged as especially critical for China. The first issue was the scientific uncertainties of climate change. The scientific debates of climate change provided Chinese scientists an opportunity to 
participate in international cooperation. The SSTC and the SPC negotiated a five-year global climate change research program, which encompassed 40 projects and involved about 20 ministries and 500 experts (Economy 1997, 24). More importantly, under the auspices of the IPCC process, the scientific community in China had gained tremendous funding and technical assistance from international organizations, such as the World Bank, the Asian Development Bank (ADB), the United Nations Environmental Program (UNEP) and the United Nations Development Program (UNDP) (Op cit., 24).

The second issue concerned the relationship between carbon reduction and the country's energy and economic development. By 1990, with 10.6\% of the global carbon dioxide emission, China had become the third largest emitter in the world (EIA emission database). China had felt pressures to respond to the climate change issues. It had to adjust its coal-dependent energy structure, improve energy efficiency, and slow its economic growth rate. Differences existed among the ministries within the NCCCG, in which the MOE and the SPC gave more priority on the economic development, rather than energy restructuring. Apparently, after the economic recession in 1989, the national economic policy during 1990-1992 was set to increase the economic growth rate.

The third issue was the position and readiness that China would formulate for the international climate change negotiations. Allying with other developing countries as one group (G77 and China), China resisted any claims of the mandatory commitment of reducing carbon emissions. The group argued that commitments should be differentiated between developing countries and developed countries, because of the historical responsibility and per capita emissions; and the developed countries should undertake the responsibility to reduce emissions first; transfer energy-efficient technologies; and 
provide financial assistance to developing countries for capacity development. In addition, the developing countries worried that strong institutional and implementation mechanisms (such as detailed reporting requirements, noncompliance procedures) might infringe on their sovereignty. Within the NCCCG of China, the traditionally powerful Ministry of Foreign Affairs and the State Planning Commission dominated the political discussions.

The United Nations Conference on Environment and Development (UNCED) was held in June 1992 in Rio De Janeiro, Brazil, with the Framework Convention on Climate Change (FCCC) signed. Industrialized countries were required to adopt policies that aimed to return emissions to 1990 levels by the end of the century. Aiming to stabilize the GHG concentrations at a level that would prevent dangerous anthropogenic interference with the climate system, the FCCC set an overall framework for intergovernmental efforts to tackle climate change. It calls on the international cooperation on sharing information on GHG emissions, national policies and best practices, as well as preparing for adaptation to the impacts of climate change. The FCCC adopts the principle of "common but differentiated responsibilities and respective capabilities", which requires the developed countries to take the lead in combating climate change and the adverse effects thereof, and gives no specific responsibilities to developing countries. The successful opposition of the differentiation among developing countries based on their different levels of development matched very well with Chinese interests (Bjørkum 2005). 


\subsection{Pre-Kyoto Preparations, 1992-1997}

Internationally, after the Rio Earth Summit, six more INC meetings had been held till the FCCC finally entered into force in 1994. One year later, at the First Conference of Parties to the UNFCCC (COP 1), some significant outcomes were reached, including the negotiation of a protocol that contains legally binding commitments for developed countries for post-2000 period, and a initiation of a pilot phase of "joint activities", called the Activities Implemented Jointly (AIJ).

The core issue of the COP 1 was the proposal of negotiating a protocol. On this issue, the Chinese delegation was skeptical of the new proposal to follow up the Convention, and expressed that it was not interested in negotiating it before the Annex I Parties had implemented all their commitments in accordance with the Convention (ENB $1995,4)$. In addition, together with the G77, China expressed their skepticism of the proposed AIJ activities, fearing the AIJ scheme would launch mandatory commitments for developing countries, thus shifting the responsibility of developed countries (ENB 1996).

Domestically, the year 1992 also proved to be a watershed of large-scale transformation from planned economy to market-oriented economy. Shortly after Deng Xiaoping's south-tour speech on economic growth, a new round of economic reform was launched, leading to a dramatic economic boom. In late 1993, the Third Plenum of the Fourteenth Party Congress adopted the document of establishing a "Socialist Market Economic System". The reform, under the formulation of "socialist market reform", allowed market forces to play a great role in allocating commodities while retaining the state the capacity to make macro-level adjustments and control (Saich 2004, 78). 
The rapid economic boom caused another round of overheating, forcing the government to adopt some retrenchment policies to achieve an economic soft-landing. To adapt to the needs of the market economy, the economic reform document adopted in 1993 proposed the need for restructuring the central-local financial system, which signified a renewed role of central government in revising de facto economic decentralization. At the same year, the State Economic and Trade Commission (SETC) was set up and the Ministry of Energy was abolished. With these efforts, the economic growth rate has been calmed from $13.4 \%$ in 1993 to $8.8 \%$ in 1997 , and inflation rate reduced from $30 \%$ by the end of 1994 to $0.8 \%$ by the end of 1997 . However, China's share in the global carbon emissions kept on growing, creeping up from 11.5\% in 1992 to $13.4 \%$ in 1997 (EIA 2010).

During this period, the responsibilities of the NCCCG were diversified into four groups, consistent with the group division of IPCC operation. These four working groups dealt with specific tasks that link international climate change regime negotiations. The four groups were (1) the Working Group for Scientific Assessments co-chaired by the State Meteorological Administration (SMA) and the Chinese Academy of Sciences (CAS); (2) the Working Group for Impacts and Response Strategies, co-chaired by the SSTC and the NEPA; (3) the Working Group for Economic Analyses co-chaired by SPC and Ministry of Eclectic Power; and (4) the Working Group for Negotiation co-chaired by MFA and the SSTC (Tiempo 1997). Other ministries and agencies were also involved in the relevant domestic policy discussions dependent on specific requirements of each working group within the NCCCG. In January 1995, the National Climate Center was established under the SMA and aimed at cooperating with international counterparts to 
enhance the research work of climate change. Whereas the SMA remains the nominal leading agency of the NCCCG, its authority in policy coordination had been greatly weakened. The structure of the NCCCG framed the future institutional arrangements for China's climate change governance.

A related program with the climate change negotiations is the Agenda 21, which was agreed in the 1992 Rio Earth Summit and set blueprints for sustainable development into the 21st century. In China, the State Council delegated the NDRC and the SSTC as two leading agencies in coordinating activities for sustainable development. In March 1994, for guiding the implementation of projects under China's Agenda 21, the administration office was established under the SSTC (predecessor of the Ministry of Science and Techonology). However, the institutional establishment of China's Agenda 21 Program and its evolution are separate from the arrangements for climate change issues (Zhou and Mori 2008, 196). With the entry of the new millennium, the roles of this program have been gradually marginalized in practice.

In 1995, the First Conference of the Parties (COP 1) to the UNFCCC convened in Berlin, negotiating detailed and binding commitments for industrialized countries to reduce greenhouse gas (GHG) emissions. After nearly three years' intense negotiations, in December 1997, at the COP 3 in Kyoto, Japan, an agreement, called Kyoto Protocol was adopted, which required industrialized countries (Annex I countries) to reduce their collective emissions of the six most important GHGs by an average 5.2\% below the 1990 level by 2008-2012. Within this group, countries are committed with differentiated targets. To facilitate developed countries in achieving targets with lower costs and promoting the sustainable development in developing countries, the Kyoto Protocol 
contains three flexibility mechanisms: the International Emission Trading (IET) scheme which creates a market to trade surplus emission credits; the Joint Implementation (JI), which allows developed countries to cooperate in carbon reduction projects and transmit emission credits on the basis of such projects; the Clean Development Mechanism $(\mathrm{CDM})$, which allows developed countries to invest in emission reduction projects in

developing countries and count the reduction against their own commitments. Although the details on operation of these mechanisms were not set out at the COP 3 and required further negotiations, the Kyoto Protocol creates a comprehensive, yet flexible GHG emission reduction regime and signifies the beginning of a long-term international effort to address climate change.

During the Kyoto Protocol negotiations, China, together with the G77, resisted any proposal that requires commitments from developing countries. They argued strongly for obeying the principle of "common but differentiated responsibility" that has been explicitly formulated in the UN Framework Convention on Climate Change (Bjørkum 2005). China and other developing countries also objected to the emission trading approach, stating that it would be an instrument that would make developed countries exempt from domestic mitigation actions. In general, the developing countries proved to be quite influential in Kyoto. No timetable and emission reduction targets were mandated for developing countries (ENB 1997, 15).

\subsection{Piloting for the Kyoto Protocol, 1997-2005}

After the Kyoto Protocol was signed in 1997, the subsequent negotiations have evolved around its rules of procedure and how to make the Protocol ready to enter into 
force. Although this had been more of a matter of how to make the agreement acceptable for certain developed countries, China continued to argue against on any compulsory emission reduction commitments to developing countries by emphasizing that its $\mathrm{CO}_{2}$ emissions per capita were sill $61 \%$ of the world average level and $21 \%$ of the OECD $\operatorname{countries}^{1}$ (He et al. 2007). Furthermore, being aware of the limited weight of acting in isolation, China tried to strengthen its solidarity with the G-77 group to enhance their joint negotiating capacity on all major issues. For the Chinese government, another concern was how China could deal with the CDM scheme, once the Kyoto Protocol could have been ratified (Harris and $\mathrm{Yu} 2005,53$ ). China took two approaches to seek some breakthrough. On the one hand, it stressed that the emission trading through CDM is a way for developed countries to avoid their responsibility and has the potential to exploit the developing countries' rights of ownership to the credits. On the other hand, China initiated four Activities Implemented Jointly (AIJ) projects (precedent of the CDM projects) by cooperating with Japan and Norway. The pilot phase of AIJ provided a practical opportunity for developing methodologies and accumulating project management experience (CCChina 2002).

To set up an administrative system adapting to market economy, in March 1998, a new round of administrative reform was launched, marked by a more powerful restructuring of governmental institutions. In the reform, the number of ministries/commissions decreased from 40 to 29. The SPC was reshuffled as State Development and Planning Commission (SDPC), the NEPA was updated to a ministerial-

\footnotetext{
${ }^{1}$ OECD stands for the Organization for Economic Co-operation and Development, an international organization of 34 countries founded in 1961to stimulate economic progress and world trade. Most OECD member countries are high-income economies and are regarded as developed countries.
} 
level agency: the State Environmental Protection Agency (SEPA). Numerous industrial ministries were dissolved or reshuffled as industrial bureaus attached to the State Economic and Trade Commission (SETC). The grand administrative reform also triggered the boom in the number of industrial associations at national level and provincial level. These associations, in the form of Government Organized Nongovernmental Organizations (GONGOs), not only served as service delivery agencies for the state, but also absorbed governmental officials who were laid off during the reform (Wu 2003). At the same time, China worked hard to resume its membership under the World Trade Organization (WTO). In November 1999, China signed agreement with the United States on the terms of WTO entry.

A few months following the State Council's institutional reconfiguration in 1998, the inter-ministerial climate change coordination committee was restructured, with a view of improving the capacity of climate change related policy coordination. The new committee, the National Coordination Committee on Climate Change (NCCCC) was chaired by the SDPC. Other leading agencies included the Ministry of Science and Technology (MOST), the Ministry of Foreign Affairs (MOFA), the State Meteorological Administration (SMA), and the State Environmental Protection Agency (SEPA). The move indicated a shift of decision makers' viewpoint of climate change from a scientific issue to a development issue. Zeng Peiyan, then director of the SDPC, held the position of leader of the coordination committee. The Secretariat of the NCCCC was set in the Department of the Regional Development of the SDPC.

In 2001, The IPCC released the Third Assessment Report on climate change, indicating the evidence of human influences on the global climate is stronger than ever. 
In November, at the COP 7 in Marrakech, Morocco, the Marrakech Accords were adopted, clarifying the modalities, guidelines and procedures for the implementation of the mechanisms under the Kyoto Protocol. The Marrakech Accords paved the way for Annex I Parties (developed countries) to ratify the Kyoto Protocol and thus bring it into force. This was seen as a significant event after the newly-elected US President George W. Bush had just announced in March that his administration would not support the Kyoto Protocol because it does not limit the emissions from developing countries and would be too costly to implement ${ }^{2}$.

The imminence of the Kyoto Protocol implementation was clearly felt by the Chinese government, which began to change its strategy from "reactive" to more adaptive. In 2002, at the World Summit on Sustainable Development held in Johannesburg South Africa, Chinese Premier Zhu Rongji announced China's ratification of the Kyoto Protocol. After that, a number of capacity building projects were approved by the National Climate Change Coordination Committee (NCCCC). Most of these projects were focused on CDM project development and sponsored by international donors and foreign governments through bilateral agreements. To ensure a balanced distribution of these capacity building projects, the NDRC and the MOST negotiated with the donors to ensure that the case studies in these CDM projects would focus on emission reduction activities in different sectors and regions. Some of these pilot projects were later developed into real CDM projects.

\footnotetext{
${ }^{2}$ Notably, in 2002, U.S. President Bush announced a voluntary commitment to reduce the GHG intensity by $18 \%$ in 10 years as an alternative to the mandatory reductions under the Kyoto Protocol.
} 
Although China had performed remarkably in quadrupling its GDP (Gross Domestic Product) while only doubling its energy use between 1980 and 2000, a new problem emerged at the turn of the century. After a steadily decreasing trend of Chinese energy demand during 1997-2001, the figure bounced back from 2002; and the energy demand grew more quickly than GDP. The principle driver of this rise is an increase in the share of GDP provided by heavy industry, driven by the economic incentives (Downs 2010). As Hochman and Zilberman (2010) argue, globalization and capital flows have lifted overall investment in China and contributed to China's economic growth, which leads to more demand for energy. In 2002, the year subsequent of China's entry into the World Trade Organization (WTO), the Foreign Direct Investment (FDI) in China reached 52.7 billion US dollars, increasing $12.6 \%$ compared with that of the previous year. China had surpassed the US and become the largest economy to attract foreign investment. Correspondingly, carbon emission has increased sharply. During 2001 to 2005, China's share in the global GHG emission had increased from $12 \%$ to $19.5 \%$, getting close to the United States, the traditional largest GHG emitter (EIA 2010). In 2005, China became the world's fourth largest economy and its third largest trading power.

The impacts of China's rapid economic development were profound. Domestically, China realized that it is essential to adapt to these new economic, social and technological situations. With the new leadership under Hu Jintao (General Secretary of the Chinese Communist Party and President) and Wen Jiabao (Premier), a new round of administrative reform started in 2003 in order to accommodate the requirements of the country's entry into the WTO. New ministerial agencies, such as the Commission of State-owned Assets Supervision and the Ministry of Commerce were established. The 
SETC (State Economic and Trading Commission), which had been responsible for industrial sector activities, were integrated into the renamed National Development and Reform Commission (formally named as the SDPC). In 2004, the Chinese Authority raised the goal of "building a resource-efficient and environment-friendly society", which signified the leaders' serious concerns on China's resources and environment issues for sustainable development. This led to a number of policies, programs and activities being initiated to restructure the energy mix and improve energy efficiency.

The domestic climate change coordination committee was subsequently reorganized and expanded, increasing its members from 7 to 12. In 2004, under the NCCCC, the National CDM Board (NCB) was established, chaired by the NDRC and the MOST. The NDRC was also appointed as the Designated National Agency (DNA), the unit for approving CDM projects and coordinating international communication and cooperation. In mid-2004, the NDRC, along with the MOST and the MOFA jointly promulgated the Interim Measures for Operation and Management of Clean Development Mechanism Projects in China, signifying China's readiness for the implementation of the Kyoto Protocol mechanisms. It soon approved its first CDM project. In August 2004, the State Council approved the Initial National Communication on Climate Change. The Initial Communication provides a detailed picture of the country's emission inventories and its activities within the context of climate change.

More flexibility has been witnessed in Chinese climate change diplomacy during this phase. As an example, in July 2005, China negotiated a new climate pact with the United States, Australia, Japan, South Korea, and India known as the "Asia Pacific Partnership for Clean Development and Climate Change". Six countries agreed to 
cooperation on developing and transferring technology to reduce GHG emissions. The pact was non-binding and was announced to complement the Kyoto Protocol, not to replace it (APP 2010).

\subsection{Managing Changes, Post-2005}

With Russia's ratification despite the US nonparticipation, the Kyoto Protocol reached the threshold and entered into force in February 2005. The entry into force strengthened the global mitigation effort by committing the Annex I countries to the legally-binding targets to limit or reduce their GHG emissions. The subsequent international negotiations have been focusing on long-term GHG reduction targets and timeframe, as well as agreement for the post-2012 period. As a party to the Kyoto Protocol, China has been actively involved in climate change negotiations aiming at creating a successor agreement. It stresses its lower per capita GHG emissions, and its special development stage of industrialization and urbanization.

Although the CDM development had a relatively late start in China, this position has changed dramatically after 2006. The CDM has been seen as a vehicle that not only stimulates foreign investment in GHG mitigation projects, but also allows China to be seen as a proactive country on climate issues. In 2005, China revised its CDM rules. Three priority types of projects were identified: development of new and renewable energy, energy efficiency improvement, and methane recovery and utilization. The administrative approval procedures were also streamlined, making project development and approval more efficient. Since 2007, China has become the leading CDM host country in the world (As a single case, China's CDM involvement will be studied as the 
second case in Chapter 6). The market-oriented emission trading system has become accepted in China. In 2008, an emission trading exchange was established in Tianjin. The exchange, duplicating the model of Chicago Climate Exchange, intends to develop and promote the GHG emission trading in China. It aims to build partnerships with research institutions, financial agencies, accreditation units, and industrial associations in China.

Continued economic growth in China has led to greater energy use and carbon emissions. A number of policies and programs have been adopted since 2004 to reverse the trend that energy consumption grew faster than economic growth. These domestic policies were aimed at adjusting energy and industrial structure and improving energy efficiency thus leading to the choice of energy intensity (energy consumption per unit of GDP) as the key indicator to measure policy effectiveness. In 2005, China announced a plan to increase the use of renewable energy from $7 \%$ to $15 \%$ of total energy production till 2020. In China's 11th Five-year Plan adopted in 2006, China pledged to realize the reduction of energy intensity by 20\% from 2005 levels during 2005-2010.

With the new slogan of "scientific development perspective", the new leadership under $\mathrm{Hu}$ and Wen has shown a higher degree of concerns about economic development, resource management, and environmental protection. In August 2005, the State Council issued the Notification on the Immediate Priorities for Building a Conservation-oriented Society and Several Opinions on Accelerating the Development of Circular Economy. In December, the State Council issued the Decision to Implement the Interim Provisions on Promoting Industrial Restructuring and the Decision to Strengthen Environmental Protection with Scientific Development Perspective. Various types of reports have been formulated and publicized through inter-ministerial cooperation to 
reflect China's concerns on sustainable development and strategies to address climate and environmental change. Some of these reports include: Climate and Environmental Change in China (2005); National Assessment Report on Climate Change (2006); China's Scientific \& Technological Actions on Climate Change (2007); China's Policies and Actions for Addressing Climate Change (2008); China's Policies and Actions for Addressing Climate Change - The Progress Report (2009); and Resolution on Making Active Responses to Climate Change.

It is reported that since 2006, China has surpassed the United States as the world's largest carbon emitter (EIA 2008). China realized the importance to explicitly explain its stance on climate change and its interests in international cooperation. After several years of gestation, in June 2007, China formally announced the National Climate Change Program, which conveyed consensus among Chinese top leaders on climate change mitigation issues (Li 2007). This new policy package focused on five key areas, namely, mitigation, adaptation, technology, international cooperation, and participation in the regional efforts. The program did not include mandatory quota and a timetable for aggregate GHG emission reductions; but it tried to integrate existing policies that appeared in relevant energy policies and the 11th Five Year Plan (personal interview with NDRC official).

In the 11th National People's Congress held in 2008, aiming to improve efficiency, reduce the cost of policy making and its execution, and straighten out problematic chains of command, several ministries were consolidated to form "Super Ministries". Five super-ministries respectively overseeing industry, transport, housing and construction, human resources and the environment were restructured, including the 
Ministry of Environmental Protection (MEP), which was upgraded from the State Environmental Protection Administration.

Under the leadership of the State Council, institutions dealing with energy conservation and emission reduction were reformed to strengthen policy coordination and enforcement. The new national climate change coordination institution, the National Climate Change Leading Group (NCCLG), is chaired by Premier Wen Jiabao. The Groups members are commissioners and ministers from 20 different ministerial agencies. The NCCLG also acts as the highest-level policy coordination organ of energy conservation and emission reductions, with the name of National Energy Conservation and Emission Reduction Leading Group (NECERLG). These arrangements indicate the central government puts three issues of energy saving, pollution reduction, and climate change together and gives them parallel significance (Qi et al. 2008). The secretariat of the NCCLG was set in the reshuffled Department of Climate Change. Su Wei, a veteran climate change negotiator from the MOFA, was appointed to head the department (Wang 2008). The commissioner of the NDRC, Ma Kai, heads the secretariats of two leading groups.

Another milestone in China's climate policy development is the gradual involvement of local governments. A series of capacity building projects or pilot projects, covering mitigation and adaptation activities, have been initiated in selected provinces and localities, under the supervision of local governments. The most prominent capacity building program is the Program for Climate Change Mitigation and Adaptation in China, initiated first in 7 pilot provinces in June 2008 and extended to 20 more provinces. In addition, to ensure the achievement of intensity and pollutant reduction goals set in the 
11th Five-year Plan, the reduction targets have been delegated to provinces and their related industrial businesses (to be studied in detail in the case of the Top-1000 Industrial Energy Conservation Program). Through such a traditional top-down approach, the government agencies beyond the center have been involved.

From late 2007, the global economy has undergone recession. International climate change mitigation has confronted new challenges. With China's economy maintaining stable growth, it successively overtook Germany and Japan as the second largest economy after the US. Its position in international climate change negotiations has received more attention. Although China declines to accept any mandatory commitments, it has been mobilizing all forces at local, provincial and national level to address climate change and develop low carbon economy. In November 2009, shortly before the COP 17 Conference in Copenhagen, Chinese Premier Wen Jiabao announced that China would reduce its carbon GDP intensity by $40 \%-45 \%$ by the 2020 , compared with 2005 levels, and increase its renewable energy share to $15 \%$ of its total energy by 2020 . This is another ambitious goal after its $20 \%$ energy intensity reduction goal set five years ago. Though it will not limit the possible increase in carbon emissions, it is the first time the issues of carbon emissions and economic development will be linked. In the speech at the Copenhagen Climate Summit, Wen Jiabao stressed Chinese efforts in carbon emission cuts, "This is a voluntary action China has taken in the light of its national circumstances. ...... We have not attached any condition to the target, nor have we linked it to the target of any other country. We will honor our word with real action. Whatever outcome this conference may produce, we will be fully committed to achieving and even exceeding the target." 
Statistics showed that energy intensity was reduced by $19.2 \%$ during 11 th Five Year Plan period. With a view of completing the $40-50 \%$ carbon intensity reduction goal by 2020, in March 2011, the reduction goal has been separated into energy and carbon intensity goals and addressed in the 12th Five-year Plan: during 2011 to 2015, China plans to reduce its energy intensity by $16 \%$ and its carbon intensity by $17 \%$. This is new progress of Chinese climate change mitigation policy. 


\section{CHAPTER V}

\section{CASE 1: CHINA'S CLIMATE CHANGE MITIGATION INITIATIVE}

\subsection{Introduction}

Chapter 4 has presented a historical overview of China's climate change policy development, which provides contextual background information for the case of China's climate change mitigation action. In the first case study, policy development is perceived as a process in which a variety of actors have formed networks and become increasingly involved in shaping and promoting climate mitigation policies through institutional improvement and policy coordination, in response to increased international and domestic concerns on climate change issues.

According to the policy network analytic framework, the policy process is manifested in the evolvement of policy networks, in which the structures and functions of policy networks are shaped by the interplay of transnational factors, national factors, as well as policy-domain specific factors. In addition, structural and interactive features of policy networks influence policy outcomes and possible policy changes.

Subsequent to the overview of the evolution of China's climate change mitigation policy, this chapter focuses on the study of features and roles of networks in climate change mitigation policy process, and analyzes relationship between policy contexts, networks and outcomes. Such arrangements generally follow the logic of the policy network analytic framework. The chapter proceeds as follows. In Section 5.2, the actors involved in the policy process are identified; and their roles and network features 
are presented. Next, the outcomes of China's climate change mitigation policy and initiative are addressed in Section 5.3. Finally, Section 5.4 concludes the case.

\subsection{Network Actors, Structures, and Interactions}

\subsubsection{Actors at Central Level}

The most important and consistent players in developing China's climate change policy are the State Council and its affiliated ministries and departments. They formed networks to address contextual requirements. Over recent years, the Central Committee of the Chinese Communist Party (CCP) and the National People's Congress (NPC) have actively promoted climate change mitigation policies and activities.

Since 1990, an inter-ministerial committee has taken on the role as the state institution that participates in climate change negotiations and coordinates climate related policies. Ministries and agencies within the committee vary in their degrees of influence. Before the restructuring in 1998, responsibility for the coordination was with the Chinese Meteorological Administration. After 1998, the NDRC, which represents the economic development interests, has played the role of pivotal agency in the coordination committee. Currently, the State Council leads national policy making and coordination among around 20 ministerial agencies involved in the policy making process. Table 5.1 gives an overview of the evolution of the coordination committee. 
Table 5.1 Evolution of China's Climate Change Coordination Committee

\begin{tabular}{|c|c|c|c|c|}
\hline $\begin{array}{l}\text { Name of } \\
\text { the Inter- } \\
\text { ministerial } \\
\text { Committee }\end{array}$ & $\begin{array}{l}\text { Year of } \\
\text { Form- } \\
\text { ation }\end{array}$ & Chairperson & $\begin{array}{c}\text { Leading Agencies and } \\
\text { other Operational } \\
\text { Agencies }\end{array}$ & Mandates/Functions \\
\hline $\begin{array}{l}\text { National } \\
\text { Climate } \\
\text { Change } \\
\text { Coordi- } \\
\text { nation } \\
\text { Group } \\
\text { (NCCCG) }\end{array}$ & 1990 & $\begin{array}{l}\text { Song Jian } \\
\text { (State } \\
\text { Councilor/ } \\
\text { Minister of } \\
\text { MOST) }\end{array}$ & $\begin{array}{l}\text { SMA; SSTC } \\
\text { (Predecessor of MOST), } \\
\text { NEPA, MOFA, SPC } \\
\text { (predecessor of NDRC), } \\
\text { MOE (dissolved in } \\
\text { 1998). Executive Office } \\
\text { at the SMA. }\end{array}$ & $\begin{array}{l}\text {-Participate in } \\
\text { international } \\
\text { cooperation on climate } \\
\text { impact assessment } \\
\text { - Frame China's } \\
\text { position in climate } \\
\text { negotiations }\end{array}$ \\
\hline \multirow{2}{*}{$\begin{array}{l}\text { National } \\
\text { Coordinatio } \\
\mathrm{n} \\
\text { Committee } \\
\text { on Climate } \\
\text { Change } \\
\text { (NCCCC) }\end{array}$} & 1998 & $\begin{array}{l}\text { Zeng Peiyan } \\
\text { (Director of } \\
\text { SDPC) }\end{array}$ & \multirow{2}{*}{$\begin{array}{l}\text { SDPC (NDRC after } \\
2003) \text { as chair agency; } \\
\text { MOFA, SMA, MOST, } \\
\text { SEPA, MOFA; and } \\
\text { other seven agencies. } \\
\text { Executive office at the } \\
\text { SDPC/NDRC. }\end{array}$} & \multirow{2}{*}{$\begin{array}{lr}\text {-Arrange } & \text { and } \\
\text { coordinate } & \text { related } \\
\text { capacity } & \text { building } \\
\text { projects } & \\
\text {-Building consensus } \\
\text { among agencies; } \\
\text {-Frame national } \\
\text { interests in negotiations }\end{array}$} \\
\hline & 2003 & $\begin{array}{lr}\text { Ma } & \text { Kai } \\
\text { (Director of } \\
\text { NDRC) }\end{array}$ & & \\
\hline $\begin{array}{l}\text { National } \\
\text { Climate } \\
\text { Change } \\
\text { Leading } \\
\text { Group } \\
\text { (NCCLG) }\end{array}$ & 2007 & $\begin{array}{l}\text { Wen Jiabao } \\
\text { (Premier of } \\
\text { the State } \\
\text { Council); } \\
\text { Vice Premier } \\
\text { and State } \\
\text { Councilor as } \\
\text { Vice Chairs. }\end{array}$ & 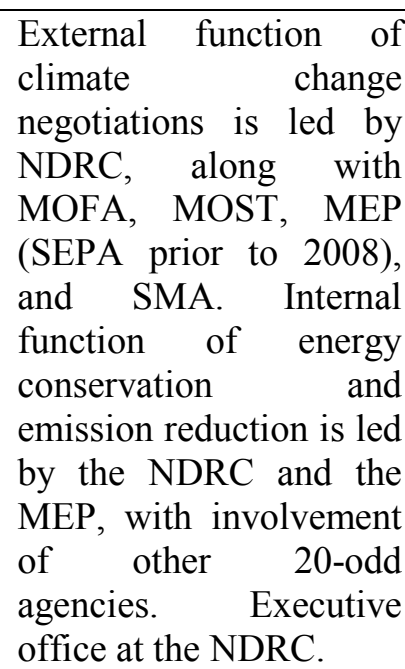 & $\begin{array}{l}\text {-Study and draft } \\
\text { national strategies, } \\
\text { policies and programs } \\
\text { - Review and develop } \\
\text { climate negotiation } \\
\text { strategies } \\
\text {-Implement programs } \\
\text { in energy conservation } \\
\text { and emission reduction }\end{array}$ \\
\hline
\end{tabular}

It can be seen from the table above that the powerful macroeconomic agencies, in particular the NDRC, have dominated the climate change policy making over the past decade. And since the mid-2000s, with the implementation and enforcement of domestic climate-related policies been given a parallel significance with other priority issues of 
energy saving, and environmental pollution control, the State Council has led the policy integration and inter-agency coordination (Qi et al. 2008).

Among agencies within the coordination committee, there are clear divisions, which have been formed by the requirements of international climate change cooperation and negotiations, and domestic economic development. Five agencies, namely the NDRC, the MOST, the MOFA, the MEP, and the SMA, are the most important ministerial agencies that influence the national climate change policy process. Their divisions are summarized in Table 5.2.

Table 5.2 Division within the Inter-ministerial Coordination Committee

\begin{tabular}{|c|c|c|}
\hline Theme & Working Group & Chair Agency \\
\hline \multirow{4}{*}{$\begin{array}{l}\text { International Climate Change } \\
\text { Negotiations, Cooperation } \\
\text { and Policy Development }\end{array}$} & Scientific Assessment & SMA and CAS \\
\hline & $\begin{array}{l}\text { Impact Assessment and } \\
\text { Technological Response } \\
\text { Strategies }\end{array}$ & MOST and MEP \\
\hline & Economic Implications & NDRC \\
\hline & FCCC-related Matters & MOFA and MOST \\
\hline 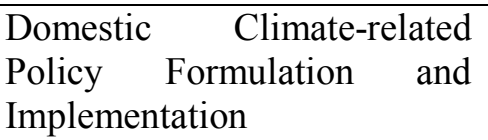 & $\begin{array}{l}\text { Energy Conservation and } \\
\text { Emission Reduction }\end{array}$ & NDRC and MEP \\
\hline
\end{tabular}

It is worth mentioning that besides the State Council and its departments, the Chinese Communist Party and the National People's Congress have shown their positive position toward proactive mitigation activities. At the 17th Party Congress held in 2007, the party secretary Hu Jintao addressed that, in order to promote economic development, China should "improve energy, resources, ecological and environmental conservation and enhance China's capacity for sustainable development. ......, (and) enhance the capacity to respond to climate change and make new contributions to protecting the global climate" (Hu 2007). At the UN Summit on Climate Change in 2009, President Hu pledged China's 
continued efforts on addressing climate change and emphasizes that "climate change is an environment issue, but also, and more importantly, a development issue" (Hu 2009).

Two workshops have been arranged for Politburo members of the Central Party Committee during 2009-2010. The lecturers are influential Chinese scholars from universities and institutions, who have been highly engaged in international climate change negotiations and domestic policy discussions.

In addition, in August 2009, ahead of the COP 15 Conference in December in Copenhagen, a resolution on climate change, named as the Resolution on Making Active Responses to Climate Change, was approved by China's top legislature, the Standing Committee of the 11th National People's Congress (NPC). The resolution praised the effectiveness of the State Council's work on climate change, emphasized the importance of the issue, and clarified guidelines, basic policies, as well as China's stance (NPC 2009). In early 2010, Wu Bangguo, Chairman of the NPC Standing Committee, reemphasized the importance of strengthening the legislative work in promoting green economy and developing low-carbon economy in China (China News 2010).

\subsubsection{Local Governments}

For a long time, climate change issues were treated as being well beyond the responsibility of local governments. The trajectory has changed since the mid-2000s. Qi et al. (2008) observed that three factors have caused the change: mandates from the central government, internalized needs, and the international market. After two mandatory targets (i.e., energy intensity and main pollutant emissions) were set in the 11th Five-year Plan in 2006, a majority of provincial governments have issued local regulations and set up provincial Energy-Saving and Emission- Reduction Coordination 
Groups, with similar composition to the national one since late 2007 (Op cit.). Provincial governments also established target responsibility and performance assessment systems. Government at local levels (provincial, municipal and county) signed target contracts with higher-tier government. Their performance will be evaluated annually to determine the appointment of the relevant officials. For local governments, the activities to enhance energy efficiency and renewable energy provide an opportunity to gain mitigation benefits without compromising its local economic priority. Furthermore, CDM market development has driven Chinese project developers to invest in carbon reduction projects. The local governments and their agencies (such as local Development and Reform Commissions, CDM promotion centers) have been important supporters and supervisors of the CDM projects.

\subsubsection{Academic Institutions, Industrial Associations and Individual Experts}

A growing number of research institutions and academic organizations have been involved in climate change policy cycles. Some of these institutions are entities directly attached to the State Council, such as the Chinese Academy of Sciences; the Chinese Academy of Social Sciences. Some of the academic institutions have close relations with member agencies of coordination committee, such as the Energy Research Institute and the National Climate Center. In China, almost all ministries and agencies at the central level have research institutes attached to them. These institutes are traditionally government-sponsored, and now restructured as Government Organized Non-Governmental Organizations (GONGOs). With the new status, these research institutions undertake independent research normally delegated and financially supported by decision-making agencies. Table 5.3 lists the key research institutes attached to 
leading agencies that deal with climate change issues. Their research broadly focuses on two areas: one is climate change sciences and technologies; the other is the impacts on development and China's corresponding strategies. Since climate change covers a wide variety of issues, in practice, there is much cooperation and information exchange among these research institutions. They provide decision makers suggestions from different but complementary perspectives.

Table 5.3 Research Institutes Involved in China's Climate Change Discussion

\begin{tabular}{|l|l|l|}
\hline \multicolumn{1}{|c|}{ Research Institutions } & Higher Authority & \multicolumn{1}{|c|}{ Main research areas } \\
\hline $\begin{array}{l}\text { Chinese Academy of Sciences } \\
\text { (a number of relevant } \\
\text { institutes) }\end{array}$ & State Council & $\begin{array}{l}\text { Scientific issues, and science-policy } \\
\text { interaction issues }\end{array}$ \\
\hline $\begin{array}{l}\text { Chinese Academy of Social } \\
\text { Sciences (In particular, the } \\
\text { Research Center for } \\
\text { Sustainable Development) }\end{array}$ & State Council & $\begin{array}{l}\text { Policy issues, sustainable development } \\
\text { strategy, climate change diplomacy, } \\
\text { international cooperation }\end{array}$ \\
\hline $\begin{array}{l}\text { Academy of Macro-economic } \\
\text { Research particular the } \\
\text { Energy Research Institute) }\end{array}$ & NDRC & $\begin{array}{l}\text { Comprehensive climate change policy } \\
\text { issues, energy policy advisory, energy } \\
\text { development strategy, international } \\
\text { cooperation }\end{array}$ \\
\hline $\begin{array}{l}\text { The Administrative Center for } \\
\text { China's Agenda 21 }\end{array}$ & MOST & $\begin{array}{l}\text { Sustainable development policy } \\
\text { research, national science and } \\
\text { technology policy }\end{array}$ \\
\hline $\begin{array}{l}\text { National Climate Center; } \\
\text { Academy of Meteorological } \\
\text { Sciences }\end{array}$ & SMA & $\begin{array}{l}\text { Climate change impacts, climate } \\
\text { adaptation policy advisory, IPCC- } \\
\text { related task work }\end{array}$ \\
\hline $\begin{array}{l}\text { China Institute of International } \\
\text { Studies Academy for }\end{array}$ & MOFA & $\begin{array}{l}\text { Climate diplomacy, climate change } \\
\text { and international relations }\end{array}$ \\
\hline $\begin{array}{l}\text { Chinese An } \\
\text { Environmental Planning }\end{array}$ & $\begin{array}{l}\text { Environmental protection and } \\
\text { economic development, environmental } \\
\text { impact assessment }\end{array}$ \\
\hline $\begin{array}{l}\text { Chinese Academy of Forestry; } \\
\text { Chinese Academy } \\
\text { Agricultural Science }\end{array}$ & $\begin{array}{l}\text { State Forestry } \\
\text { Administration; } \\
\text { Ministry } \\
\text { Agriculture }\end{array}$ & $\begin{array}{l}\text { Afforestation and Reforestation } \\
\text { of }\end{array}$ \\
\hline
\end{tabular}

Universities also make great contributions to the research on climate change policies. Some prominent contributors include Beijing University; Tsinghua University; 
Renmin University of China, Fudan University, etc. Sensing the great importance of explaining China's climate policy to the outside world, since the COP 6 in 2001, China has sharply increased the share of delegates coming from academic agencies for participating in the FCCC conferences. A top-level climate change expert panel, consisting of 12 scientists from key Chinese research institutions was established in early 2007 to provide strategic scientific support for decision making at the central level (personal interview). Another example is that for preparing the national communication report, under the joint guidance of the SMA, the MOST and the CAS, six governmentaffiliated research institutes have jointly conducted national GHG inventory Project (Zhou et al. 2008).

In China, industrial associations act as intermediaries linking government with industrial businesses. These sectoral associations, in the form of GONGOs, have received large amount of governmental resources, but the state also pushes them to be selfsufficient and partially separate from the government. Most influential industrial associations evolve from industrial ministries and still have strong influences on industries. Sectoral associations contribute more practically to the information exchange and policy consultation on the study of climate change. For example, the Association of Energy Conservation has been actively involved in the design and implementation of industrial energy conservation programs.

In general, researchers, experts and the public have enjoyed more freedom to voice their opinions which can reflect their individual ideologies and interests. Although individual experts tend to receive less attention than the authoritative organizations, their opinions can sometimes bring vibrant policy discussions. An example is that before the 
Copenhagen conference in 2009, there was a heated debate initiated by Hu Angang, a famous scholar from Tsinghua University. With a more cosmopolitan perspective, he challenged China's unwillingness to accept a mandatory mitigation commitment during the Post-2012 period (Liu and Yi 2009); however, his proposition was soon questioned by others, including some from the Chinese climate delegation. Hu insisted that he would not change his proposition and argued that was a better solution for China's future development.

\subsubsection{Other Non-state Actors}

Besides academic institutions and industrial associations, there are other important non-state actors, including energy-intensive businesses, NGOs (NonGovernmental Organizations), mass media. In general, these actors are relatively weak actors who have constrained space to play and limited resources to influence the state actors.

Business groups have a wide variety of stakes in climate change policy development. The major industries of interest are energy intensive companies in fields of fossil fuels, automobiles, power generation, among others. However, the corporatization reforms since 1990s have decentralized much authority of supervision from the central government to provincial and other local-level governments and the state would no longer subsidize enterprises that were unprofitable (Richerzhagen and Scholz 2008). Because climate change policies are limitedly debated outside central government and potential conflicts exist between local economic interests and mitigation measures, industrial companies' role in climate policy process has been marginalized. Still, about 100 large-scaled industrial businesses are under the leadership and supervision of the 
central government, represented by the State-owned Assets Supervision and Administration Commission (SASAC) established in 2003. These companies have closer linkage with central government agencies; but like the other companies, they are more concerned with the impact of potential climate regulations on their economic performance.

In Western democratic countries, NGOs can play a variety of roles, including setting the policy agenda, providing policy advices recommendations, applying political pressure, monitoring government actions, and assisting policy implementation (Raustiala 2001); while in China, the NGOs, especially the grassroots NGOs are not significant actors in the policy making process, because of being constrained by government administrative regulations and lack of funds and human resources (Economy 1997; Richerzhagen and Scholz 2008). Over recent years, there has been some improvement in that the NGOs in China are allowed and encouraged to initiate some awareness building programs, providing a complement to official actions. According to Zhao and Mori (2008), eight environmental NGOs have jointly proposed an action plan for combating climate change. In 2007, forty NGOs launched Energy Saving Citizen Actions to raise public awareness.

The media coverage on climate change issues has been increasing remarkably. The media has been used to support official initiatives or provide supervision of policy implementation (Richerzhagen and Scholz 2008). Most media and NGOs regard themselves as cooperative partners with government, and they actively engage in reporting the progress of international climate negotiations and domestic policy development and practices. 


\subsubsection{Interactive Features of Policy Process}

The state and non-state actors identified above perform their functions in climate change policy development process through their interactions. The interactions, among and within state and non-state actors, are concentrating on major issues in which actors form networks in negotiating and advancing particular policy options. These interactions enable effective policy formulation and development. In China, climate policy networks are primarily driven by key government agencies at the central level, and can be broadly grouped into three functionally defined clusters, as shown in Table 5.4. Each cluster has a number of different government agencies. The market and civil society actors with distinctive tasks and functions are also involved in these clusters.

Table 5.4 Composition and Focused Issues of China's Climate Policy Network

\begin{tabular}{|c|c|c|c|c|}
\hline $\begin{array}{l}\text { Policy Focus } \\
\text { (Cluster) }\end{array}$ & $\begin{array}{c}\text { Decision-making } \\
\text { Agency }\end{array}$ & $\begin{array}{c}\text { Core Network } \\
\text { Membership }\end{array}$ & $\begin{array}{c}\text { Other Key } \\
\text { Government Actors }\end{array}$ & $\begin{array}{l}\text { Market and Civil } \\
\text { Society Actors }\end{array}$ \\
\hline $\begin{array}{l}\text { Economic } \\
\text { Development } \\
\text { and Mitigation }\end{array}$ & \multirow{3}{*}{$\begin{array}{l}\text { The State Council, } \\
\text { supported by the } \\
\text { Central Party } \\
\text { Committee and } \\
\text { the National } \\
\text { People's Congress }\end{array}$} & NDRC & $\begin{array}{lr}\text { Relevant } & \text { member } \\
\text { agencies } & \text { within } \\
\text { NCCLG; } & \text { local } \\
\text { government } & \end{array}$ & $\begin{array}{lr}\text { Academic } & \text { research } \\
\text { institutions } & \text { and } \\
\text { universities; business } \\
\text { actors; grassroots } \\
\text { NGOs, mass media }\end{array}$ \\
\hline $\begin{array}{l}\text { Climate } \\
\text { Diplomacy }\end{array}$ & & $\begin{array}{l}\text { MOFA, } \\
\text { NDRC }\end{array}$ & $\begin{array}{lr}\text { Relevant } & \text { member } \\
\text { agencies } & \text { within } \\
\text { NCCLG } & \\
\end{array}$ & $\begin{array}{lr}\text { Academic } & \text { research } \\
\text { institutions } & \text { and } \\
\text { universities } & \\
\end{array}$ \\
\hline $\begin{array}{l}\text { Climate Impacts } \\
\text { and Technical } \\
\text { Strategies }\end{array}$ & & $\begin{array}{l}\text { SMA, MOST, } \\
\text { CAS, NDRC }\end{array}$ & $\begin{array}{lr}\text { Relevant } & \text { member } \\
\text { agencies } & \text { within } \\
\text { NCCLG } & \\
\end{array}$ & $\begin{array}{lr}\text { Academic } & \text { research } \\
\text { institutions } & \text { and } \\
\text { universities } & \\
\end{array}$ \\
\hline
\end{tabular}

The interactions among actors of policy networks have been evolving, reflecting the changes and interactive play of domestic and international contests. In general, the interactions of the policy networks are characterized by following features:

(1) The State Council has led climate change policy making and implementation, as well as policy coordination. Consistent with other findings of the Chinese policy 
process (Peng 2003; Pang and Zou 2008), in climate change mitigation policy making, the administrative measures and relevant policies developed by the State Council are reinforced by the political advocacy of the Central Committee of the Party. For example, at the Politburo study meeting in the early 2010, President and also the Party General Secretary $\mathrm{Hu}$ Jintao stressed that China must recognize the importance, urgency and difficulty of dealing with climate change, and the leadership will be working hard to steer efforts to realize the goal of $40-45 \%$ reduction of carbon intensity, of which China has shortly promised at the Copenhagen Climate Summit (ChinaDaily, 2010). In addition, the domestic climate policies and regulations have been facilitated by more legislative involvement of the National People's Congress, as shown by the passage of a resolution on responding to climate change in 2009 (NPC 2009).

(2) The NDRC maintains a pivotal position at the ministerial level in coordinating and advancing the domestic climate policy process. Institutional and personnel arrangements within the NDRC are continuously adjusted in response to international and domestic political and policy needs. For example, in 2008, two new departments were established within the NDRC, i.e., the Department of Climate Change and the Department of Resource Conservation and Environmental Protection. The two departments are responsible for external and internal climate-related issues respectively (personal interview). In order to strength communication and dialogue in international climate change negotiations and cooperation, China also adjusted its personnel arrangements. Xie Zhenhua, former minister of the SEPA, became the vice-minister of the NDRC and the chief climate change negotiator. Su Wei, a veteran climate change negotiator from the Department of Laws and Regulations of the Ministry of Foreign 
Affairs (MOFA), now acts as the chief of the Department of Climate Change and participates intensely in international climate negotiations.

(3) Although climate change policy is primarily discussed within a small number of institutions (Liu and Yi 2009), expert consultation has gained more weight. Numerous academic institutions, universities, associations and think-tanks are involved in the process and contribute to the policy agenda setting, alternative policy discussions, public awareness building, and capacity development activities.

(4) The climate change actor network in China has expanded to cover local governments, businesses and civil society actors, who have diversified interests and capacity; however, they are still peripheral actors. With the implementation of more climate mitigation policies and programs, more active performance of network actors can be expected, which interacts with the ongoing political and administrative reform initiatives.

\subsection{Climate Change Policy Outcomes}

\subsubsection{Policy Outputs}

In the early phases of climate policy development, China's climate mitigation policy was not found in forms of laws, regulations or guidelines by government, most of the policy statements existed in speeches and articles of government officials, with a view of clarifying the national position on climate change issues (Qi et al. 2007). Although China still rejects a mandatory mitigation cap on the ground of its unchanged status as a developing country, with mounting pressures on its growing contribution on carbon emissions and its climate stances, the central government has shifted its perspective of 
climate change challenges from more of a scientific and environmental issue to predominantly a development issues. Without sacrificing the economic development which may cause higher unemployment and social instability, an important measure is to decouple the link between development and energy use, and to integrate the climate change into national development plans. In 2002, in the Communist Party Congress, China's leaders outlined a goal of quadrupling the country's 2000 Gross Domestic Products (GDP) by 2020, while only doubling energy consumption.

Over the past decade, a number of policies and measures have been adopted and implementation, which involved a variety of state and non-state actors in the process. Table 5.5 shows major climate change policies and measures adopted that contribute to mitigation benefits.

Some of these policies cover a wide range of sectoral areas that require a group of specialized agencies to negotiate a policy solution, and the Eleventh Five-year Plan provides a comprehensive development framework to guide relevant ministries or local governments to develop policies in a reasonably coherent way. Another feature is that diverse policy tools have been introduced, such as regulative measures, administrative rules, laws, voluntary action, and market-based measures. The policy goals set by these policies and measures have been used as reference scenario for evaluating policy performance and analyzing future potential. In addition, the participation of climate mitigation activities has permeated to local areas, and local governments work in matching climate change issue with the local priorities. 
Table 5.5 Major Climate Change Policies and Measures Adopted in China

\begin{tabular}{|c|c|c|c|c|}
\hline Policy/Measure Name & Agency & Objectives/ Mitigation Targets & Type & Year \\
\hline $\begin{array}{lrr}\text { China's } & \text { Targets } & \text { on } \\
\text { Carbon Emission } & \text { Cuts } \\
\text { beyond the Kyoto } & \end{array}$ & $\begin{array}{l}\text { State } \\
\text { Council }\end{array}$ & $\begin{array}{l}\text { Reducing carbon intensity (carbon } \\
\text { emission per unit of GDP) by } 40 \text { - } \\
45 \% \text {, below } 2005 \text { levels by } 2020\end{array}$ & $\begin{array}{l}\text { Policy } \\
\text { Statements }\end{array}$ & 2009 \\
\hline $\begin{array}{l}\text { Program for Climate } \\
\text { Change Mitigation and } \\
\text { Adaptation in China }\end{array}$ & NDRC & $\begin{array}{l}\text { Helping local governments build } \\
\text { capacity; Drafting local climate } \\
\text { strategies in accordance with the } \\
\text { national program. }\end{array}$ & $\begin{array}{l}\text { Pilot } \\
\text { Projects } \\
\text { (from } 7 \\
\text { provinces) } \\
\end{array}$ & 2008 \\
\hline $\begin{array}{l}\text { China's Policies and } \\
\text { Actions for Addressing } \\
\text { Climate Change }\end{array}$ & $\begin{array}{l}\text { State } \\
\text { Council }\end{array}$ & $\begin{array}{l}\text { Proposing a coordinated response } \\
\text { toward national and international } \\
\text { challenges }\end{array}$ & $\begin{array}{l}\text { Framework } \\
\text { Policy }\end{array}$ & 2008 \\
\hline $\begin{array}{l}\text { National Building Codes } \\
\text { for Residential and } \\
\text { Commercial Buildings }\end{array}$ & $\begin{array}{l}\text { Ministry of } \\
\text { Construc- } \\
\text { tion Plan }\end{array}$ & $\begin{array}{l}\text { a } 50 \% \text { reduction of building's total } \\
\text { operation load based on a building's } \\
\text { energy consumption during the } 1980 \mathrm{~s}\end{array}$ & $\begin{array}{l}\text { Regulatory } \\
\text { Instruments }\end{array}$ & 2008 \\
\hline $\begin{array}{l}\text { National Climate Change } \\
\text { Program }\end{array}$ & $\begin{array}{l}\text { State } \\
\text { Council }\end{array}$ & $\begin{array}{l}\text { Outlining activities both to mitigate } \\
\text { GHG emissions and to adapt to the } \\
\text { impacts of potential climate change }\end{array}$ & $\begin{array}{l}\text { Framework } \\
\text { Policy }\end{array}$ & 2007 \\
\hline $\begin{array}{l}\text { Closing Inefficient } \\
\text { Industrial Plants }\end{array}$ & $\begin{array}{l}\text { NDRC } \\
\text { Plan }\end{array}$ & $\begin{array}{l}\text { Closing inefficient cement and steel } \\
\text { factories with outdated production } \\
\text { capacity of } 250 \text { million tons and } 55 \\
\text { million tons, respectively, by } 2010 \text {. }\end{array}$ & $\begin{array}{l}\text { Regulatory } \\
\text { Instruments }\end{array}$ & 2007 \\
\hline $\begin{array}{l}\text { Medium and Long Term } \\
\text { Development Plan for } \\
\text { Renewable Energy }\end{array}$ & $\begin{array}{l}\text { NDRC } \\
\text { Plan }\end{array}$ & $\begin{array}{l}\text { An investment of } 263 \text { billion USD by } \\
2020 \text { on renewable energy, and raise } \\
\text { the percentage of renewable energy } \\
\text { to } 10 \% \text { of total energy consumption } \\
\text { by } 2010 \text { and } 15 \% \text { by } 2020 \text {. }\end{array}$ & $\begin{array}{l}\text { Policy } \\
\text { Framework }\end{array}$ & 2007 \\
\hline $\begin{array}{l}\text { Energy } \quad \text { Efficiency } \\
\text { Appliance Standards }\end{array}$ & $\begin{array}{l}\text { NDRC } \\
\text { Plan }\end{array}$ & $\begin{array}{l}\text { Reduce residential electricity use by } \\
10 \% \text { by } 2010, \text { by promoting } \\
\text { mandatory minimum efficiency } \\
\text { standards }\end{array}$ & $\begin{array}{l}\text { Regulatory } \\
\text { Instruments }\end{array}$ & 2007 \\
\hline $\begin{array}{lr}\text { Top-1000 } & \text { Industrial } \\
\text { Energy } & \text { Conservation } \\
\text { Program } & \text { (presented as } \\
\text { Case } 3 \text { in Chapter. 7) }\end{array}$ & $\begin{array}{l}\text { Inter- } \\
\text { agency } \\
\text { plan, led by } \\
\text { the NDRC }\end{array}$ & $\begin{array}{l}\text { Cutting energy use of the } 1,000 \text { most } \\
\text { energy-intensive enterprises from } 9 \\
\text { industrial sectors }\end{array}$ & $\begin{array}{l}\text { Voluntary/ } \\
\text { Regulatory } \\
\text { Program }\end{array}$ & 2006 \\
\hline $\begin{array}{l}\text { China's 11th Five-Year } \\
\text { Plan }\end{array}$ & $\begin{array}{l}\text { National } \\
\text { People's } \\
\text { Congress }\end{array}$ & $\begin{array}{l}\text { Reducing energy intensity by } 20 \% \text {, } \\
\text { and reducing the main pollutants by } \\
10 \% \text { below } 2005 \text { levels by } 2010\end{array}$ & $\begin{array}{l}\text { Framework } \\
\text { Policy }\end{array}$ & 2006 \\
\hline $\begin{array}{l}\text { Vehicle Fuel Economy } \\
\text { Standards }\end{array}$ & $\begin{array}{l}\text { NDRC } \\
\text { Plan }\end{array}$ & $\begin{array}{l}\text { The standards will be implemented in } \\
\text { two phases. By 2008, average } \\
\text { domestic passenger vehicles are } \\
\text { required to meet } 36 \text { mpg } \\
\text { requirement. }\end{array}$ & $\begin{array}{l}\text { Regulatory } \\
\text { Instruments }\end{array}$ & $\begin{array}{l}2005 ; \\
2008 \\
\text { (Phase } \\
\text { Two) }\end{array}$ \\
\hline $\begin{array}{l}\text { Clean Development } \\
\text { Mechanism (CDM) } \\
\text { Management Rules } \\
\text { (Presented as Case } 2 \text { in } \\
\text { Chapter 6) }\end{array}$ & $\begin{array}{l}\text { Inter- } \\
\text { agency } \\
\text { committee } \\
\text { led by the } \\
\text { NDRC }\end{array}$ & $\begin{array}{l}\text { Regulate the CDM project } \\
\begin{array}{l}\text { Management (entry requirement, } \\
\text { priority projects, } \\
\text { procedures) }\end{array}\end{array}$ & $\begin{array}{l}\text { Regulatory } \\
\text { rules for } \\
\text { carbon } \\
\text { market } \\
\text { trading }\end{array}$ & $\begin{array}{l}2004 ; \\
\text { revised } \\
\text { in } \\
2005\end{array}$ \\
\hline
\end{tabular}

Source: Pew 2007; Leggett et al. 2008; IEA 2010 
With the experience accumulated, China has identified focused areas of mitigation-related action, as shown in China's Policies and Actions for Addressing Climate Change, issued by the State Council in 2008. These action areas include (1) Restructuring the economy and enhancing industrial competitiveness; (2) saving energy and improving energy efficiency; (3) developing renewable energy and optimizing energy mix; (4) developing recycling economy to reduce GHG emissions; (5) promoting afforestation campaign and enhancing carbon sequestration capacity; and (6) intensifying R\&D efforts (State Council 2008).

\subsubsection{Policy Performance}

As discussed above, the main climate change mitigation actions promoted over the last decade was largely due to the increased international pressures and domestic concerns on the impacts of resource and environmental constraints on sustained economic development. However, with rapid GDP growth, in absolute values, China's energy consumption and carbon emissions have been continuously on the rising trend. Figure 5.1 shows China's carbon emissions during 1990-2008, compared with the US and the EU countries. Before 2001, carbon emissions in China were $45-55 \%$ of the US level and $60-75 \%$ of the EU countries. However, driven by its rapid and persistent economic growth, especially after entering into the WTO, China's carbon dioxide emissions increased quickly and overtook the emissions of the EU in 2003 and those of the US in 2006. 


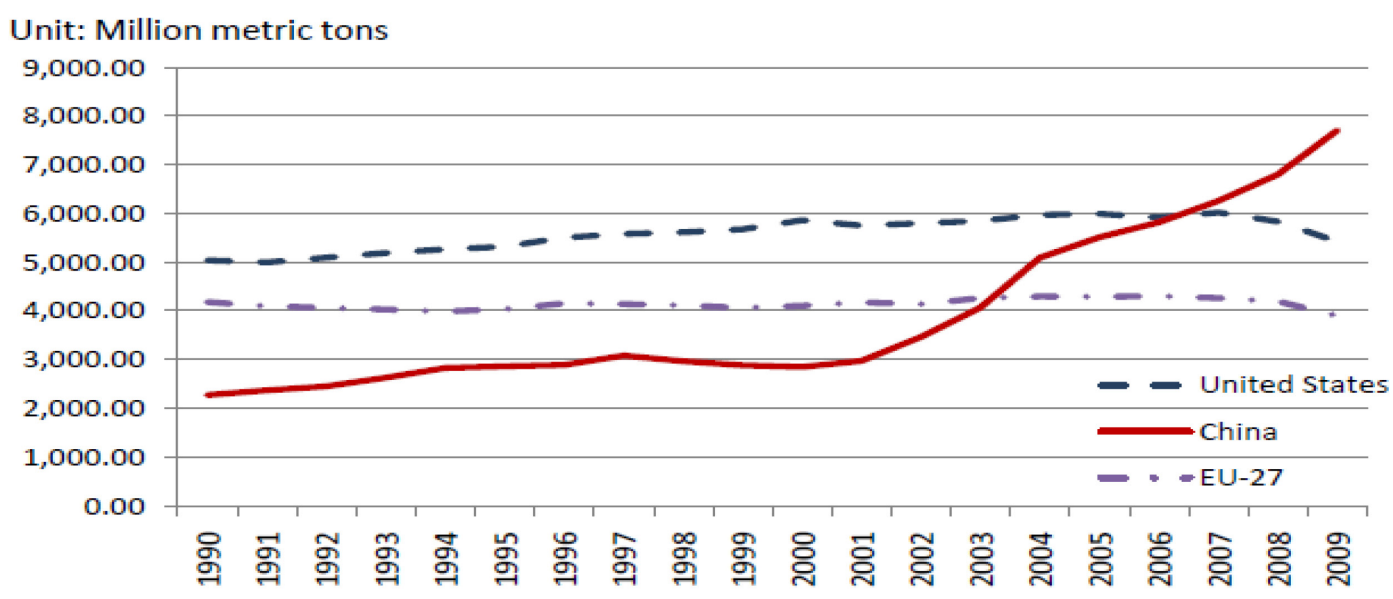

Figure 5.1 Growth of China's Carbon Dioxide Emissions

Source: EIA 2010

In fact, what made Chinese leaders worried most since early 2000s was the situation that the energy consumptions, as well as accessory carbon emissions may have risks of increasing at higher rates than the GDP growth rates (see Figure 5.2 below).

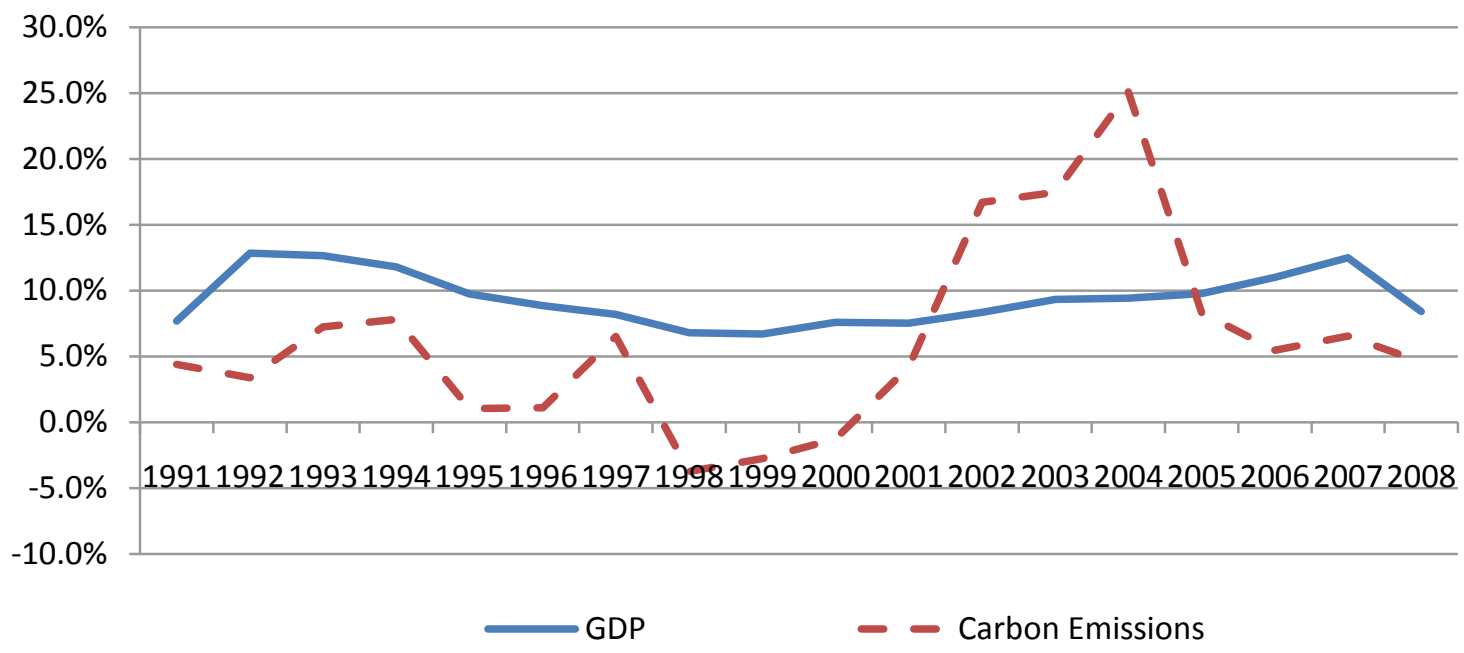

Figure 5.2 Annual Growth Rate Changes of GDP and Carbon Emissions in China Source: EIA 2010; NBS 2009 
Seen from the Figure above, the annual GDP growth rate in China stabilized around $10 \%$ in recent years, while carbon emissions have undergone a sharp growth during 2001-2005. With a number of policies and measures implemented during this period, from 2006, the abrupt carbon growth trend has been stopped.

The Chinese government has employed carbon intensity as key indicator to measure its energy-saving and corresponding mitigation performance. The decrease of carbon intensity shows the country's achievements in energy efficiency improvement and its strategy in avoiding the economic slowdown. The central government seriously treats energy intensity reduction (20\% reduction during 2006-2010) as a political target and requires relevant agencies, localities and sectors to strictly follow it.

Internationally, China confronts increased pressure to reduce absolute GHG emissions. The Clean Development Mechanism (CDM) project development provides such a scheme that China can voluntarily participate and the GHG reductions are measured in absolute terms. Although disputes exist, the credits from CDM are measureable, reportable and verifiable. The CDM institutional arrangements in China effectively strengthened its competence in the global carbon market (Ganapati and Liu 2008). With more experience gained, China attempts to establish its own cap-and-trade system domestically. Two carbon-trading exchanges have been put into operation in Tianjin and Beijing, which are supposed to provide an innovative platform for trading surplus credits among regulated businesses domestically, and successfully linking with other international carbon trading schemes.

The absolute carbon emission reductions are also calculated to demonstrate China's efforts in reducing or slowing down the GHG emissions. For example, in the 
National Climate Change Program promulgated in 2007 (NDRC 2007), China announced that an accumulated 800 million tce (tons of coal equivalent) of energy were saved by economy restructuring and technical improvement during 1990-2005, which is equivalent to a reduction of 1.8 billion tons of $\mathrm{CO}_{2}$ emissions. Besides, through promoting new energy efficiency policies, a further 670 million reduction of $\mathrm{CO}_{2}$ emissions has been achieved during 2006-2008 in China (State Council 2009).

However, using absolute $\mathrm{CO}_{2}$ emission reduction figures to evaluate policy performance is not without problems. One is credibility of the identification of reference scenarios. Can the historical development trends be taken as reference scenario or the targets set in the policies taken as the reference? The selection and measurement is still murky. The other problem is the lack of transparency and capacity in reporting some sensitive emission data in China. For example, research conducted by the Chinese Academy of Sciences (CAS) in October 2008 projected that China's GHG emissions may more than double within the next two decades; however, Tu (2009) notes that the current GHG emission data was not given in the research. In addition, Seligsohn (2010) claims that China has less experience in GHG emission data collection and analysis, so it is urgent to improve its capacity primarily in emission data analysis and in creating a replicable and updatable system.

\subsection{Conclusive Summary}

China has been involved in global climate change scientific discussions and political negotiations since late 1980s. Consistent with the development of international climate change regime, the focus of domestic policy discussions on climate change has 
shifted from a scientific issue to a development issue. More bureaucratic agencies have been involved in policy making and implementation; and the NDRC, the MOFA, and the MOST have gradually become the leading ministerial agencies in shaping China's climate change mitigation policies. Most formal climate change mitigation policies were adopted and implemented after the mid-2000s, reflecting the requirements of participating in the negotiation of global climate change regime, and the constraints of domestic environmental and energy resources. In general, China is regarded as an active participator in climate change mitigation activities.

There has been increasing interaction among government, market and civil society actors in participating in climate change mitigation activities. However, in China, the state government at central level, led by the State Council, dominates the climate policy making process. Local governments, private businesses, and other civil society actors, with diverse interests and capacities, are still weak actors. However, research institutions (such as universities, research institutes, and industrial associations) have gained more weight in policy consultation and advising. In addition, seen from the history of China's climate change policy development and implementation performance, on the one hand, with the adoption and implementation of various types of climate change mitigation policies, the interactions among government, market and civil society actors have significantly increased; on the other hand, with the capacity enhancement and experience accumulation, China has demonstrated greater proactiveness and enthusiasm in promoting mitigation activities. However, China's readiness and proactiveness is the result of joint influences of international, national, and specific-policy factors, not a single one. 
China's reforms since late 1970s have clearly led to an extremely varied pattern of administration and development. With economic transition towards market economy and economic integration with the world, structures and interactions of actor networks have kept on evolving. Although the extent of government's intervention in economic and social development is frequently in debate, the relations between government and enterprises have been transforming towards more market-based, and localities have earned greater freedom from the higher levels. Under these contexts, innovative climate change mitigation policies have been allowed to pilot and diffuse to a larger scale. These policies include management rules that promote market-based CDM project development (presented as Case 2), and the Top-1000 Industrial Energy Conservation Program (presented as Case 3), which owns strong voluntary origins. It is fair to say that fragmentation of power between state and society is accompanied by the wider adoption of market-oriented policies and other flexible policies.

The economic reforms in China led to a relaxation of political control over the economy and society, in part by design and in part by default (Saich 2004, 222). Accordingly, the social structure is redefined and civil society actors have gained more freedom and flexibilities in pursuing their own economic interests. Although a variety of civil society actors have been involved in the climate change mitigation activities in China, there is no evidence that their engagement is spontaneous and in tune with the mission targets set by government. Therefore, it is fair to say that roles and status of nonstate actors in ensuring effective policy implementation have been well recognized; however, as a group, their impacts on policy formulation and decision making are still limited. 
Finally, climate change mitigation covers a wide range of sectors. With the development of international climate change regime, China has established a network of actors to conduct and coordinate national climate related action. The complexity of coordinating climate change mitigation and adaptation activities between diverse ministerial agencies, between central government and local governments, and between state and society has increased. Seen from the historical restructuring of Chinese interministerial coordination committee, no single agency has such a powerful organizational authority to coordinate complex interests and concerns from other ministerial agencies. Therefore, the State Council becomes an inevitable institution to chair the institutional coordination and organize policy integration. Along this process, both the central party committee and the national congress have provided important support to the State Council. 


\section{CHAPTER VI}

\section{CASE 2: CLEAN DEVELOPMENT MECHANISM IN CHINA}

\subsection{Introduction}

The Clean Development Mechanism (CDM) regime is a project-based scheme under the Kyoto Protocol. It enables developed countries with emissions reduction commitments to use the credits generated, named as the Certified Emission Reductions (CERs), to count against their obligatory compliance targets through investing in emission reduction projects in developing countries. On the other hand, developing countries, through voluntarily participation, can gain access to necessary technologies and funds needed for sustainable development. The CER trading between developed countries and developing countries is realized in a global carbon market. According to the CDM regulations, host developing country government takes the responsibility to approve proposed projects based on national priorities.

As a result of its increasing GHG emissions and great mitigation potential, China's role and action in developing project-based CDM projects have been given serious international concern. At the same time, the CDM provides China with an important incentive to enhance capacity and participate in global carbon reduction effort. With the country becoming the world leader in gaining CER credits, China has learned how to use the CDM scheme to its advantage.

This chapter uses the policy network approach to examine how the state and non-state actors have formed networks in promoting CDM projects in China. Following this introduction, the next section contextualizes the environment of CDM 
implementation, focusing on how the CDM scheme has been initiated in China. Subsequently, Section 6.3 describes the further development and improvement of CDM institutions and actor network in China, which lead to the market performance and other outcomes in Section 6.4. Finally, the concluding summary is presented in Section 6.5.

\subsection{Contextual Background}

\subsubsection{CDM Background}

The introduction of the Clean Development Mechanism (CDM) concept started years before the Kyoto Protocol was formally negotiated in 1997. As the precursor to today's CDM and JI (Joint Implementation) projects, the Activities Implemented Jointly (AIJ) initiated its pilot phase from 1995 till 2000 and developed about 150 GHG reduction and sequestration projects in over 40 countries (Michaelowa 2002). The AIJ contributed to the experience learning in the GHG emission reduction activities prior to the Kyoto Protocol. With the AIJ's progress in awareness building and capacity improvement, the CDM gained gradual recognition though the concerns on the procedures and risks remained (Kaupp et al. 2002; Bhandari 2003). It was not until the Seventh Conference of the Parties (COP 7) to the UNFCCC in 2001 that the CDM modalities, guidelines and procedures were adopted, which paved the way for further CDM institutional development.

Under the Kyoto Protocol, the Conference of the Parties serving as the Meeting of the Parties (CoP/MoP), the Executive Board (EB), and the Designated Operational Entities (DOEs) are the key entities to the governance of the CDM. The CoP/MoP has the overall authority over matters pertaining to the CDM, in that it provides guidance to the 
$\mathrm{EB}$, makes decisions on rules of procedure, and maintains an equitable distribution of the CDM projects amongst non-Annex I countries. The EB is charged with the supervision and approval of the CDM projects through affiliated panels or working groups. The DOEs are accredited by the EB to specifically perform the validation, verification and certification functions for a CDM project. Project proponents can select one DOE to validate its project and another DOE for project verification and certification.

To promote a standardized system in project approval and decide whether the project would generate sustainable benefits, the host country is required to establish a focal agency, called Designated National Authority (DNA). The DNA performs functions of establishing national criteria and management rules; elaborating the national guidelines and procedures for project approval; and ensuring the compliance of CDM projects with relevant national policy and regulatory regimes (UNEP 2004).

A complete CDM project follows a number of essential steps, known as CDM cycle. Figure 6.1 below shows the processes of a CDM project, the needed documents and the responsible entities involved in the process. 

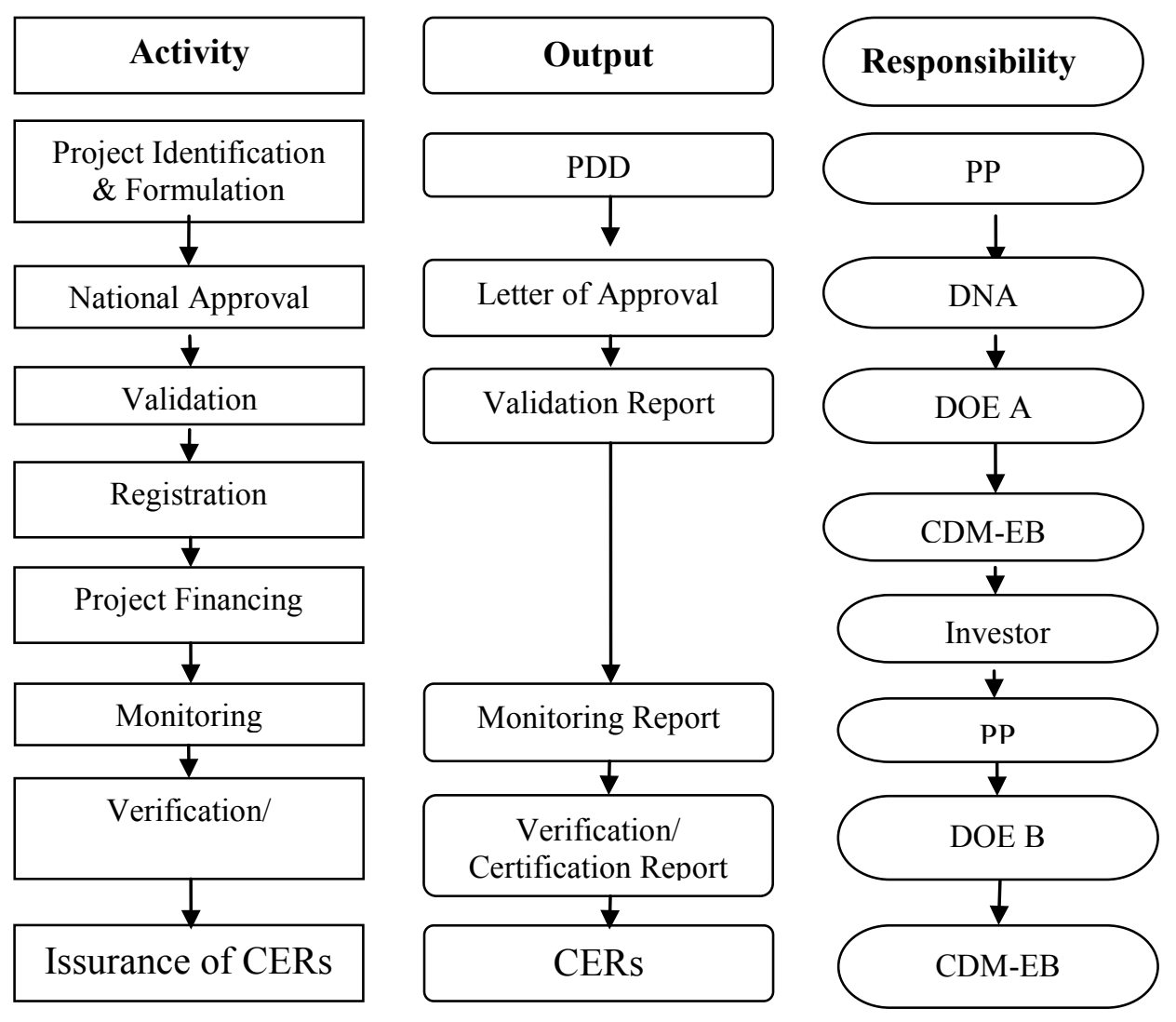

Figure 6.1 Processes and Parties Involved in a CDM Project

Note: PP-Project proponents/participants; DNA-Designated National Authority; DOE-Designated Operational Entity; EB-Executive Board; PDD-Project Design Document; CER-Certified Emission Reductions

Source: UNEP 2004, 12; CCPO 2004

Clean Development Mechanism gained momentum after the Kyoto Protocol's entry into force in early 2005 and the emergence of the global carbon trading market, especially the European Union Emission Trading Scheme (ETS). As of March 2010, 4968 CDM projects have been developed by 76 developing countries in the world. In terms of the stages of project development, 2062 projects have been registered by the EB and more than 600 projects have been issued the Certified Emission Reductions (CERs). The accumulative emission reductions from these projects are expected to be 2835.6 
million tons of $\mathrm{CO}_{2}$ by 2012 (CD4CDM 2010). Although there is uncertainty about the global climate change regime after 2012, there is no indication that the enthusiasms for the carbon trading industry among companies and investors worldwide have been weakened.

\subsubsection{Capacity Building Projects in China}

As mentioned in Chapter 4, during the early international negotiations, China opposed many of the market-based international mechanisms and argued against a compulsory mitigation commitment for developing countries. China's position is to insist the "common but differentiated responsibilities" principle, which can be explained that developed countries should take the lead in reducing GHG emissions as well as providing financial and technical support to developing countries, while the first priority for China remains sustainable development and poverty eradication.

During this early stage, China's attitude towards initiating CDM project was reluctant and noncommittal and Chinese officials repeatedly stressed the importance of studying potential costs and benefits of the CDM, in particular the disputable issues of technical risks and political risks (Szymanski 2002). During the mid-1990s, China initiated four AIJ pilot projects in cooperation with Japan and Norway (MOFA 2002). The preliminary evaluation of the four AIJ pilot projects was positive and beneficial. This made China realize that capacity building should be enhanced through exercises of learning-by-doing with regard to baseline-setting, project management, and national institutional processing issues.

Capacity building is reflected in many ways, such as research and development, business communication and negotiations, technology transfer, product renovation, and 
market information. After the COP 6 Conference in 2001 when the CDM modalities and procedures were established, numerous CDM activities were implemented in China under the sponsorship of international and bilateral donors. There are several reasons that donors were keen to support CDM capacity building in China. First, they expect great potential of getting carbon credits from China with lower costs. Second, the donors feel the significant need for China to gain more insights into the CDM. More importantly, such cooperation can enhance the host country's capacity to initiate the carbon emission reduction activities. Table 6.1 lists several major capacity building projects.

Table 6.1 Major CDM Capacity Building Projects in China

\begin{tabular}{|c|c|c|c|c|c|}
\hline Donor & WB/ GTZ & CIDA & $\mathrm{ADB}$ & $\begin{array}{l}\text { UNDP/ UN } \\
\text { Foundation }\end{array}$ & $\mathrm{EU}$ \\
\hline $\begin{array}{l}\text { Project Title/ } \\
\text { Chinese } \\
\text { Counterpart }\end{array}$ & $\begin{array}{lr}\text { China CDM } \\
\text { Study on } \\
\text { Methodology } \\
\text { and } \\
\text { Application/ } \\
\text { MOST }\end{array}$ & $\begin{array}{l}\text { Canada- } \\
\text { China } \\
\text { Cooperation } \\
\text { in Climate } \\
\text { Change/ } \\
\text { NDRC }\end{array}$ & $\begin{array}{l}\text { Opportunities } \\
\text { for CDM in } \\
\text { the Chinese } \\
\text { Energy } \\
\text { Sector } \\
\text { /MOST }\end{array}$ & $\begin{array}{l}\text { Building } \\
\text { Capacity for } \\
\text { the CDM in } \\
\text { China/ NDRC }\end{array}$ & $\begin{array}{l}\text { EU/China } \\
\text { Partnership in } \\
\text { CDM } \\
\text { Development }\end{array}$ \\
\hline Sectors & $\begin{array}{l}\text { Power sector and } \\
\text { renewable } \\
\text { energy field }\end{array}$ & $\begin{array}{l}\text { Renewables, } \\
\text { urban } \\
\text { transportation, } \\
\text { and sinks }\end{array}$ & Renewables & $\begin{array}{l}\text { Renewables, } \\
\text { energy } \\
\text { efficiency, and } \\
\text { coal bed } \\
\text { methane }\end{array}$ & Renewables \\
\hline $\begin{array}{l}\text { Project } \\
\text { purposes/ } \\
\text { Activities }\end{array}$ & $\begin{array}{l}\text { Methodology } \\
\text { study, capacity } \\
\text { building, } 6 \text { CDM } \\
\text { case studies, } \\
\text { assessing the } \\
\text { Chinese CDM } \\
\text { market }\end{array}$ & $\begin{array}{l}\text { Capacity } \\
\text { building and } \\
\text { poverty } \\
\text { reduction to } \\
\text { meet Canada' } \\
\mathrm{s} \text { international } \\
\text { climate change } \\
\text { objectives }\end{array}$ & $\begin{array}{l}\text { Capacity } \\
\text { building, } \\
\text { providing } \\
\text { consulting } \\
\text { service for } \\
\text { small-scale } \\
\text { CDM } \\
\text { projects }\end{array}$ & $\begin{array}{l}\text { Capacity } \\
\text { building, } \\
\text { project } \\
\text { approval } \\
\text { process, } 3 \text { pilot } \\
\text { projects, } \\
\text { information } \\
\text { dissemination }\end{array}$ & $\begin{array}{l}\text { Capacity } \\
\text { building, } \\
\text { identify } \\
\text { barriers and } \\
\text { opportunities, } \\
\text { evaluate the } \\
\text { emission } \\
\text { reduction } \\
\text { benefits }\end{array}$ \\
\hline $\begin{array}{l}\text { Donor's } \\
\text { Contributions }\end{array}$ & US\$ 970,000 & $\mathrm{C} \$ 5,000,000$ & US\$ 775,000 & US\$ $1,458,000$ & Euro 907,574 \\
\hline Duration & $2002-2004$ & $2002-2004$ & $2002-2003$ & 2003- 2006 & $2003-2004$ \\
\hline
\end{tabular}

Note: WB-World Bank; GTZ-German Agency for Technical Cooperation; CIDA-Canada International Development Agency; ADB-Asian Development Bank; UNDP-United Nations Development Program; EU-European Union; MOST-Ministry of Science and Technology; NDRC-National Development and Reform Commission

Source: World Bank 2004; Zhang 2005 
These projects had a wide variety of coverage, including the CDM country studies, capacity building activities, international workshops for awareness, CDM methodologies, market opportunity studies, CDM technology options, case studies, as well as barrier analysis and promoting policies and initiatives. The NDRC and the MOST were jointly responsible for program identification, site selection and relevant coordination activities.

Not all the cooperative capacity building projects got access to Chinese market. An example was the withdrawal of Dutch CERUPT (Certified Emission Reduction Unit Procurement Tender) Program in 2001, because of domestic bureaucratic hurdles and the changing priorities by both sides (Zhang 2005). Nevertheless, the emergence of more capacity building projects indicated that the Chinese government attempted to make the best use of the projects to develop its expertise and improve the institutional and human capacity. In fact, some projects from these case studies became real CDM projects.

One of the important prerequisites for CDM credit trading between developing countries and developed countries is the establishment of a carbon market, where the transaction can be operated. Although China is a party to the Kyoto Protocol as early as 2002, making it an eligible party to participate in the CDM scheme; however, the Kyoto Protocol had not entered into force until 2005. Fortunately, along with the Kyoto Protocol's taking into effect, the European Union (EU) commenced operation of its own Emission Trading System (ETS) from January 1, 2005 across the 25 member states.

The essence of the ETS is the trading of limited EU emission allowances (EUAs) which were allocated to 11400 installations, accounting for around 52\% of the EU's total $\mathrm{CO}_{2}$ emissions or about $30 \%$ of its overall greenhouse gas emissions (EEA 2005, 28; EU 
2005, 7 ). The National Allocation Plans for the EU ETS transferred a big share of the credit demand to the covered installations, so the private sectors are supposed to increase their demand in the future; on the other hand, the EU emission allowances (EUAs) were allowed to link with JI/CDM credits, making the EU emerging as the center of carbon trading in the world.

At this time, China began to realize it can receive economic and political benefits through more involvement in CDM project development and diffusion (personal interview). The CDM has become a vehicle that not only stimulates investment in the cleaner energy technologies and economic development; it also allows China to be viewed as a proactive player on climate change issues. However, because of the longterm "wait and see" climate mitigation policies, it soon found itself lagging far behind many developing countries, such as India, Brazil, and Mexico, in the number of pipeline projects. The key issue for the decision makers to tackle was to develop a set of institutions that can synergize its development benefits and help domestic developers gain market competence.

\subsection{Developing CDM Institutions and Actor Network}

\subsubsection{CDM Policy Development}

With the progression of the CDM regime and the development of international emission reduction trading market, the Chinese government realized the imperative to promulgate and implement domestic CDM rules in order to strengthen effective management of the CDM projects, safeguard national rights and interests, and ensure the proper operation of project activities. 
In June 2004, the NDRC, the MOST, and the MOFA jointly promulgated the Interim Measures for Operation and Management of CDM Projects in China (hereinafter referred to as "Interim Measures"), specifying the legal framework for CDM projects for the first time. According to the "Interim Measures" (NDRC 2004), Chinese CDM project activities should comply with Chinese laws and regulations as well as China's sustainable development strategies and policies, and should meet the general requirements of national economic and social development planning. In addition, the CDM project activities should promote the transfer of environmentally sound technology to China.

The "Interim Measures" also identified three priority areas for implementing domestic CDM projects: energy efficiency improvement; development and utilization of new and renewable energy sources; and methane recovery and utilization. Nevertheless, China did not stimulate specific measures to boost these projects in a CDM form. The reason is that the three areas are already embedded in other policies, in particular energy policies, so the incentive policies were not specifically made just favorable for CDM projects.

The "Interim Measures", which offers trial management rules for guiding CDM project implementation, had left several important issues unclear, such as credit ownership, possibility of unilateral CDM, royalty fee collection and usage. On October 12, 2005, the "Interim Measures" was rescinded and replaced by Measures for Operation and Management of CDM Projects in China (hereinafter referred to as "Formal Measures"). By approval of the National Climate Change Coordination Committee (NCCCC), the "Formal Measures" was jointly issued by the NDRC, the MOST, and the MOFA, as well as the Ministry of Finance, The document has been regarded as the 
essential CDM management policy in China, that promotes and supports the efficient completion and systematic progress of CDM project activities (ERI 2009, 3).

With regard to ambiguous issues of credit ownership, possibility of the unilateral CDM project, royalty fees, some clarifications were made in the new measures. Table 6.2 compares the concerned items in the two measures, which reflected the CDM policy adjustment by the Chinese government.

Table 6.2 Comparison of the CDM Measures of Two Versions

\begin{tabular}{|c|c|c|}
\hline Items & $\begin{array}{c}\text { Interim Measures (June } \\
30,2004)\end{array}$ & $\begin{array}{l}\text { Formal Measures } \\
\text { (October 12, 2005) }\end{array}$ \\
\hline Project owner & $\begin{array}{lr}\text { Chinese } & \text { funded or } \\
\text { Chinese } & \text { holding } \\
\text { enterprises } & \end{array}$ & Same \\
\hline $\begin{array}{l}\text { Unilateral } \\
\text { CDM project }\end{array}$ & Not mentioned & $\begin{array}{l}\text { If no foreigner buyer is determined when the project is } \\
\text { submitted for national approval, the emission reductions } \\
\text { generated by the projects will be transferred into the } \\
\text { national account }\end{array}$ \\
\hline $\begin{array}{l}\text { Ownership of } \\
\text { CERs }\end{array}$ & $\begin{array}{l}\text { CER revenues are owned } \\
\text { jointly by the government } \\
\text { and the owner }\end{array}$ & $\begin{array}{l}\text { Same. (Reasons given: Emission reduction source is } \\
\text { owned by the Government of China; emission reductions } \\
\text { from specific CDM projects belong to the project owner.) }\end{array}$ \\
\hline $\begin{array}{l}\text { Royalty fee } \\
\text { (CER } \\
\text { distribution) }\end{array}$ & $\begin{array}{l}\text { Be decided by the } \\
\text { Government of China. } \\
\text { Before the decision, } \\
\text { revenue belongs to the } \\
\text { project owner. }\end{array}$ & $\begin{array}{l}\text { For projects in the priority areas, royalty fees of } 2 \% \text { of the } \\
\text { CER revenue are charged. The fee for } \mathrm{N}_{2} \mathrm{O} \text { projects is } 30 \% \\
\text { and for HFC and PFC projects, it amounts to } 65 \% \text {. } \\
\text { Projects already approved by the DNA before October } 12 \text {, } \\
2005 \text { are exempt from fees. }\end{array}$ \\
\hline $\begin{array}{l}\text { Use of the } \\
\text { royalty fees }\end{array}$ & Not mentioned & Detailed provisions will be in formulation \\
\hline
\end{tabular}

Source: NDRC 2004; NDRC 2005

By comparison, the central government has not loosened the strong CDM entry requirements. The "Formal Measures" allows development of the unilateral CDM project, but with the premise of transferring the emission reductions to its national account. Also, the second version regulates the royalty fee that project owners must pay to the national government, differentiated by the project types. Obviously, the emission reductions in China are treated as "national resources". All these rules facilitate the government's 
intervention of the CDM activities, and more importantly, government also maintains a say in setting the CER price, in case the CERs are traded at dumping prices (Abele 2005).

The CDM "Formal Measures" had remained intact since its promulgation in 2005. However, to improve the management of CDM projects and accommodate new development requirements, the Chinese DNA, namely the NDRC, has issued a series of supplementary regulations in the form of gazette or notes. Some of the important regulations include the improvement of CDM project application and approval procedures, the CDM project implementation arrangements in Hong Kong, and regional grid baseline emission factors (CCChina 2010).

\subsubsection{CDM Institutional Actors in China}

China adopted three-tiered model as its national CDM management structure. The three-tiered institutions include the National Coordination Committee on Climate Change (NCCCC), the National CDM Board and Designated National Authority (DNA). Their responsibilities and compositions are shown in Table 6.3.

Seen from Table 6.3, on the top level of national CDM management institutions is the NCCCC, which is responsible for the review and coordination of CDM policies. The National CDM Board (NCB) lies at the second level. The NCB conducts the concrete CDM project review and management activities. The third level is the NDRC, which is appointed by the Chinese government as DNA. The NDRC plays a vitally important role on China's CDM management and implementation. Both the NCCCC and the NCB are chaired by the NDRC, which issues formal project approval on behalf of the Chinese Government. The Department of Climate Change set up in the NDRC in 2008 (the Office of Climate Change during 2003- 2008) serves as the secretariat of the 
NCCCC and the National CDM Board, and organizes the review of the CDM application documents. China's three-tiered institutional structure not only allows multiple ministries and actors to participate in the project review and approval processes, but also enables broader stakeholder participation in CDM implementation (ERI 2009; personal interview).

Table 6.3 Features of China's CDM Institutions

\begin{tabular}{|c|c|c|c|}
\hline Institutions & Set-up Time & Main Responsibilities & Members \\
\hline $\begin{array}{l}\text { National } \\
\text { Climate } \\
\text { Change } \\
\text { Coordination } \\
\text { Committee } \\
\text { (NCCCC) }\end{array}$ & $\begin{array}{c}1998 \\
\text { Reshuffled } \\
\text { as NCCLG } \\
\text { after } 2007\end{array}$ & $\begin{array}{l}\text { Formulate and coordinate national } \\
\text { climate change policies, measures; } \\
\text { - Review CDM policies, rules and } \\
\text { standards; } \\
\text { - Approve members of the CDM } \\
\text { Board. }\end{array}$ & $\begin{array}{l}\text { Chaired by the NDRC; Vice } \\
\text { Chairmen and members are } \\
\text { senior officials from } 14 \\
\text { ministerial agencies. }\end{array}$ \\
\hline $\begin{array}{l}\text { National CDM } \\
\text { Board (NCB) }\end{array}$ & 2004 & 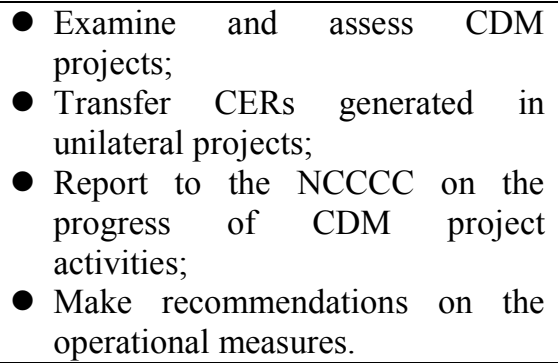 & $\begin{array}{l}\text { Co-Chairs: } \\
\text { NDRC } \\
\text { MOST } \\
\text { Vice Chair: } \\
\text { MOFA } \\
\text { Board members: } \\
\text { SEPA (MEP after 2008), } \\
\text { SMA, MOF, MOA. }\end{array}$ \\
\hline $\begin{array}{l}\text { Designated } \\
\text { National } \\
\text { Authority } \\
\text { (DNA) }\end{array}$ & 2004 & $\begin{array}{l}\text { - Accept CDM project application; } \\
\text { - Issue national approval letter, } \\
\text { based on the Board's decision; } \\
\text { - Supervise the implementation of } \\
\text { CDM project activities; } \\
\text { - International Communication and } \\
\text { cooperation }\end{array}$ & NDRC \\
\hline
\end{tabular}

Note: NDRC-National Development and Reform Commission; MOST-Ministry of Science and Technology; MOFA-Ministry of Foreign Affairs; SEPA-State Environmental Protection Administration; SMA-State Meteorological Administration; MOF-Ministry of Finance; MOA-Ministry of Agriculture; NCCLG-National Climate Change Leading Group

Source: NDRC 2004; NDRC 2005

The national CDM management and implementation institutions have been gradually improved over the past few years, signified by the establishment and operation of two new centers: National CDM Project Management Center and China CDM Fund Management Center. 
National CDM Project Management Center was established under the Energy Research Institute (ERI), a policy advisory organization under the NDRC. The Center is under the guidance of the Department of the Climate Change of the NDRC to promote the development of $\mathrm{CDM}$ and international cooperation on climate change. The Management Center has provided the NDRC administrative support for CDM project approval since 2007, including expert review, project monitoring and supervision, inventory registration, data management, consultative service, international cooperation.

The CDM "Formal Measures" had introduced the use of royalty fees generated from CER revenues as a pool fund for encouraging specific CDM projects. The management and operation of the fund came into effect with the establishment of the CDM Fund Management Center. The Center, established in November 2007, is under the sponsorship of the Ministry of Finance, and serves as secretariat of the CDM Fund Examination Council, which comprises NDRC, MOFA, MOF and MOST and other relevant agencies.

The fund comes from royalty fees collected from current CDM projects, as well as donations and loans from financial institutions. In ways of grant, concession loan and other financial instruments, the fund is used to provide support for energy efficiency and clean energy projects and other climate change activities, including capacity building, public awareness, mitigation and adaptation (ERI 2009). Since the Fund was established in 2007, the detailed information about fund use has not been revealed (personal interview).

Although national CDM institutions dominate CDM project management, there has been increased involvement of local governments in CDM project promotion and 
supervision in recent years. More than 27 provinces and municipalities have established CDM centers to market CDM development activities, provide capacity trainings, and help project proponents seek potential credit buyers (Schroeder 2009). From 2007, the CDM projects are required to get approval from local governments before the applications are sent for Board review. Industrial associations with strong government background have also been involved. Many of these associations have the advantages of close ties with the business sector and a good knowledge of governmental preferences and policies.

\subsubsection{Non-State CDM Actors}

The international design of CDM scheme allows for the participation of nonstate actors in rule-setting and policy implementation. As a result, constellations of nonstate actors have been involved in the CDM project development in China. The non-state actors under the CDM scheme mainly include project proponents (state-owned enterprises or private companies) and consulting companies who work together with project proponents in various CDM processing stages. But compared with the state actors, non-state actors play only minor roles in policy making and implementation process.

Although the project developers are voluntary to participate in the CDM activity, many local businesses in China, lacking awareness, motivation and capacity, follow the will of the government to implement CDM projects. At the early stage of the project development, the preparation of the Project Design Document (PDD) was mainly prepared by a few recommended foreign businesses. Owing to governmental agencies' support and the incentives from carbon market, dozens of domestic companies have emerged and provided comprehensive consulting services for the project proponents, 
especially project design and document compilation. With more entrants involved, the market has become more competitive and the developers get more choices to choose cooperators and compare the offers. Although abilities to provide services by these consulting companies differ in terms of quality in general, their competence has greatly strengthened due to capacity enhancement, lower fee charging, and the advantages of being familiar with the local situations (Abele 2007).

Academic institutions also actively facilitate CDM project development by participating in methodology design, technical advisory, and CDM policy analysis. The work has expanded from focusing on natural and technological sciences to the topic of economics, market analysis and project management. In the case that the projects are consistent with national economic policies and have great potential to duplicate in CDM forms, but there are no existing methodologies for new CDM projects to take for reference, the government agencies, led primarily by the NDRC and the MOST, will invite and support experts from universities, research institutes, and think tanks to conduct relevant research and develop methodologies (personal interview).

With more and more CDM projects entering the pipeline, the relative slowness of the Designated Operational Entity (DOE) and the CDM Executive Board (EB) in project validation, registration and verification has become the bottleneck of further project development (personal interview). In addition to strengthen regular communications with these international $\mathrm{CDM}$ regulatory agencies, China has cooperated with the EU to develop China's own DOEs. The main purpose of such arrangement is to shorten project processing time and reduce the transaction costs, mainly for domestic projects. Currently, two entities have been selected: China Quality Certification Center 
and China Environmental United Certification Center. Both entities have close relations with the ministerial agencies (ERI 2009).

The NGOs in China are rarely involved in CDM activities. Most Chinese NGOs regard other environmental issues; their concern on the climate change issues has just begun (Schroeder 2009; Mertha 2008). Foreign investors, businesses and financial institutions have been active in promoting China's CDM project development. Besides capacity building projects in the early stage, these actors have displayed great initiative in providing training and marketing service, and participating in appropriate methodology development. Although CDM project development and credit trading in China rely extensively on these foreign firms; compared with the government actors, their influence on the development of more favorable CDM rules is still limited. Instead, only the representative agencies of foreign governments are active in trying to influencing CDM policy making through bilateral political advisory programs (Schroeder 2009).

\subsubsection{Domestic Project Approval Procedures}

CDM project approval procedures were established in the CDM measures. The project developers first submit application to the DNA (the NDRC in China). The CDM Board then reviews CDM projects from the aspects of participation qualification; PDD document; baseline methodology and emission reductions; price of CERs; terms relating to funding and technology transfer; crediting period; monitoring plan; and expected sustainable development effectiveness. Figure 6.2 shows the normal CDM project approval procedures in China.

The days to approve a CDM project by the NCB have been greatly shortened. Currently, the CDM Board holds biweekly meetings to discuss the proposed projects. 
Before the NDRC (China's DNA) passed on the project request for decision by the Board, it solicited comments by expert review. The NDRC then approves or rejects the request based on the decision reached by the National CDM Board in 20 days. Since 2007, when the projects are submitted to the NDRC for approval, the proponents also need to notify the local NDRC branch, so that the local governments can keep track of the development of local CDM projects.

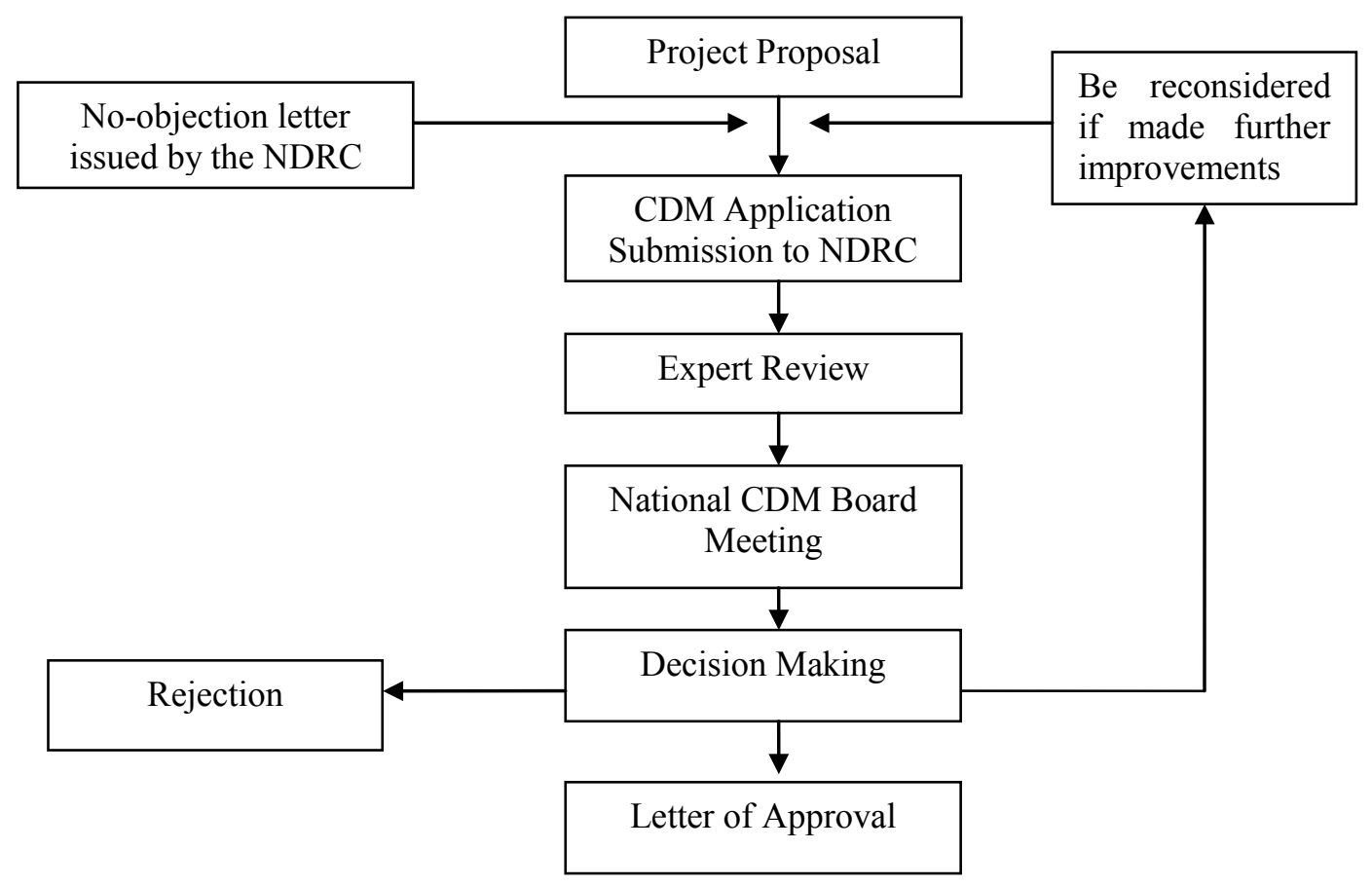

Figure 6.2 Flowchart of CDM Approval Procedures

Source: IGES 2005

In practice, some CDM projects are submitted for validation before they get approval by the DNRC. This is mainly because project developers and the partners want to test the validity of methodologies. Even so, the DNA's approval is prerequisite before the projects are later sent for EB's registration. 


\subsubsection{Interactions of Network Actors}

The CDM scheme involves a variety of state and non-state actors, and it has initiated a new form of network that collectively contributes to the emission reduction activities. Generally, interactions among network actors are shaped and influenced by three factors. The first one is the procedures and directives of the CDM rules, formulated by the Executive Board of the FCCC. All the CDM project developers from developing countries follow the same rules. The EB has the power to review the applications and decide whether the project can be processed to next level of the project cycle. The second influencing factor comes from the carbon credit market. It is the vitality of the carbon market that drives non-state actors, in particular private businesses to involve in the CDM development in order to pursue their economic benefits. The third factor is traditional top-down policy process, where the higher government leads the policy making and implementation, and makes the decision of approval. Since the project developers have insufficient capacity and resources in initiating CDM projects by themselves, the relevant governmental agencies take initiative in providing capacity-building service, such as pilot projects, technical and financial assistance, and training programs. In terms of the CDM management in China, these three forces act together and could not be distinctly separated. Under the political uncertainties of international climate change regime, China has taken a pragmatic approach and made deliberate arrangements in maximizing the benefits from this carbon offset market.

Within the Chinese CDM policy making network, government agencies at the central level are closely interacted. The NDRC, as a comprehensive macro-economic regulatory department, acts as the nexus agency in directing and coordinating the project 
development. Such an arrangement highlights China's centralized governance structure and NDRC's dominant role in policy evaluation. It also allows central government to balance institutional interests among related ministries without exerting big changes. The involvement of multiple government entities enables a broader integration of the CDM scheme into national development policy making.

In order to promote CDM projects in a larger scope, local governments have been assuming more responsibilities in developing CDM projects to accommodate to the local development priorities. This is supported by the following evidence: (1) local governments are responsible for disseminating the CDM information and arranging relevant training activities; (2) local governments should be knowledgeable of the CDM scheme since it can potentially generate additional benefits other than traditional benefits from project operation; (3) local government can participate in CDM project identification, and formulate incentive measures to encourage project development; and (4) local NDRC branches need to present the approval letter to the proposed CDM projects within its jurisdiction, before the projects are submitted to the CDM Board for approval. Therefore, the support from local governments has become important prerequisite for the project approval by the National CDM Board.

The interactions among non-state actors themselves and between state and nonstate actors are generally low in China. Two reasons have been identified (Schroeder 2009). One is due to the nature of carbon market competition: all market actors are competing for economic profits, so they remain a healthy distance. The second reason is that with China's transition from planned economy to market economy, the direct intervention from the state actors has reduced. However, the strong position of state 
actors has forced market and civil society actors to prefer more cooperative measures, instead of lobbying against governmental regulations.

\subsection{CDM Project Development and Policy Adaptation}

\subsubsection{CDM Market Performance}

Since the CDM is a market mechanism that embraces competition among credit suppliers, it is possible to outline the competence by comparing the certified credits among host countries. Since China has developed its rules for CDM management, the CDM projects have been developed under the fast track. Until October 2010, China has developed $2211 \mathrm{CDM}$ projects at the different stages of the pipeline, accounting for $40 \%$ of the total projects. The expected CERs generated from these projects till 2012 are estimated to be 1.54 billion CERs, $54.4 \%$ of the total. In terms of CERs that have been issued and can be used for trading and banking, 223 million CERs have been issued, 2.8 times of the figure of India, which ranks the second in the market (CD4CDM 2010).

China's CDM projects are mixture of various types. Though a great majority of the projects come from renewable energy projects (e.g., hydro, wind, biomass) and energy efficiency projects, however, industrial projects, especially 11 HFC (hydrofluorocarbon) projects and $27 \mathrm{~N}_{2} \mathrm{O}$ projects, generate one third of credits (CD4CDM 2010). Although the approval of such industrial CDM projects has been abandoned since 2007, China has been unfavorably commented for flooding the carbon market with huge amount easy-to-get credits. In addition, there are doubts about whether the carbon reduction credits generated are really additional, since there is insufficient convincing 
evidence to prove that the project activities would not have happened without the CDM (e.g., Lewis et al. 2010).

The CDM projects are dispersed widely in China. Almost all provinces have CDM projects developed. However, the geographic locations of projects roughly have two features: the industrial projects with large credits are mainly from the east, which is much higher in economic outputs and personal income; the majority of renewable projects with less credit generation are normally from the west, which is rich in natural resources but poor in term economy.

\subsubsection{Evolution of CDM Policy Measures}

The domestic CDM Measures, which has not been changed after its adoption in 2005, is only a framework rule to guide CDM project approval and management. Although CDM is in essence a carbon offset market mechanism that is driven by carbon price, however, the whole project process, from its preparation to full operation and credit trading, is significantly influenced by a series of international and domestic political factors. In China, to ensure the CDM project development to achieve the maximum benefits and compete for larger market share, the NDRC, China's DNA in the CDM project management, has made supplementary adjustments to adapt to new situations. These adjustments have been widely regarded, by foreign carbon market actors and some policy researchers, as deliberate interventions of the Chinese government to the market-oriented carbon reduction activities. Table 6.4 shows some of supplementary policy regulations in the form of notices adopted since 2005 . 
Table 6.4 Supplementary CDM Policy Regulations in China

\begin{tabular}{|c|c|c|c|}
\hline Name of Notice & Year & Type/sector & Main Content \\
\hline $\begin{array}{lrr}\text { Standardizing } & \text { CDM } & \text { Project's } \\
\text { Consultation } & \text { Service } & \text { and } \\
\text { Evaluation } & & \end{array}$ & 2006 & $\begin{array}{l}\text { Market } \\
\text { regulations }\end{array}$ & $\begin{array}{l}\text { Regulate the CDM Consultation } \\
\text { Service and consulting fee } \\
\text { collection }\end{array}$ \\
\hline $\begin{array}{l}\text { Examination and Approval } \\
\text { Procedures Concerning } \\
\text { Project Application }\end{array}$ & 2006,2007 & $\begin{array}{l}\text { Procedure } \\
\text { improvement }\end{array}$ & $\begin{array}{l}\text { Standardize CDM project } \\
\text { approval procedure; involve local } \\
\text { government in the process }\end{array}$ \\
\hline $\begin{array}{l}\text { Determining Baseline Annual } \\
\text { Emission Factors of Power Grids }\end{array}$ & 2006,2007 & Electricity & $\begin{array}{l}\text { Set baseline for electricity } \\
\text { generating CDM projects }\end{array}$ \\
\hline $\begin{array}{l}\text { Adding RMB into the CER Price } \\
\text { Unit }\end{array}$ & 2008 & $\begin{array}{l}\text { Market } \\
\text { regulations }\end{array}$ & $\begin{array}{l}\text { Counteract the impacts of } \\
\text { continued change of exchange } \\
\text { rates on the project examination }\end{array}$ \\
\hline $\begin{array}{l}\text { Arrangement of CDM Projects in } \\
\text { Hong Kong SAR }\end{array}$ & 2008 & $\begin{array}{l}\text { Market entry } \\
\text { regulations }\end{array}$ & $\begin{array}{l}\text { Encourage Hong Kong } \\
\text { develop CDM projects }\end{array}$ \\
\hline $\begin{array}{l}\text { Informing the NDRC of CDM } \\
\text { Projects after } 2 \text { August } 2008 \text {. }\end{array}$ & 2008 & $\begin{array}{l}\text { Procedure } \\
\text { improvement }\end{array}$ & $\begin{array}{l}\text { Demonstrate the prior } \\
\text { consideration of the CDM before } \\
\text { undertaking project }\end{array}$ \\
\hline $\begin{array}{l}\text { Income Tax Policies concerning } \\
\text { the CDM Fund and the Involved } \\
\text { Project Enterprises }\end{array}$ & 2009 & $\begin{array}{l}\text { Market } \\
\text { regulations }\end{array}$ & $\begin{array}{l}\text { Provide corporate income tax } \\
\text { incentives available to CDM } \\
\text { enterprises and China CDM Fund }\end{array}$ \\
\hline $\begin{array}{l}\text { Explanation to Issues concerning } \\
\text { China's Wind Power Capacity } \\
\text { Discount }\end{array}$ & 2009 & $\begin{array}{l}\text { Renewable } \\
\text { energy }\end{array}$ & $\begin{array}{l}\text { Explain the pricing system of } \\
\text { wind projects in China }\end{array}$ \\
\hline
\end{tabular}

Source: ERI 2009; CCChina 2010

There have been many debates about China's CDM regulations. For example, during 2005-2007, eleven HFC (Hydro-fluorocarbons) CDM projects were approved and registered. The HFC-23, a by-product of HCFC-22 (Hydro-chlorofluorocarbons) manufacturing, is a potential greenhouse gas trapping 11700 times more heat per unit than $\mathrm{CO}_{2}$. The international community criticized the projects of contributing little to sustainable development. China subsequently argued that a rate of $65 \%$ of the revenue from HFC CDM projects would be charged for supporting priority projects in the future. On the other hand, starting from 2007, no HFC abatement projects have been approved by the central government. 
Another example is the entry requirements for the CDM development. According to the CDM Measures, only Chinese funded or Chinese-holding joint-venture enterprises within the territory of China are eligible to develop CDM projects with foreign buyers. This has been regarded as an important constraint to foreign investors' involvement in the emissions reduction activity promotion and willingness in technology transfer (ERI 2009; Schroeder 2009). After a few years' insistence by the Chinese government, a new measure was promoted recently that Hong Kong enterprises are allowed to implement CDM projects on the Mainland (China5e 2010).

Theoretically, the price of CER credits from CDM projects shall be determined by the credit demand and supply. However, since China leads in the CDM registration and CER supply, to avoid vicious price competition among domestic developers, the NDRC has set the unofficial contract price for the CER credits, unwilling to approve CDM projects valuing CERs below 7-9 Euros per ton, depending on the types of projects (ERI 2009). Although this has induced many complaints from investors of developed countries and to some extent limited domestic developers' interests, the government's reply was to keep transaction fair for domestic firms and no vying-for-lower-prices is allowed. Since China is the dominant supplier in the CDM credit market, many countries began to use China's pricing for negotiating equivalent prices with credit buyers.

\subsubsection{Sustainable Benefits}

Although sustainable development is much reiterated in China's political and economic life, there is no officially recognized set of indicators for a quantified assessment of a project's contribution to sustainable development. The proposed CDM 
projects are evaluated more on the basis of their impacts within clearly defined priority areas than strictly by a quantified measurement of sustainable development (IGES 2005).

Sustainable development goals are arguably met in China's CDM projects. The project which could contribute more to the local communities is less competitive and not specially treated with preferential fiscal and taxation conditions at the moment. The large industrial emission reduction projects, to some extent, have restrained the development of small priority projects. This is not unusual because CDM is basically a market-based mechanism and the cheaper credits from industrial projects are more cost-competitive and more attractive to market buyers.

\subsection{Conclusive Summary}

China's participation in the CDM scheme significantly contributes to the global climate mitigation activities. Although it initially resisted the scheme, arguing that developed countries may shift carbon emission reduction burdens to developing countries through this trading system; however, with the implementation of some pilot projects and final establishment of CDM operating regulations, China has gradually accepted this market-based scheme. Like other developing countries, no cap targets are set for China's emissions under the Kyoto Protocol, meaning that emission reductions generated voluntarily from CDM projects can be traded with developed countries. For the Chinese government and relevant project developers, the CDM scheme is regarded as an opportunity to make full use of its incomparable emission reduction potential and low abatement costs. The effective management of CDM projects means to promote 
mitigation efforts for sustainable development and enhance competence in the carbon trading market.

Though a latecomer, China has led the CDM project development since 2007. Well-organized networks consisting of a wide range of state and non-state actors have contributed to China's leading status in the CDM governance and market competition. In the early stage of the CDM development, relevant agencies at central level promoted pilot projects in selected provinces and sectors under the technical and financial assistance from international donors. Later, awareness and capacity building projects had been established nationwide to effectively disseminate relevant knowledge and expertise of CDM development and carbon trading to actors involved. With the Kyoto Protocol's entry into force, it is the vitality of the carbon market that attracts project proponents and local governments to involve in the CDM development and pursue economic benefits. Meanwhile, the National CDM Board concentrates on the identification of priority projects, and ensures the project development in line with the national sustainable development needs. In general, China's CDM governance network facilitates its higher manageability in promoting $\mathrm{CDM}$ and reallocating funds for maximizing national interests.

Seen from the current CDM development in China, administrative and market forces are two major forces that affect the CDM development process. The NDRC in China acts as the nexus agency in the action network for project review and approval. Such an arrangement highlights China's traditional centralized governance structure and the NDRC's dominant role in domestic CDM-related policy making. It also allows central government to balance the institutional and sectoral interests without incurring 
more uncomfortable changes. With the aim of gaining maximized economic and social benefits from CDM development, the relationship between the NDRC and other Board agencies is generally collaborative.

CDM is a market mechanism that allows China to trade certified credits with developed countries. Although the carbon credit trading is among businesses; however, in China, the governments at central and local levels have both been highly involved in the process of CDM development. At the local level, governments act much like profitseeking businesses (Qi et al. 2008). Though a streamlined project approval system has been established and more domestic actors have gained more competence, there is no indication from this case that shows the activeness of the project development is due to the decreased political control in the policy process.

China adopts the three-tiered system to manage CDM activity. The ad hoc management committee, the National CDM Board, which is co-chaired by the NDRC and the MOST, ranks between the national climate change coordinating committee and the Designated National Agency (i.e., the NDRC). The members of the Board are relevant departments from member ministries and agencies. There are regular communications within ministries, and for important issues, to be discussed among coordinating committee members. In 2007, the coordinating committee at the top-tier was reshuffled and the State Council has been chairing the committee since then. Therefore, the authority and power to coordinate CDM project development have enhanced. 


\section{CHAPTER VII}

\section{CASE 3: TOP-1000 INDUSTIRAL ENERGY CONSERVATION PROGRAM}

\subsection{Introduction}

The early 1990s witnessed the explosive growth of voluntary environmental programs in industrialized countries, which reflects the changing relations between government and business and political recognition of this less intrusive approach (Mol et al. 2000). Voluntary environmental programs can affect behavior and provide environmental benefits. However, the importance, form, and results of such policy arrangement differ according to countries and political-institutional settings (Mol et al. 2000). Though still characterized by its centralized regulative tradition, however, modeled on international sectoral target-setting programs, China formally adopted a pilot voluntary program in 2003 and attempted to diffuse it countrywide through the Top-1000 Industrial Energy Conservation Program (Top-1000 Program).

Chapter 7 examines the emergence, shape and functioning of China's Top-1000 Industrial Energy Conservation Program, as the second case. The program, implemented since March 2006, covers China’s 1000 largest industrial enterprises from nine energyintensive sectors, which account for one-third of China's prime energy consumption. The program requires the provincial governments to sign contracts with local enterprises and supervise the enterprises to reach the energy efficiency goals.

The chapter is organized as follows. In Section 7.2, the contextual background of the program is presented, which mainly focuses on issues of international development of industrial voluntary programs, and domestic contexts of promoting energy 
conservation activities. Section 7.3 documents the development the Top-1000 Program and the features of the policy networks. The Program has generated from an initial pilot project in Shangdong Province, and evolved to a nation-wide relevant large-scaled enterprises, and finally became a comprehensive target-setting program that involves governments at provincial and local levels. Section 7.4 studies outcomes of formulating and implementing the Top-1000 Program. Finally, conclusions of the case are drawn in Section 7.5.

\subsection{Contextual Background of the Program}

The contextual environment poses impacts on policy making and development. Framed by the policy network approach, this section outlines three contextual factors that have influenced the emergence and shaping of China's voluntary energy efficiency program, in particular, the Top-1000 Program. These three factors are: (1) the practice of international voluntary agreements in industries; (2) domestic industrial administrative structures; and (3) the needs to improve energy efficiency in industrial sectors.

\subsubsection{International Voluntary Agreements}

Many industrialized countries have adopted wide variety of policies and programs to improve energy efficiency and reduce carbon emissions in industrial sectors. These policies include: regulations and standards, taxes and charges, voluntary agreements, subsidies, financial incentives, research and development programs and information dissemination (IPCC 2007). In practice, these policy instruments are integrated to address various industrial energy efficiency improvement needs (Price and Jiang 2001). Since 1990s, Voluntary agreement programs has emerged as a pragmatic 
and flexible way to the need of dealing with energy efficiency challenges in many industrialized countries in Europe, Japan and North America (Price 2005; Mol et al. 2000; Morgenstern et al. 2007).

Voluntary agreements take on many forms with varying levels of scope and stringency; however, virtually all voluntary agreements involve some agreements between government and industry to facilitate voluntary actions to achieve desirable environmental and social objectives beyond compliance to regulated obligations (Morgenstern et al. 2007; Storey 1996). Some drivers of promoting voluntary agreements include offering flexibility both to participating firms and to government agencies; increasing the cost efficiency; reducing production costs; improving corporate reputation; accelerating the application of best available technology and avoiding a strong political opposition (Eichhorst and Bongardt 2009).

Although the voluntary agreements can potentially affect the participants' behaviors and offer environmental and social gains, and they are normally set at the same or slightly stricter than the business-as-usual scenario, evaluating and comparing the effectiveness of voluntary agreements proved to be difficult, because of the lack of realistic, agreed-upon baseline, overlapping of relevant activities, different metrics and evaluative criteria employed (Price 2005; Morgenstern et al. 2007). A series of evaluations show that most voluntary agreements have failed in achieving significant reductions in emissions beyond business-as-usual scenario and contributing to the major changes in behavior (Johannsen 2002; Helby 2002; Darnall and Carmin 2003; Morgenstern et al. 2007). Based on some comparative studies among countries, voluntary 
agreements can be better developed in the countries with a history of good cooperation between government and industry (De Clercq 2002; Mol et al. 2000).

\subsubsection{Administrative Structure in Industrial Sectors}

China has established an integrated, multilevel bureaucratic system to regulate and supervise the industrial activities. In China, the most important hierarchical relationship in industrial economic development is between the center and localities, which is supposed to be a relationship of leading and implementation (Zhao 2002). In reality, however, two forms of hierarchy co-exist in the Chinese bureaucratic system, which are commonly termed as "line and area relationships". Line relationships refer to the direct vertical relations between higher and lower level functional units of regulative administrative hierarchies. For example, the provincial bureaus of environmental protection replicate the functions of the Ministry of Environmental Protection (MEP), and receive directions from the MEP. Area relationships represent administrative hierarchical relations between local governments and administrative units within their jurisdiction, with the local government holding full authority for administrative management and economic development at local levels. For example, the provincial-level bureaus of environmental protection are financed by provincial government, which also holds the power to determine the key leaders of the agency. The dominance of line relationships leads to the development of industrial systems; while the dominance of area relationships supports a policy of local self sufficiency. Although the line and area relationships vary over time in China, the localities have gained greater independence and influence through the reforms to "pursue their own development strategies within broadly defined guidelines" (Saich 2004, 123). 
Administrative reforms of central government have been conducted to make it more suitable for a market economy. In 1998, most of the ministries that traditionally feature command and control policies in industrial sectors merged into one newly established institution: the State Economic and Trade Commission (SETC). In 2003, the SETC was abolished and many of its functions were transferred to the National Development and Reform Commission (NDRC), which is mainly responsible for comprehensive planning and policy coordination. Some disbanded industrial ministries were transformed into industrial associations and currently function as linking agent between the government and industry.

The enterprises are important economic and corporate actors in China, but traditionally, they are owned and organized by the government. The state-run enterprises, normally in manufacturing and large in scale, were divided into two types: ministerial enterprise and local government enterprise. The reform has transformed more ministerial enterprises into the local government enterprise group. In the case of the Top-1000 Program, almost all the enterprises were traditionally owned and managed by industrial ministries; however, currently only $20 \%$ of these enterprises are under direct control of central government, while $80 \%$ of them are owned by provincial governments.

The design and implementation of the industrial management programs take place within the webs of relatively stable and ongoing relationships between some of the key government agencies and enterprises. Figure 7.1 frames the relations of these key government and corporate actors. 


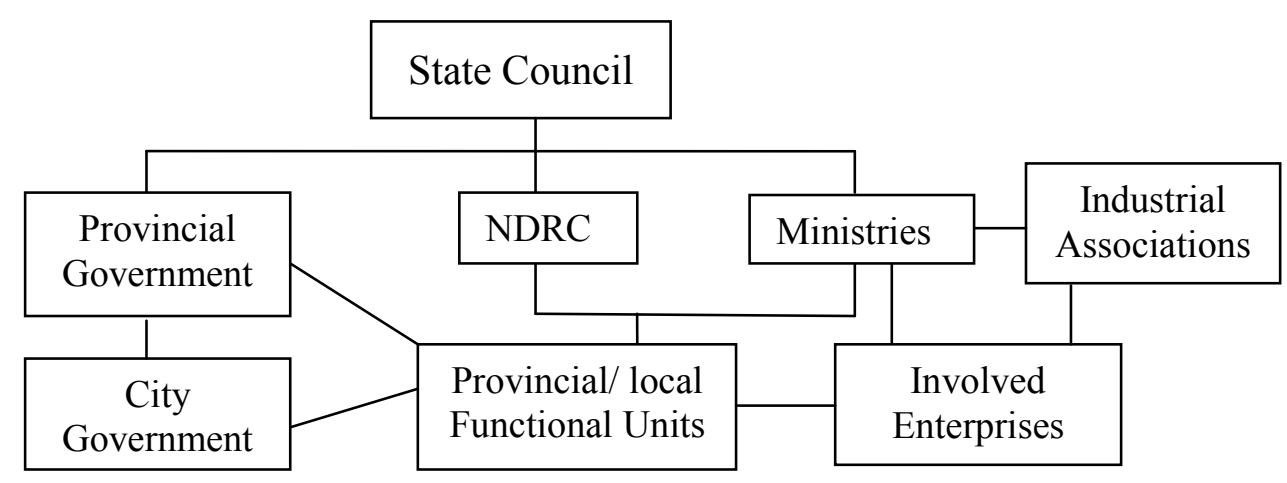

Figure 7.1 Framework of Actors in China's Industrial Management

\subsubsection{Imperative for Enhancing Energy Efficiency}

From 1980 to 2000, energy intensity (the amount of energy used per unit of GDP) in China declined steadily at an average annual rate of 5 percent (Kan 2008). Despite this improvement, the overall efficiency of energy utilization is still low by global standards. The energy intensity in China is two times the world average, and unit energy consumption for major energy-consuming products is $20-40 \%$ higher than advanced international standards. Since early 2000s, GDP has maintained high growth rates, but the progress rate in energy intensity reduction has slowed. From 2003 to 2005, with the dramatic growth of heavy industry and energy demand, the downward trend in energy intensity was reversed (Table 7.1). The key environmental pollutant emissions of $\mathrm{SO}_{2}$ and Chemical Oxygen Demand (COD) increased fast. 
Table 7.1 The Growth Rates of Selected Energy-related Indicators (2000-2005)

\begin{tabular}{|c|c|c|c|c|c|c|}
\hline & 2000 & 2001 & 2002 & 2003 & 2004 & 2005 \\
\hline GDP & $8.4 \%$ & $8.3 \%$ & $9.1 \%$ & $10.0 \%$ & $10.1 \%$ & $10.4 \%$ \\
\hline $\begin{array}{c}\text { Energy } \\
\text { Consumption }\end{array}$ & $3.53 \%$ & $3.35 \%$ & $6 \%$ & $15.28 \%$ & $16.14 \%$ & $10.56 \%$ \\
\hline Energy Intensity & $-4.52 \%$ & $-4.57 \%$ & $-2.82 \%$ & $4.77 \%$ & $5.5 \%$ & $1.13 \%$ \\
\hline $\mathrm{SO}_{2}$ & - & $-2.4 \%$ & $-1.1 \%$ & $12.0 \%$ & $4.5 \%$ & $13.1 \%$ \\
\hline $\mathrm{COD}$ & - & $-2.8 \%$ & $-2.7 \%$ & $-2.5 \%$ & $0.5 \%$ & $5.6 \%$ \\
\hline
\end{tabular}

Note: GDP-Gross Domestic Product; COD-Chemical Oxygen Demand Source: NBS 2001-2006

In response, since 2003, the Chinese government has taken new approaches to deepen its reforms in energy-related sectors, including the restructuring of energy management agencies and the adoption of a series of policy instruments (Andrew-Speed 2009). The National Energy Leading Group under the State Council and the Energy Bureau of the NDRC were set up in 2003. The Department of Resource Conservation and Environmental Protection (DRCEP) under the NDRC was established to take over energy conservation oversight missions left by the disbanded SETC, as well as to strengthen the policy coordination with environmental protection agencies. Moreover, the central government introduced the key slogan of building an "environment-friendly and resource-saving society".

A disconnection between national policies and local implementation has been identified as the main reason that drives the increase of the energy intensity in China, because economic development is given a top priority, and the unwillingness or lack of capacity have made the implementation of top-down approach at the local levels very weak (Eichhorst and Bongardt 2009; Andrew-Speed 2009). To make the reform stepwise and incremental, implementing voluntary agreements in industrial sectors is regarded as important in energy efficiency improvement, at least in the near future ( $\mathrm{Hu} 2007)$. 


\subsection{Network Development of the Top-1000 Program}

\subsubsection{Pilot Voluntary Program in Shandong Province}

In 1999, the US-based Energy Foundation funded a research program to evaluate and develop innovative energy-efficiency policies for China's industrial sectors. The program was directed by the then State Economic and Trade Commission (SETC). China Energy Conservation Association (CECA), an independent non-profit social entity under the leadership of the NDRC and the General Administration of Quality Supervision, Inspection and Quarantine (GAQSIQ), are responsible for the program implementation, with the technical assistance provided by the Lawrence Berkeley National Laboratory (LBNL). After assessing various domestic policies and guidelines for energy conservation, as well as international advanced energy efficiency policies, in 2000 , the program team suggested to the SETC that voluntary agreements that result from the negotiation between government and business could provide an innovative approach more compatible with the market economy.

A series of surveys and investigations had been conducted for selecting the most appropriate pilot projects. The iron and steel sector was chosen because of its features of larger energy-efficiency potential, stronger capacity in sector management, and more motivation for improved international competitiveness following China's accession to the WTO (World Trade Organization). Regarding location, Shandong Province was chosen mainly due to its advantages of well-established energy efficiency regulations at the provincial level and the presence of a number of energy service agencies, which could provide assistance to pilot enterprises in the areas of energy auditing, assessment, data 
collection, and information dissemination. Finally, Jinan Iron and Steel and Laiwu Iron and Steel were identified as pilot enterprises for voluntary program.

After negotiations between the Shandong Economic and Trade Commission (ETC) and the two enterprises, the voluntary agreements were signed in April 2003. The program set a base year of 2002 and a target year of 2005, and developed performance targets based on physical energy intensity measured by energy consumption per ton of steel. According to the consensus reached, the two enterprises agreed to take measures to improve efficiency and realize the goal of saving 300,000 tce aggregately within three years, which was 137,500 tce higher than the original enterprise energy saving targets (Hu 2007). The Shandong ETC agreed to adopt a list of supporting policies for the two enterprises, including information dissemination, positive publicity, tax exemption and financial assistance. The CECA, as the third party, was to provide necessary technical support and advisory service for the enterprises and Shandong ETC. The network of the pilot program is shown in Figure 7.2.

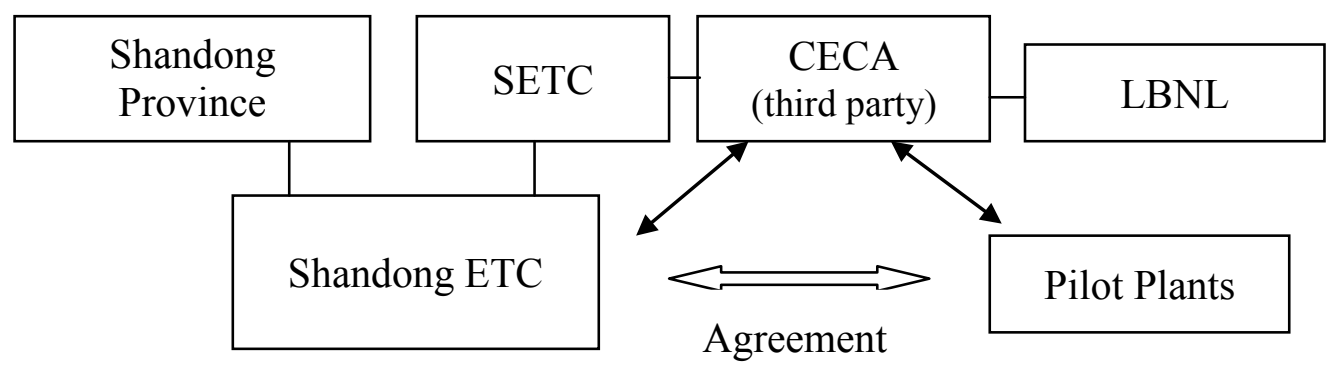

Figure 7.2 Framework of Actors in Shandong Pilot Voluntary Program

Note: SETC-State Economic and Trade Commission; ETC-Economic and Trade Commission; CECAChina Energy Conservation Association; LBLN-Lawrence Berkley National Laboratory (US) 
The voluntary pilot program was considered a success due to its compliance of the 3-year energy efficiency targets and the experience and knowledge accumulated. Over this period, the energy consumption per ton of steel in two enterprises had reduced by $9-9.5 \%$, and a total of 422,000 tce had been saved, $40 \%$ more than the target listed in the voluntary agreement (Price et al. 2010). The successful implementation of the voluntary pilot program in Shandong provided a stimulus for adopting this tool at the national level.

\subsubsection{Initiation of the Top-1000 Program}

The development of the Top-1000 Industrial Energy Consumption Program began as early as 2005 (Sinton 2006). The Program drew many conceptual and practical elements from other international and domestic energy efficiency programs, including the voluntary programs. The NDRC lead the program design, with the support of the Energy Foundation. As one of the key initiatives of the 11th Five-Year Plan (2006-2010) for improving industrial energy efficiency in China, the Program was launched in April 2006 by the Department of Resource Conservation and Environmental Protection (DRCEP) of the NDRC, together with some other central agencies.

The program covered 1008 large-scaled, financially independent enterprises from nine major energy consuming industries (i.e., iron and steel, petroleum and petrochemicals, chemicals, electric power generation, non-ferrous metals, coal mining, construction materials, textiles, and pulp and paper) that each consumed a minimum of 180,000 tce in 2004. The energy consumption of these enterprises accounted for more than 33\% of national and 47\% of industrial energy use in 2004 (Price and Wang 2007). 
The goal of the Top-1000 Program was to reach the aggregate energy saving of 100 million tce during the period of 2006-2010.

The Program set 2005 as baseline year. The unit energy consumption levels, based on the domestic best practice, international best practice, and sectoral best practice, are considered important evidence for determining energy saving targets. On the basis of the analysis of the energy-saving potentials in the industries and the location of the enterprises, the NDRC separated the 100 million tce energy-saving targets into provinces. Target-setting for the Top-1000 enterprises is generally a top-down process, although there are constant information exchanges between NDRC, provincial functional units, and enterprises. In mid-2006, the targets for each enterprise were publicized. A two-tier contracting system was set up to ensure the program monitoring and implementation. At the upper tier, provincial governments signed the responsibility documents with the NDRC; and at the lower tier, similar to the voluntary program piloted in Shandong, energy-saving target contracts were signed between local governments and participating enterprises.

\subsubsection{Actors and Policy Network}

Although getting access to the reliable information about which agencies or individuals have been involved in designing the program is hard, with the implementation of the program, it is easier to examine the development of the action network. This also provides an alternative option to study the features of the policy network and its influences to the policy outcomes. The actors involved in implementing the Top-1000 Program have clear divisions of responsibilities. They can be broadly categorized into three groups: government actors whose main responsibilities are to design the 
management rules and supervise the program implementation; business actors which refer to the Top-1000 enterprises involved in the program; and civil society actors which include industrial associations that provide technical assistance. The number of Top-1000 enterprises declined during 2006-2008 due to closure and combination. Table 7.2 shows these actors and the functions.

Table 7.2 Actors and Their Functions in the Top-1000 Program

\begin{tabular}{|c|c|c|}
\hline Type of Actor & Name & Function \\
\hline \multirow{5}{*}{$\begin{array}{l}\text { Government Actors } \\
\text { (Central) }\end{array}$} & NDRC & Program design and coordination, daily administration \\
\hline & NELG & Overall guidance and coordination \\
\hline & NBS & Statistical information collection and management \\
\hline & GAQSIQ & Supervision of quality of the program operation \\
\hline & SASAC & $\begin{array}{l}\text { Supervision of major state-owned enterprises (supervising } \\
197 \text { state-run enterprises) }\end{array}$ \\
\hline $\begin{array}{l}\text { Government Actors } \\
\quad \text { (Provincial) }\end{array}$ & $\begin{array}{l}\text { Provincial } \\
\text { Functional } \\
\text { Units }\end{array}$ & $\begin{array}{l}\text { Tracking, supervision, and management of the energy } \\
\text { saving activities of the enterprises under their jurisdictions } \\
\text { (supervising } 811 \text { enterprises) }\end{array}$ \\
\hline $\begin{array}{l}\text { Civil Society Actors } \\
\text { (Government operated) }\end{array}$ & $\begin{array}{l}\text { Industrial } \\
\text { Associations } \\
\text { (e.g., CECA) }\end{array}$ & $\begin{array}{l}\text { Creating indicator and evaluation system, providing energy } \\
\text { auditing service, and assessing energy-saving potentials }\end{array}$ \\
\hline Business Actors & $\begin{array}{l}\text { Top-1000 } \\
\text { Enterprises }\end{array}$ & $\begin{array}{l}\text { Undertaking energy audits, reporting implementation } \\
\text { progress, improving technical and management capacity to } \\
\text { reach energy saving targets (1008 enterprises in total in } \\
2006)\end{array}$ \\
\hline
\end{tabular}

Note: NDRC-National Development and Reform Commission; NELG-National Energy Leading Group; NBS-National Bureau of Statistics; SASAC-State-owned Assets Supervision and Administration Commission; GAQSIQ-General Administration of Quality Supervision, Inspection and Quarantine; CECAChina Energy Conservation Association

Source: NDRC 2006

No supporting policies and measures were established at the commencement of the Top-1000 Program. The initial implementation plan developed in 2006 only provided general policy guidelines for energy-saving activities. In this plan, administrative measures were underlined to ensure the effective achievement of the energy-saving targets (NDRC 2006). The administrative award and punishment rules were adopted to regulate the province-level governments and involved enterprises. The responsible 
government officials would be evaluated annually on whether the energy conservation targets have been met. The well-performing entities would be awarded and their achievements publicized. The enterprises which fail in meeting the targets would not be given the annual rewards or honorary titles, and the leaders would not be promoted.

\subsubsection{Evolution of the Top-1000 Program Network}

Over the first year of the Top-1000 Program in 2006, total energy saving of 20 million tce had been realized (NDRC and NBS 2007). However, the national energy intensity reduction target set in the 11th Five Year Plan was not accomplished. National energy intensity reduced by $1.23 \%$ in 2006 against $4.4 \%$ per year, the equivalent annual reduction rate needed to meet the national plan of $20 \%$ intensity reduction between 2005 and 2010 .

To guarantee the target accomplishment, the State Council enforced more rigorous measures. The national $20 \%$ energy intensity reduction targets were disaggregated to all provincial levels. Depending on the local conditions and capacities, the reduction targets in each province vary from $12 \%$ to $25 \%$. The allocation plan of the targets was first drafted by the NDRC and its attached research institute, namely Energy Research Institute, was highly involved. After soliciting comments from all provincial parities, the NDRC finalized the implementation proposal and submit to the State Council for approval. The provincial targets were in turn broken down the required quota to a city level, but not to a company level (personal interview). Stronger administrative accountability requirements were added as the government at lower level is responsible for assessing the progress and reporting to the upper-level government regularly. 
Thus, the Top-1000 Program became incorporated into a much larger scale of energy efficiency initiatives for application in China, however, the program began to be less voluntary, but more obligatory. Figure 7.3 shows the policy network of actors that are involved in the Top-1000 Program and the later extended initiatives. In this network, the interactions with clearly defined targets to achieve are marked with bold lines.

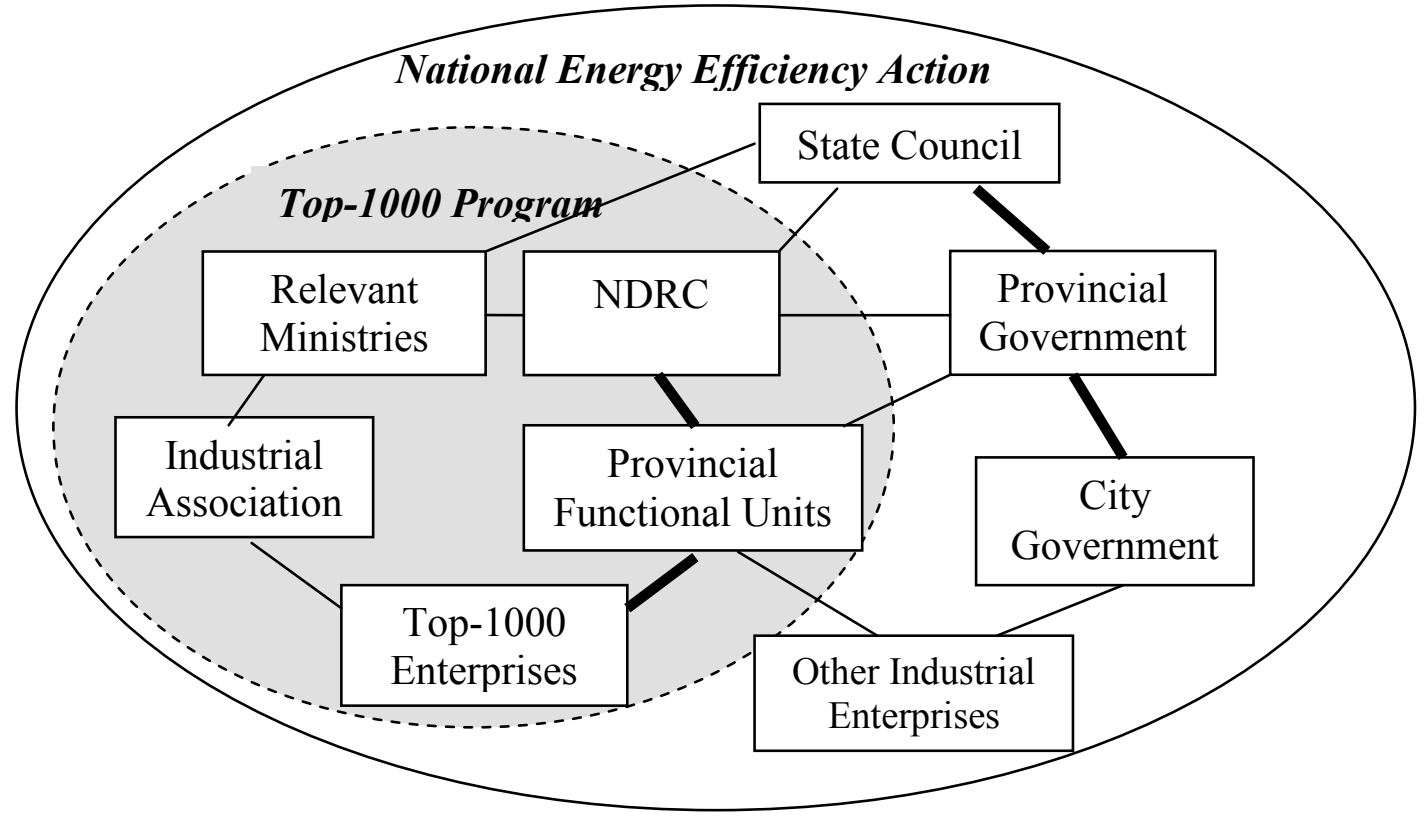

(Bold: links with concrete targets to achieve)

Figure 7.3 Top-1000 Program Actor Network and its Extension

With the parallel implementation of the energy efficiency improvement initiative and the Top-1000 Program, a series of supporting policies and measures have been formulated and adopted by central government. The Ministry of Finance, the State Bureau of Taxation, the Ministry of Science and Technology and The Ministry of Environmental Protection, though without formal role, all participated in designing and 
implementing supporting policies. Table 7.3 broadly categories these activities into three areas: capacity building activates, funding and financial incentives, and complementary programs and policies adopted. These policies have effectively changed the participants' behavior and contributed to the target fulfillment (personal interviews with policy researchers from Liaoning Province). A series of legislative regulations, policies, measures, and programs have been developed and enforced to complement the program implementation, such as the Ten Key Energy Saving Projects, National Climate Change Program, Energy Conservation Law (revised), and Monitoring and Evaluation Measures for Energy Conservation and Emission Reduction Activities (Kan 2008; Price et al. 2010; State Council 2010).

In addition, to ensure the effective achievement of the energy-saving targets, the administrative award and punishment rules were adopted to regulate the province-level governments and involved enterprises: the responsible government official will be evaluated annually on whether or not the energy conservations targets have been met. The well-performed entities that have typical values will be awarded and their achievements will be publicized. The enterprises which fail in meeting the targets will not be given the annual rewards or honorary titles. The leaders in the state-owned enterprises will not receive the annual award and the responsible officials will not be promoted. 
Table 7.3 Follow-up Activities of the Top-1000 Program

\begin{tabular}{|c|c|c|}
\hline $\begin{array}{l}\text { Follow-up } \\
\text { Activities }\end{array}$ & Description & Achievements \\
\hline $\begin{array}{l}\text { Capacity } \\
\text { building } \\
\text { activities }\end{array}$ & $\begin{array}{l}\text { - In October } 2006 \text {, a series of training sessions for the } \\
\text { Top- } 1000 \text { enterprises in five regional locations, covering } \\
\text { topics of energy conservation measurement, energy } \\
\text { auditing and statistics, case study, energy-saving } \\
\text { technology options. } \\
\text { - A series of energy statistics training sessions were held } \\
\text { by the NBS. The development of a national auditing } \\
\text { standard is in process. } \\
\text { - In } 2007 \text {, the Top- } 1000 \text { enterprises undertook energy } \\
\text { audits and identified energy-saving opportunities. } \\
\text { Outside experts from public and private agencies } \\
\text { provided technical assistance for the energy auditing. } \\
\text { - Technical assistance and on-site training }\end{array}$ & $\begin{array}{l}\text { By August 2007, a } \\
\text { total of } 967 \text { energy } \\
\text { audit reports and } 836 \\
\text { energy conservation } \\
\text { plans had been } \\
\text { complemented and } \\
\text { submitted to the } \\
\text { NDRC. }\end{array}$ \\
\hline $\begin{array}{ll}\text { Funding } & \text { and } \\
\text { financial } & \\
\text { incentives } & \end{array}$ & $\begin{array}{l}\text { - In 2007, a total of } 23.5 \text { billion RMB ( } \$ 3.4 \mathrm{~B}) \text { were } \\
\text { allocated to support energy-efficiency activities. In } \\
2008,41.8 \text { billion RMB }(\$ 3.9 \mathrm{~B}) \text { were allocated. } \\
\text { - The detailed rules of rewards and rebates for industrial } \\
\text { energy conservation were adopted. } \\
\text { - Most provincial governments received financial support } \\
\text { to develop local energy conservation centers. } \\
\text { - Central government announced to reduce the tax rebates } \\
\text { for exports of energy-intensive products. } \\
\text { - The enterprises with higher energy intensity level will be } \\
\text { charged with higher electricity prices. Since } 2007 \text {, the } \\
\text { local governments have gained authority to allocate the } \\
\text { levied fees. } \\
\text { - International donors are encouraged to invest in China's } \\
\text { energy conservation activities. }\end{array}$ & $\begin{array}{l}\text { There were strong } \\
\text { incentives for energy } \\
\text { conservation and } \\
\text { industrial } \\
\text { restructuring towards } \\
\text { less energy intensive. }\end{array}$ \\
\hline $\begin{array}{l}\text { Complementary } \\
\text { programs and } \\
\text { policies adopted }\end{array}$ & $\begin{array}{l}\text { - The Eleventh Five-Year Plan of Energy Development } \\
\text { (April, 2007) } \\
\text { - Comprehensive Working Scheme of Energy } \\
\text { conservation and Emission Reduction (May, 2007) } \\
\text { - National Climate Change Program (June, 2007) } \\
\text { - Energy Conservation Law (Revised, October, 2007) } \\
\text { - Statistical Monitoring and Evaluation Measures for } \\
\text { Energy Conservation and Emission Reduction Activities } \\
\text { (November, 2007) } \\
\text { - National Climate Change Action Plan (October, 2008) }\end{array}$ & $\begin{array}{l}\text { Energy conservation } \\
\text { and } \\
\text { reduction activition } \\
\text { have been identified } \\
\text { as key priorities to } \\
\text { support sustainable } \\
\text { development. }\end{array}$ \\
\hline
\end{tabular}

Source: Price et al. 2009; Wu 2009

\subsection{Results of the Program}

The energy savings of the Top-1000 enterprises came from the improvement of energy management, retrofits of industrial processes, as well as closure of small, 
inefficient production processes within enterprises. According to the official data, the initial program target of absolute energy saving of 100 million tce to 2010 had already been reached by the end of 2008 (NDRC 2009). The government at all levels then began to turn its attention to reaching the national energy intensity reduction targets, which is still hard to accomplish. Price et al. (2010) have estimated that, depending on the GDP growth rate, the Top-1000 Program could contribute to somewhere between approximately $10 \%$ and $25 \%$ of the savings required to support China's efforts to meet a $20 \%$ reduction in energy intensity by 2010 . Table 7.4 shows the outcomes of the Top1000 Program, as well as overall progress of energy efficiency improvement efforts.

Table 7.4 Progress of the Top-1000 Program and the National Program

\begin{tabular}{|c|c|c|c|c|c|c|c|}
\hline Program & $\begin{array}{c}\text { Targets during } \\
2006-2010\end{array}$ & Item & 2006 & 2007 & 2008 & 2009 & Remark \\
\hline \multirow{2}{*}{$\begin{array}{l}\text { Top-1000 } \\
\text { Program } \\
\text { (April 2006) }\end{array}$} & \multirow{2}{*}{$\begin{array}{l}\text { - save energy } \\
\text { of } 100 \text { million } \\
\text { tce }\end{array}$} & $\begin{array}{l}\text { Aggregate } \\
\text { energy saved } \\
\text { (million tce) }\end{array}$ & 20 & 70.48 & 106.2 & - & \multirow[b]{2}{*}{$\mathrm{C}$} \\
\hline & & $\begin{array}{l}\text { Number of } \\
\text { involved } \\
\text { enterprises }\end{array}$ & 998 & 953 & 922 & - & \\
\hline \multirow{3}{*}{$\begin{array}{l}\text { National } \\
\text { Action on } \\
\text { Energy } \\
\text { Intensity } \\
\text { Reduction } \\
\text { (June, 2007) }\end{array}$} & \multirow{3}{*}{$\begin{array}{lr}\text {-reduce } & \text { energy } \\
\text { intensity } & \text { (EI) } \\
\text { by } 20 \% & \\
\text {-reduce } & \mathrm{SO}_{2} \\
\text { emissions } & \text { by } \\
10 \% & \\
\text {-reduce } & \mathrm{COD} \\
\text { by } 10 \% & \end{array}$} & $\begin{array}{l}\text { Aggregate } \text { EI } \\
\text { change rate }\end{array}$ & $-1.23 \%$ & - & $-10.1 \%$ & $-14.4 \%$ & OP \\
\hline & & $\begin{array}{l}\text { Aggregate } \mathrm{SO}_{2} \\
\text { change rate }\end{array}$ & $1.8 \%$ & $\begin{array}{c}- \\
3.14 \\
\%\end{array}$ & $-8.95 \%$ & $-13.1 \%$ & $\mathrm{C}$ \\
\hline & & $\begin{array}{l}\text { Aggregate } \\
\text { COD change } \\
\text { rate }\end{array}$ & $1.2 \%$ & $\begin{array}{c}- \\
4.66 \\
\%\end{array}$ & $-6.61 \%$ & $-9.66 \%$ & OP \\
\hline
\end{tabular}

Note: C- target completed; OP- target on progress

Source: NDRC and NBS 2007; NDRC 2009

It should be noted that the Top-1000 Enterprises Energy Use Report 2007 (NDRC and NBS 2007), jointly released by the NDRC and the National Bureau of Statistics (NBS), includes a more complete analysis and comparison of sectoral performance. In the subsequent years, the NDRC has become the only body reporting on 
program performance and no information on sectoral progress has been provided. Furthermore, according to Price et al. (2010), there is little transparency in the data reporting for the Top-1000 Program, and there is no third party reviewing or verifying the reported results at all levels.

What has caused the Top-1000 Program deviate from the route of voluntary program? Liu (2010) identifies three reasons: (1) the urgency and stringency of the compliance of the goal set in the 11th Five-Year Plan; (2) the increased probability of disagreement among involved actors, who have varying interests and resources; and (3) the realistic complexity in arranging such a voluntary agreement in a country that is experiencing significant changes.

\subsection{Conclusive Summary}

The Top-1000 Industrial Energy Conservation Program was derived from the pilot industrial voluntary project implemented in Shandong Province, which was modeled on foreign practices and guided by international agencies. The original idea of introducing voluntary agreement was to test whether policy instruments built on the consensus between government and industry can be taken as an alternative approach to top-down controls. Although the pilot project in Shandong showed a promising start, and the initial design of the Top-1000 Program did enable governments at local levels and involved enterprises to jointly make and implement energy efficiency plans consistent with the national goals; however, the case study shows that the Top-1000 Program has deviated from the voluntary approach, and the traditional top-down regulations and management are treated to be more effective and irreplaceable. 
The Top-1000 Program acts as an important policy experiment that encourages more communications between local governments and the enterprises in their jurisdictions. The program also provides incentives to local governments and involved enterprises to cooperate in enhancing industrial energy efficiencies. However, the effective implementation of the program needs to be coordinated with other relevant policies, and eventually depends on the capacity improvement of the involved actors. In addition, the network members within the program are not well-connected, due to the fact that all government, business, and civil society actors do little in sharing and exchanging information and other resources, or arranging concerted efforts for mutual goals. Instead, the local governments and the enterprises passively accepted the targets set by the central government, with little involvement from the civil society actors.

Same as the other two cases, the economic reforms have, to a great extent, separated the business with the government, leaving enterprises more maneuver in making their own decisions according to market development. But the enterprises in China lack resources and powers to negotiate with the governments; even numerous industrial associations are incapable. As seen from the case, the resultant implementation and follow-up activities of the Top-1000 Program privileges central government decision making against negotiation of voluntary targets.

As for the influence of political control on the participation from non-state actors, the decrease of the political control is seen as a trend in the development of Chinese political regime, and could not be clearly revealed in a case that covers a relatively short period of time, nor could it be taken as the causal factors that influence the proactiveness of non-state actor performance. As a matter of fact, in the Top-1000 
Program, the initiatives of the non-state actors have been marginalized during the program process.

Finally, the Top-1000 Program was initially designed by the NDRC and some other agencies at the central level, but its effective implementation could not be achieved without participation of provincial governments. With the expansion of the program to cover almost all industrial enterprises at all scales, the needs for shared responsibility and policy coordination between ministries and provinces increased. The case demonstrates that since 2007, the State Council has been leading the policy development and integration, and the promotion of energy conservation activities. 


\title{
CHAPTER VIII
}

\begin{abstract}
ANALYSIS AND DISCUSSION
The historical and institutional development of China's climate change mitigation policy process has been presented through three selected cases, namely the national climate change mitigation initiative in general, and two specific cases of the CDM project management and the Top-1000 Industrial Energy Conservation Program. This chapter contains a comprehensive comparative analysis of the findings presented in the previous three cases. Such a comparative analysis sheds light on key features of policy networks in different policy arrangements, which can facilitate in-depth understanding of the dynamics of China's policy making processes.

This chapter is arranged as follows. Section 8.1 conducts the within-case analysis, which treats each case of policy arrangements individually and tests hypotheses concerning relationship between environmental contexts, features of policy networks, and policy outcomes. Subsequently, in Section 8.2, specific policy features across cases are analyzed to generate some commonalities to understand China's policy process. In the final section of 8.3, findings from the within-case analysis and the cross-case analysis will be synthesized to test the validity of the fragmented authoritarianism model developed by Lieberthal and Oksenberg (1988).
\end{abstract}

\subsection{Hypothesis Testing through Within-case Analysis}

As shown in Section 2.6, four hypotheses have been suggested as follows based on the preliminary study of the policy network approach. These hypotheses highlight the formulation and functions of policy networks in China's climate change mitigation policy 
processes. The present section summarizes the hypothesis testing results from the empirical findings of the three cases (within-case study). Table 8.1 shows the results by taking three cases together. As seen in the table, the impact of state-society interaction on the policy proactiveness provides a good approximation in two of the three cases. Furthermore, the involvement of the State Council in decision making can be positively predicted by the complexity of responsibility sharing among state actors, although the degree and approach to which the State Council is involved varies in different policy arrangements.

Table 8.1 Empirical Support for the Hypotheses

\begin{tabular}{|l|c|c|c|}
\hline Hypotheses & Case 1 & Case 2 & Case 3 \\
\hline $\begin{array}{l}\text { H1: Increasing interaction between government, business, and } \\
\text { civil society actors will increase the likelihood of China taking a } \\
\text { more proactive approach to develop effective climate change } \\
\text { mitigation policy. }\end{array}$ & + & + & 0 \\
\hline $\begin{array}{l}\text { H2: More fragmentation in the distribution of regulative power } \\
\text { will increase the likelihood of China's utilizing more innovative } \\
\text { policy instruments and measures. }\end{array}$ & 0 & N/A & N/A \\
\hline $\begin{array}{l}\text { H3: Decreasing political control in policy development and } \\
\text { implementation will encourage other actors, in particular non- } \\
\text { state actors, to exert greater effort in shaping mitigation policy. }\end{array}$ & 0 & N/A & N/A \\
\hline $\begin{array}{l}\text { H4: Increasing demand for shared responsibilities between } \\
\text { ministries and provincial governments will increase the } \\
\text { likelihood of stronger coordination by the central government. }\end{array}$ & + & + & + \\
\hline
\end{tabular}

Scale: +: confirming; -: disconfirming; 0: neither conforming or disconfirming; N/A: not applicable

Hypotheses 2 and 3 are not applicably tested in Case 2 and 3. Both cases failed in providing enough long time to exhibit clearly the trend of fragmentation of the power distribution, as well as the extent of the political control. Although Case 1 is applicable in testing both hypotheses, however, being lack of direct causal relationship between underlying variables the case study neither confirms nor disconfirms the hypotheses. 
It should be noted that although empirical studies in the three cases generally support the first hypothesis and the last hypothesis. But the reliability is not without limitations. The primary reason lies in the fact that all hypotheses are on the basis of personal familiarity of the practical China's climate policy process and the understanding of features and roles of the working policy networks. Although the policy network analytic framework is in theory a casual model, it only contains some inclusive concepts in the model and could not capture numerous influencing variables in the real life. Given nonlinearity of a policy process and complex causal-effect relationships in the cycle of policy development, it might be more appropriate to claim that the relationship among variables tested in above hypotheses are not causal, but instead, dialectic and correlational.

\subsection{Results of the Cross-case Analysis}

The purpose of the using multi-case study approach is to enhance the generality of understanding a broader phenomenon (Gerring 2004), and enhance the probability of capturing novel findings that may exist in data (Eisenhart 1989). The three cases of different policy arrangements can contribute to a better understanding of the nature of China's policy making process on climate change and of roles and influences of policy networks involved in the process. In this section, the cross-case analysis is taken to summarize some commonalities and features from policy making processes of the three cases.

Notably, in this study, it is risky to claim that the comparability requirement of

doing multi-case study is favorably met, since the controlled comparison across cases is 
almost not possible for nature events (George and Bennett 2005; Gerring 2004), and the three cases are hierarchically at two levels (one generic case of national mitigation policy making and two nested cases of specific mitigation programs). However, since all the three cases follow the same analytic framework and share overlapping timeframe, some factors and features are summarized to reflect the commonality or uniqueness of China's climate change policy processes.

The section first addresses key features of policy network development in the three cases. The analysis, conducted from 8.2.1 to 8.2.3, is framed by the three components in the policy network analytic framework, namely, policy contexts, network features; and policy outcomes. Treating the policy making process as dynamic and cyclical, Section 8.2.4 summarizes key features of the mitigation policy process in China.

\subsubsection{Contextual Factors that Affect the Policy Network}

Contextual factors provide precondition for understanding the origins of policy networks. Although three cases vary with their scopes and functional specificities, as identified in the case studies, the emergence and form of policy networks are all influenced by three major factors of international, domestic, and policy-specific contexts. Policy networks evolve with the development of these contextual factors. Table 8.2 summarizes the key contextual factors in the three cases. 
Table 8.2 Key Factors in the Three Cases

\begin{tabular}{|c|c|c|c|}
\hline $\begin{array}{l}\text { Environmental } \\
\text { Contexts }\end{array}$ & Case 1 & Case 2 & Case 3 \\
\hline $\begin{array}{l}\text { International } \\
\text { factors }\end{array}$ & $\begin{array}{l}\text {-Development of the } \\
\text { climate change regime } \\
\text { (FCCC, Kyoto } \\
\text { Protocol, and other } \\
\text { agreements); } \\
\text {-Global economic } \\
\text { development } \\
\text {-Diplomacy and } \\
\text { international relations }\end{array}$ & $\begin{array}{l}\text {-Development of the } \\
\text { Kyoto Protocol and its } \\
\text { mechanisms } \\
\text {-CDM Institutional and } \\
\text { organizational } \\
\text { development } \\
\text {-Development of global } \\
\text { carbon market }\end{array}$ & $\begin{array}{l}\text {-Experience from } \\
\text { international joint } \\
\text { environmental policy } \\
\text { making } \\
\text {-Experience from target- } \\
\text { oriented energy efficiency } \\
\text { programs }\end{array}$ \\
\hline Domestic Factors & $\begin{array}{l}\text {-Status of economic } \\
\text { development } \\
\text {-Progress of political } \\
\text { and economic reforms } \\
\text {-Administrative } \\
\text { restructuring reform } \\
\text { and impacts }\end{array}$ & $\begin{array}{l}\text {-Experience of adopting } \\
\text { market-based measures } \\
\text {-Priority areas of } \\
\text { developing CDM } \\
\text { projects } \\
\text {-Administrative } \\
\text { restructuring and impacts }\end{array}$ & $\begin{array}{l}\text {-Economic Goals set by the } \\
\text { national government } \\
\text {-Energy and industry related } \\
\text { policies } \\
\text {-Administrative } \\
\text { restructuring and impacts }\end{array}$ \\
\hline $\begin{array}{l}\text { Policy-Specific } \\
\text { Factors }\end{array}$ & $\begin{array}{l}\text {-Coordination of } \\
\text { climate policy with } \\
\text { other development } \\
\text {-Experience and } \\
\text { capacity in } \\
\text { implementing similar } \\
\text { policies } \\
\text {-Division of } \\
\text { responsibilities among } \\
\text { governmental agencies }\end{array}$ & $\begin{array}{l}\text {-Domestic CDM } \\
\text { measures and changes } \\
\text {-CDM approval and } \\
\text { management } \\
\text {-Experience of CDM } \\
\text { Pilot Projects }\end{array}$ & $\begin{array}{l}\text {-Top-1000 Program design } \\
\text { and improvement } \\
\text {-Experience gained from } \\
\text { pilot projects in Shandong } \\
\text {-Imperative of enhancing } \\
\text { energy efficiency in } \\
\text { industrial sectors }\end{array}$ \\
\hline
\end{tabular}

The three contextual factors are also not independent from each other. Rather, a complex combination of the contextual factors has led to the variations of policy networks. In general, the development of international climate change regime and the development of Chinese politics and economy are the most important determinants. Furthermore, these contexts do not affect policy networks in the same way. For example, although both the CDM project management and the Top-1000 Program were formally initiated in the mid-2000s, the former case is more influenced by the international factors of Kyoto Protocol's entry into force and carbon market development, while the latter case 
is more determined by the imperatives of reducing the domestic energy consumption of key industrial enterprises.

Since Case 2 and 3 are nested within Case 1, the national mitigation policy development provides context for the cases of specific policy arrangements. Furthermore, experience and knowledge accumulated from international and domestic practices are common factors of the three cases and affect existing policy systems and actor relationships.

\subsubsection{Structural and Interactive Features of Policy Networks}

Policy networks play a crucial role in shaping responses to external factors. As presented in the cases, a variety of state, market and civil society actors have been involved in policy processes. The state actors include the central governing apparatus (mainly the State Council, and the numerous commissions and ministries affiliated with the State Council), the provincial and local governments, and diverse kinds of civil society actors (research institutions, universities, public media, NGOs, etc.). Table 8.3 summarizes the extent of the involvement of some of the key actors presented in the three cases.

Since Case 1 dealt with the general climate change policy process, the State Council, which receives substantial input from ministries and commissions, leads policy formulation and development, as well as policy implementation. Among the ministerial level, a coordination committee has been evolving, focusing on the issues of economic development, international negations, and national mitigation and adaptation strategies. Among ministerial agencies, the NDRC is the core agency in coordinating and advancing domestic climate policy process. 
Table 8.3 Levels of Actor Involvement in Climate Policy Making in Three Cases

\begin{tabular}{|l|c|c|c|}
\hline \multicolumn{1}{|c|}{ Actors } & Case 1 & Case 2 & Case 3 \\
\hline The State Council & ++ & $/$ & + \\
\hline NDRC & ++ & ++ & $/$ \\
\hline MOFA & ++ & ++ & $/$ \\
\hline MOST & + & $/$ & / \\
\hline SEPA/MEP & + & $+($ after 2007) & ++ \\
\hline SMA and CAS & + & + & + \\
\hline Provincial governments & $+($ after 2007$)$ & $/$ & + \\
\hline $\begin{array}{l}\text { Research institutes, universities, } \\
\text { think tanks, etc. }\end{array}$ & + & + & + \\
\hline Industrial Associations & + & + & $/$ \\
\hline Large-scaled enterprises & + & + & + \\
\hline Other Industrial enterprises & + & + & $/$ \\
\hline Public media & + & + & $/$ \\
\hline Traditional NGOs & + & + & + \\
\hline Market intermediaries & & + & + \\
\hline
\end{tabular}

Scale: ++: very strong influence; +: moderately strong influence; /: Some influence but not strong or not directly

Case 2 and Case 3 deal with two specific policy arrangements: Case 2 focuses on the national response of the international carbon emission trading system, while Case 3 focuses on domestic industrial energy efficiency enhancement issues. Both cases were adopted at the same period. The two departments within the NDRC play as the key actors in managing the two programs: the Department of Climate Change (also the Secretariat of the NCCLG) for the CDM project management and the Department of Resource Conservation and Environmental Protection (also the Secretariat of the NECERLG) for the Top-1000 Program.

The provincial governments have been playing increased roles in supervising the program implementation. For the CDM case, studies show that since 2007, many provinces have become enthusiastic in promoting CDM project development (e.g., Qi et al. 2008), even though the project approval decision is still made by the National CDM 
Board at the central level. As for the case of the Top-1000 Program, the engagement of provincial governments in energy conservation is through contract signing with involved enterprises and accepting annual performance evaluation by the central government. Comparatively, the provincial governments have a higher involvement in the policy process in Case 3.

Market and civil society actors are important policy implementers, thus their involvement influences policy processes and outcomes. However, their roles and levels of involvement vary depending on the forms of the policy arrangements. Under the CDM scheme, attracted by the potential benefits from carbon trading, market and some civil soceity actors are spontaneously involved in the activities. Their performance is affected by the interplaying factors of carbon prices in the market and the extent of government interventions. The role of the government is to regulate the trading behaviors and ensure that the projects contribute to sustainable development. Alternatively, under the Top1000 Program, the provincial governments and involved enterprises are networked by the mandatory targets. The members of the actor network increase when more rigorous targets are set to accomplish. Whereas detailed award and punishment rules have been made to strengthen administrative management, few market-based measures and incentives have been provided to strengthen the effective cooperation between local governments and enterprises.

\subsubsection{Policy Outcomes}

This section analyzes the policy outcomes of the three cases from two general criteria: effectiveness and legitimacy. Effectiveness is analyzed by the extent how the policy arrangements are consistent with the more general policy goals and the extent to 
which the objectives of the policy arrangements have been achieved. Legitimacy is evaluated from the accessibility of actors and the communicative quality of participation.

China does not accept a binding commitment on carbon emission reductions. Its climate change mitigation policy is to emphasize its position as a developing country and the validity of following the principle of "common but differentiated responsibility and capacity" in international climate negotiations. Realizing its increased carbon emissions due to rapid economic growth, China has made continued effort in limiting the growth of energy intensity, and actively participated in international climate change negotiations and cooperation. The CDM project development and the Top-1000 Program are important activities within China's climate change policy framework. Table 8.4 shows the objectives and performance of the three presented cases.

Generally, the three cases have shown China's transition towards proactiveness in promoting climate change mitigation activities. Case 1 and 2 do not have compulsory quantitative targets to reach; therefore, China's activities are actually voluntary. The implicit purpose is to balance the economic development and emissions reductions and gain co-benefits from them. Furthermore, China's position towards active participation and international cooperation also reflects that the country is sensitive to its international image of a rapidly growing power. For Case 3, the Program was initially implemented with a clear but fixed quantitative energy-saving target; however, when the proposed target had been achieved, the program failed in providing further incentives to the involve actors to save energies. In addition, unlike the CDM project development, the calculation of the amounts of real energy conservation in the Top-1000 Program case lacks rigorous measurement and verification. 
Table 8.4 Effectiveness of Policy Arrangements in Three Cases

\begin{tabular}{|c|c|c|c|}
\hline $\begin{array}{c}\text { Policy } \\
\text { Effectiveness }\end{array}$ & Case 1 & Case 2 & Case 3 \\
\hline $\begin{array}{l}\text { Included } \\
\text { Policies }\end{array}$ & $\begin{array}{l}\text { A series of climate- } \\
\text { specific and climate- } \\
\text { related policies }\end{array}$ & $\begin{array}{l}\text { The Interim Measures in } \\
\text { 2004; formal Measures in } \\
2005 \text { and other related } \\
\text { adjustments }\end{array}$ & $\begin{array}{l}\text { Top-1000 Industrial } \\
\text { Energy Conservation } \\
\text { Program and related } \\
\text { measures }\end{array}$ \\
\hline Attributes & $\begin{array}{l}\text { Various types: regulatory } \\
\text { instruments, incentives, } \\
\text { voluntary agreements, } \\
\text { public investment, etc. }\end{array}$ & $\begin{array}{l}\text { Domestic response to the } \\
\text { international market-based } \\
\text { emission trading scheme }\end{array}$ & $\begin{array}{l}\text { Domestic regulatory } \\
\text { policy with voluntary } \\
\text { features }\end{array}$ \\
\hline $\begin{array}{c}\text { Policy } \\
\text { Objectives }\end{array}$ & $\begin{array}{l}\text { - to promote energy } \\
\text { conservation and enhance } \\
\text { energy efficiency } \\
\text {-to promote renewable } \\
\text { energy development } \\
\text {-to reduce energy } \\
\text { intensity by } 20 \% \text { during } \\
2005-2010\end{array}$ & $\begin{array}{l}\text { - to streamline the project } \\
\text { approval process } \\
\text { - to promote the CDM } \\
\text { project development and } \\
\text { contribute to sustainable } \\
\text { development }\end{array}$ & $\begin{array}{l}\text { - the involved } 1008 \\
\text { enterprises should reach } \\
\text { the aggregate energy } \\
\text { saving of } 100 \text { million } \\
\text { tons during 2006-2010 }\end{array}$ \\
\hline $\begin{array}{l}\text { Leading } \\
\text { Agency }\end{array}$ & $\begin{array}{l}\text { The State Council and } \\
\text { cabinet ministries }\end{array}$ & $\begin{array}{l}\text { The NDRC, MOST, and } \\
\text { MOFA }\end{array}$ & The NDRC \\
\hline $\begin{array}{l}\text { Consistency } \\
\text { with Other } \\
\text { Policies }\end{array}$ & $\begin{array}{l}\text { The energy intensity } \\
\text { reduction objective is } \\
\text { consistent with goals set } \\
\text { in the Five-year Plan. }\end{array}$ & $\begin{array}{l}\text { - the priority areas were } \\
\text { identified encourage CDM } \\
\text { projects }\end{array}$ & $\begin{array}{l}\text { - The Program becomes } \\
\text { part of national action } \\
\text { in reducing energy } \\
\text { intensity }\end{array}$ \\
\hline $\begin{array}{c}\text { Performance } \\
\text { and } \\
\text { Objective } \\
\text { Accomplishme } \\
\text { nt }\end{array}$ & $\begin{array}{l}\text { China had reduced its } \\
\text { energy intensity by } 15.6 \% \\
\text { at the end of } 2009 \text {, and } \\
\text { the } 20 \% \text { reduction goal is } \\
\text { within reach (Xie } 2010 \text { ). } \\
\text { The final result was } \\
19.1 \% \text { reduction by } 2010 \text {. }\end{array}$ & $\begin{array}{l}\text { - No quantitative CDM } \\
\text { development targets. } \\
\text { - The leading CDM host } \\
\text { country in the world } \\
\text { - Positive impacts on } \\
\text { China's sustainable } \\
\text { development } \\
\text { - Be consistent with priority } \\
\text { areas. }\end{array}$ & $\begin{array}{l}\text { By the end of 2008, an } \\
\text { aggregate energy saving } \\
\text { of } 106.2 \text { million tce has } \\
\text { been reached. Thus the } \\
\text { original objective was } \\
\text { achieved two years in } \\
\text { advance. }\end{array}$ \\
\hline $\begin{array}{l}\text { Follow-up } \\
\text { Activities }\end{array}$ & $\begin{array}{l}\text { The } 2020 \text { carbon emission } \\
\text { intensity goals have been } \\
\text { set and will be } \\
\text { decomposed into } \\
\text { provinces }\end{array}$ & $\begin{array}{l}\text { - Further actions depend on } \\
\text { the development of } \\
\text { international climate regime } \\
\text { - Possibility in initialing } \\
\text { domestic carbon emission } \\
\text { system }\end{array}$ & $\begin{array}{l}\text { The enterprise energy } \\
\text { efficiency activities will } \\
\text { be incorporated in the } \\
\text { provincial target setting }\end{array}$ \\
\hline
\end{tabular}

In terms of the legitimacy of the policy arrangements, the three cases have shown the improved involvement of various actors in policy making processes. The climate change coordination committee has extended to cover more than 20 ministerial agencies, and effective mitigation activities have been implemented with the adoption of 
policies and measures. The information concerning the development of climate change regime and its relevance to China's policy and practices has been widely reported by public media and become more accessible to the public. Another significant feature is the growing power of local governments and government-operated research institutions in shaping the relevant policies and providing feedback advice for policy change. However, as shown in Case 2 and 3, the governmental actors are still dominating the policy discussion and decision making, with little participation from business actors. Important information about policy progress and possible disputes is lacking due to issues of transparency and openness.

\subsubsection{Key Features of Climate Change Mitigation Policy Process in China}

When treating policy making as a dynamic process, multiple case studies have reflected some key features of Chinese climate change mitigation policy process, as indicated in the following:

- Encouraging policy experiment and diffusion

In China, climate change policy making, implementation, and coordination is complex and actor participation is dispersed over many different levels and sectors. To ensure policy practicability and consistency, China normally begins with testing policies or programs on a smaller scale. Once pilot projects prove to be successful, the experience and practices will be diffused on a large scale and will involve more actors. As needed, necessary improvement and adjustment will be made. The CDM project development takes this approach, starting from the AIJ cooperation projects and CDM capacity building projects and later moving to projects that can be certified and traded in the market. China's Top-1000 Program adopted in 2006 represents an exemplary case. The 
Program is derived from experience gained in two voluntary pilot projects implemented in Shandong Province (Price and Wang 2007). The most recent case is the launch of the Locality Low Carbon Pilot Program. To explore an effective low-carbon governance system nationwide, five provinces and eight cities have been selected by the NDRC to promote energy conservation and emission reduction (People's Daily 2010).

- Active employment of policy tools

The importance of climate mitigation policy is seen in the adoption and implementation of a series of regulatory, financial and information-based climate change policies (NDRC 2007; Richerzhagen and Scholz 2008). New policy tools include voluntary agreements and carbon market trading. These reflect the changes in statesociety relations and government-market relations. The adoption of new policy tools exerts influence over the structure of the network, as well as the behaviors and interactions of the actors involved. The case studies have shown China's proactiveness in promoting innovative policy tools.

- The central government's strong roles in the policy process

The strong dominance of the central government ensures the state's ability to develop policy in a significant and large-scale way. The cases reflect that in China, the transformation of the climate mitigation issue from the international level to the local level is highly reliant on the mandates of Chinese central government. Debates exist concerning to what extent localities can be freed to make decisions; however, the capacity building, information dissemination, and technological assistance are all reliant on the mobilization and support of the central government. The current climate mitigation policy making process has been institutionalized. Comparatively, Chinese administrative 
bureaucracies, which influenced by the Communist Party, are less influenced or pressured by interests groups or other external political forces. Their institutional features can facilitate policy making and promote effective policy implementation, although they may harm the interests of other groups in an "implicit" manner by minimizing their ability to influence policymaking.

- More focus on the action network development

In China, decision making takes place from a top-down approach. However, the policy making process in China remains flexible, even though it may not be transparent to less informed outsiders; thus the analysis of structural and interactive features of actor networks is more focused on the policy implementation stage. The decision makers attach importance to the effectiveness of the policy implementation and are ready to make changes on the basis of past successes or failures. For this purpose, a variety of civil society actors, especially actors from academic institutions and universities have been encouraged to get involved in the policy process as a way to link policy implementation with potential policy changes.

\subsection{Reflections on the Fragmented Authoritarianism Model}

After having summarized findings of case studies through the within-case analysis and the cross-case analysis, this section addresses the general policy making process issue by verifying whether the widely referred to fragmented authoritarianism model is still viable to explain the climate change mitigation policy process in contemporary China. 
As introduced in Chapter 2, the fragmented authoritarianism model was developed to capture the main features of the Chinese policy making process. According to the model, despite the authoritarian nature of the Chinese political system, in most cases, the bureaucratic structure of authority below the very peak of the Chinese political system is highly fragmented. Consensus building is central to the policy process, and the policy processes are protracted, disjointed and incremental (Lieberthal and Oksenberg 1988, 22-24). Lieberthal (1992) further argues fragmentation and disjointedness in decision making is structurally based and has been enhanced by reform policies regarding procedures. In addition, the fragmented authoritarianism model recognizes the impacts of procedural changes on the decision making under the reform: the extent to which bureaucratic organs respond in disciplined fashion to instructions from higher levels has been reduced (Lieberthal 1992, 9).

According to Lieberthal $(1992,10)$, "the fragmented authoritarianism model acknowledges the great insights offered from elite-oriented rational-actor approaches and from a cellular conception of the system." And it "adds a third necessary ingredient to the equations: the structure of bureaucratic authority and the realities of bureaucratic practice that affect both the elite and the basic building blocks of the system".

However, the stereotypical characteristics of the fragmented authoritarianism model do not totally fit with the empirical findings from these case studies of China's climate change policy development. In fact, to a significant degree, the development of China's climate change mitigation policies have shown some features that might raise question about some aspects of the fragmented authoritarianism model. 
First, although various bureaucracies have been involved in policy formulation and implementation stages, which certainly increased difficulties to achieve agreement among an array of bodies; however, there is clear division of responsibilities among government units and policy communities formed around generic and specific climate change mitigation policies. Government is often the initiator, and later, the manager of the policy networks; and the central government dominates the policy process. Such "networked" communities cut across formal bureaucratic lines and evolve with policy development. In addition, since governments at lower levels generally accepted the targets set by the upper-level government and have been seriously trying to accomplish the objectives, little evidence indicates that bureaucratic agencies involved in policy process are trying to promote and protect their own interests and compete with others. Although there remain complaints and disputes from provinces about the distribution of energy intensity reduction shares, the central government has responded with persuasion and some adjustments. The aggregate targets have not been lowered.

Second, the fragmented authoritarianism model, through studies of economic decision making in China, argues the policy making process in China is protracted, disjointed, and incremental because of the structural fragmentation and procedural bargaining. However, the case study findings showed that the policy making process is not always slow in China and that beyond structural and procedural features of government institutions, there are other factors that have influenced the responsiveness of decision making. These include pressures and assistance from the international community; actions of developed countries and some developing countries, as well as the environmental and resource constraints of domestic economic development. 
Third, the model gives much focus to the decision making of authority below the very peak of the Chinese political system, and assumes that policies are the outcomes after a series of negotiations, bargaining, and resource exchanges towards consensus building. Alternatively, the policy network approach employed in this study views the policy making process as a dynamic and iterative policy learning cycle. Due to a lack of experience and consensus, policy making is most often action-oriented and takes a testand-trial approach. As the case studies have shown, most of the Chinese climate change policies are shaped after long deliberation and continual improvement, derived from a series of pilot projects. Given the sheer size and diversity of the country, the approach, to some extent, breaks the deadlock of policy coordination and development. The government leads the development of the action network. On the basis of information feedback from policy implementation and advices gained from relevant actors, the government makes policy adjustments and changes.

The fragmented authoritarianism model suggests that bargaining among bureaucracies is the approach to create consensus to mitigate the conflicts of interests. It makes no reference to Chinese cultural heritage. As a matter of fact, a cultural analysis provides some explanations of why both hierarchy and consensus can simultaneously apply in China. Culturally, China has the heritage of Confucius, which demands loyalty and obedience. Subordinate disagreement and defiance are not tolerated in order to maintain the image of unity. This may give the impression that the policy actor networks in China are distinct from those of Western democracies and are more collaborative, which definitely reduces the costs for policy bargaining and persuasion, but this may also be the result of a situation of feigned compliance (Pye 1992; Nordqvist 2007). Currently, 
the information is still limited and less accessible as regards the extent and permanence of the consensus reached among all involved government, market, and civil society actors.

It is undeniable that by adding structural and procedural ingredients into consideration, the fragmented authoritarianism model has enhanced our understanding of the Chinese policy process. However, to strengthen its explanatory power and incorporate important observations and conclusions from the case studies, the prescribed focus on the structures among government agencies shall be expanded. Gaining insights from the policy network approach, Figure 8.1 suggests some broader relationships that have emerged with China's market-oriented reform and integration into the world economy, and deserve future in-depth study. In addition, the roles and influences of the Communist Party and cultural values should be considered.

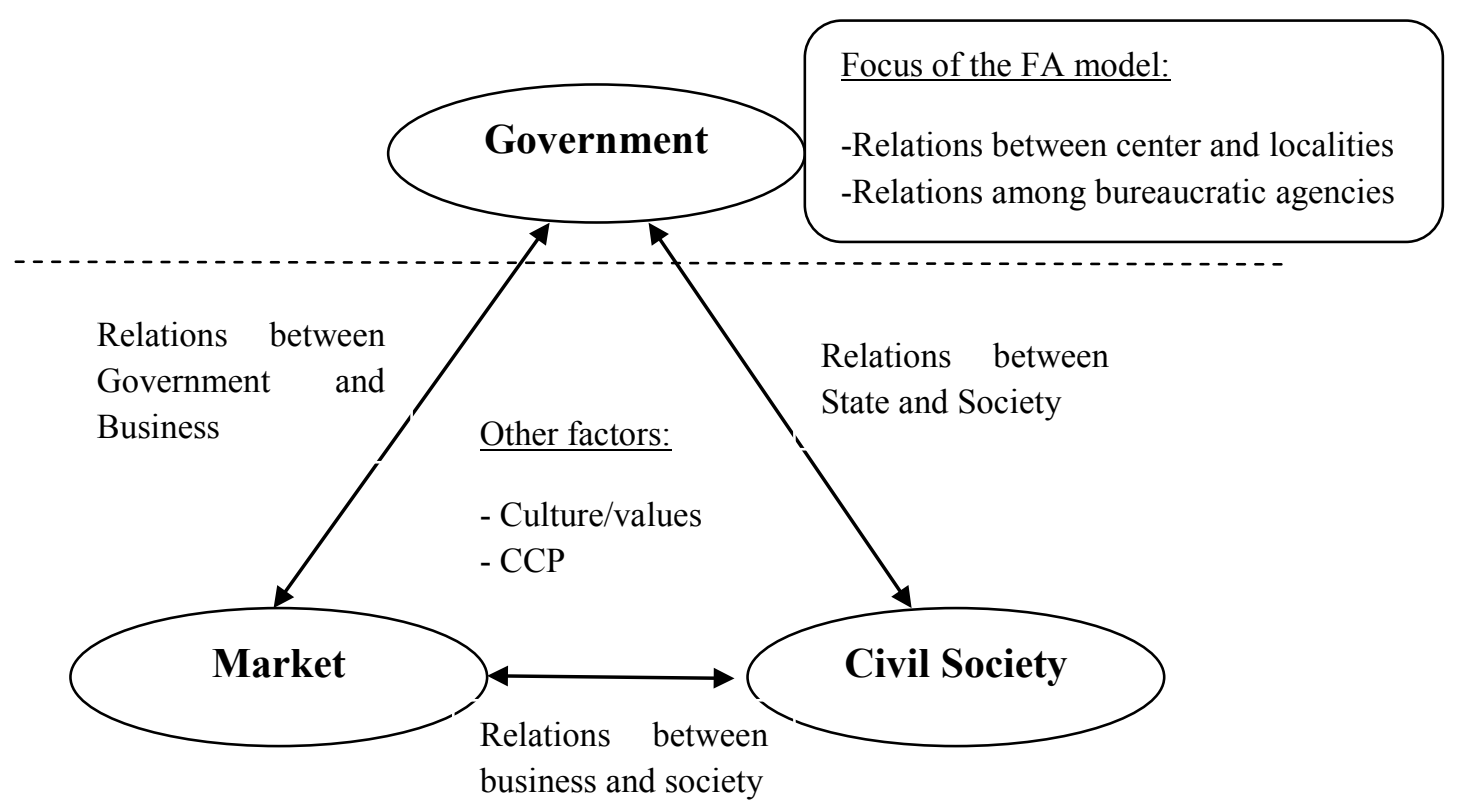

Note: FA-Fragmented Authoritarianism; CCP

Figure 8.1 Relationships among Actors in Expanded Policy Networks 
It should be noted that although China has become more active in promoting climate change mitigation policies and action, the overall strategies to deal with international climate regime negotiations are still hesitant and cautious. Fearing that more action might cause more commitment and that the international regimes established by the developed countries might damage the country's interests, the Chinese central government has acted strategically to protect its economic and political autonomy. This explains why even though many innovative policies and measures have been introduced, they are complementary options designed to achieve broader development goals. Through cooperative governance and collective action, the Chinese government believes it can build consensus with core economic sectors and retain core political values which it believes will fit its needs and the society in the long run. 


\section{CHAPTER IX}

\section{CONCLUSIONS AND FUTURE RESEARCH}

In this last chapter, a concluding analysis of the implications of the policy network approach and the case studies of the emergence and implementation of climate change mitigation policies in China will be made. This chapter is divided into four sections. Following this introductory section, Section 9.1 presents conclusions drawn from the three detailed case studies of different mitigation policy arrangements. Next, limitations of the study are discussed. Finally, in Section 9.3, suggestions for future research are presented.

\subsection{General Conclusions}

Guided by the policy network analytic framework, and through performing three case studies, this study examines the historical development of China's climate change mitigation policy making process. The within-case analysis was conducted to verify the hypotheses concerning causal relationships among key policy network constructs. The cross-case analysis was taken to compare the key features of policy process related with different policy arrangements. The generalized findings were subsequently used to study the viability of the fragmented authoritarianism model in analyzing current policy process in China. In general, major conclusions to be formulated on the basis of this study can be summarized as follows:

First, although Chinese climate change mitigation policy outcomes cannot be

claimed to be an unambiguous success, the increased openness of the policy network in China, reflected from the wider accessibility and involvement of the state actors and non- 
state actors, can be positively related with the proactive engagement in promoting policy performance. The aspect of the openness of networks proved to be improved in all three cases, as seen from the fact that since the mid-2000s, local governments and various nonstate actors have been more involved in the policy development, especially at the policy implementation stage. Generally speaking, greater openness of network relations, linked by either market forces or regulative forces, appeared to induce positive policy outcomes and they allowed for pragmatic participation and resource exchange. However, too great an openness of networks may potentially bring higher levels of conflicts, thus eventually weakening efficiency and effectiveness, and add difficulties to consensus-building and cooperation within the network.

Second, under the Chinese unitary political regime, the state actors, especially the central government, play paternalistic roles in the climate change policy making process by setting up initiatives to encourage exchange and cooperation among various players. The Chinese government has established the coordination committee in the late 1980s to integrate relevant policies and coordinate international negotiations and domestic action. To better coordinate the interests of various parties, the State Council has led the coordination committee and promoted energy intensity reduction activities. The strong dominance of central government in the policy making process, on the one hand, facilitates the application and diffusion of carbon emission reduction activities; on the other hand, it limits the full exertion of market forces and induces negative impacts on the formation of authentic voluntary agreements, which are jointly developed and implemented by government and the regulated actors. 
Third, with respect to the emergence and functioning of climate change mitigation policy arrangements, it can be concluded that domestic factors weigh more than international contextual factors and the policy-specific factors. This should not be surprising in that China is still in the process of urbanization and industrialization, and does not accept any obligatory emission reduction commitment unless the developed countries take the lead in doing what it perceives to be their duties. On the other hand, the reforms of Chinese political system have provided more space and freedom for selecting innovative policy instruments and measures, and improving policy effectiveness by valuing policy evaluation and incremental change.

Fourth, although the fragmented authoritarianism model, as a popular policy process model, depicts the impacts of China's decision-making actor network structure on its policy process, it has some difficulties in explaining China's current climate change policy making process, which is characterized by the fact that China has established and continuously been retrofitting its institutionalized policy making system. In the Chinese context, the climate change policy process can be seen as action-oriented, incremental, and heavily relying on trial and error exercises. This is because from a dynamic perspective, policy development is also a learning process as all the involved actors seek to manage conflicts and accumulate experience for achieving goals.

Fifth, with respect to the application of the policy network approach in studying the policy process, it can be concluded that the approach can be used to reflect the institutional features of the Chinese policy making system. Although in general, the Chinese policy structure is fairly hierarchical, the system is adapting to the changes and reshaping influences. The study of the Chinese "policy network" serves as a means to 
investigate how these actors interact and to help explain the dynamics of their functions in the policy development process. Networks exist when the actors have differentiated power and resources and they are dependent on others to reach goals. Of course, the policy network in China has distinctive features. Notably, the policy network approach does not provide the full story of policy development and change. Certain factors such as capacity and cultural features need to be integrated in the study. In addition, given the complexity and randomness of natural events, the causal relations implicit in the policy network model are better to be taken as "probabilistic", rather than "deterministic".

Lastly, it is worth mentioning here that this comprehensive examination of China's climate change mitigation policy development treats policymaking as an interactive and learning process, and the explanation is from a Chinese perspective. As an important determinant of policy processes and changes, policy performance evaluation has a stake in the understanding of policy development. However, no real consensus has been reached as regards the evaluation of China's performance in climate change mitigation policy and action. Because the relevant discussions are mixed with disputes on ethics, equitability, and moral values, it makes an objective evaluation of policy performance very difficult, if not almost impossible. China insists that because of its status as a developing country, priority should be given to development and developed countries should take the lead in terms of mitigation activities. Such a stance and viewpoint has been supported by a majority of Chinese government officials, researchers and the public; however, this viewpoint has been increasingly challenged by other countries. To reconcile the controversy over the evaluation of China's actural policy performance, more international exchange and cooperation is likely to enhance the 
country's mitigative capacity and readiness to be more responsible. Similarly, more indepth analyses of process-oriented policy study, combining theoretical reflections and historical and empirical examinations are needed. In this regard, it is fair to say that this study provides an explanation of China's climate change policy making process with the emphasis more on Chinese viewpoints and is designated to supplement the ongoing discourse in the Western academia.

\subsection{Limitations of the Study}

The research has made a significant step forward in explaining China's climate change mitigation policy development by adopting the policy network approach and employing multiple-case study method. It has contributed to a better understanding of the dynamics of policy making process in contemporary China; however, the following limitations should be pointed out.

First, the study largely relies on the case study approach, and three cases are selected. However, the latter two cases are nested within the first case. Although the CDM project management case and the Top-1000 Program case do deepen our understanding of the policy making process beyond generic national policy arrangements and contribute to the generalization of some important findings, the two cases are not parallel with the first one, making the cross-case comparison lack validity. In addition, with more policies and measures being adopted and implemented, to gain greater access across these specific policy arrangements could have revealed further findings of process features, but could have been impossible with the constraints of time and resources available. 
Second, the policy network analytic framework has been employed to guide the search for empirical evidence in the three cases. Although the adopted framework provides the required structure and direction to address the research questions, it only covers some broad construct factors to simplify the complexity of policy processes, and may lose some other important messages that did not fit the model. As seen from the case studies, the issue of mitigation capacity in China has been neglected, but it is undoubtedly the basis for policy development and decision making. Moreover, the framework is developed as a causal model, which has strong power in making a controlled comparison to draw causal inferences, but it is more preferable to identify the historical juncture point in advance. When the long timeline of policy development is considered, policy outcomes are more often influenced by complicated "historical and institutional" factors that could not be easily identified by the model itself.

Third, in this study, the policy network in the policy-making process is heavily focused on formal relationships among institutional members. In reality, the formal networks among institutions are intertwined with individual networks, such as kinship, colleagueship, and "Guanxi" (personal relationships); and the relationships between network members are not rigid and linked by other strands, depending on specific policy issues. Future research is needed to observe and study how these multi-strand networks are connected, interrelated, and evolved in shaping and influencing policies.

Fourth, compared with Western democracies, the divisions of actors into government, private sector, and civil society in studying a Chinese "network" is not without controversy. How independent are these actors? Doesn't the Chinese government have strong influences on business and civil society? Over-dependence on the 
government makes the analysis of other actors' independent attributes or behaviors (e.g., preference) very difficult. To what extent is or should the actor network be integrated is an unavoidable puzzle that the country continues to address and hopes to solve through its policy reforms.

Lastly, although a series of interviews and site visits have been conducted, the accessibility to high-level officials proved to be difficult and a transparent policy processing system is still lacking and remains a very sensitive issue in China, especially at the decision making stage. Most Chinese interviewees showed their sympathies for China's current active behavior (though they have not been better recognized by the international community), instead of having great interest in discussing the process issues. In the Chinese context, to get access to governmental officials or other key persons, researchers need the ability to build and develop personal relationships and gain their trust. At the same time, the ability to deal with the access problem will also depend on government's willingness in promoting administrative reforms towards more accountability and transparency.

\subsection{Suggestions for Future Research}

China's development is changing itself and influencing the world. To examine China's climate change policy making process, one must go beyond the understanding of "what has happened", but "how" and "why" these have happened in such manners. By doing so, one also provides an empirical case for further understanding the changing political and policy system in China. Although the study generates some useful results, they are not exhaustive, and it opens up a number of future research directions. 
To understand China's climate change policy process not only depends on the theories that link the potential variables, but also requires rigorous empirical evidence to verify relevant theories. Currently, the explanatory functions of using policy network theory need to be strengthened; potential variables that have impact on policy processes need to be identified. On the other hand, the multiplicity and complexity of causes of social phenomena make it difficult to explain with one single approach; therefore, it is important for the policy network approach to combine or complement other explanatory paths.

The analysis of the policy network can be conducted in a quantitative and formal way, and this has induced growing academic interest. In general, such type of analysis, the so-called social network analysis, is descriptive in nature; but it can graphically portray the structures of issue-specific networks based on the collected attribute data of actors. Social network analysis is conductive to the understanding of network structures and interactions, and even the corresponding changes if dynamic model is used; therefore, the method deserves more attention.

One of the foci of the research is on studying the roles and functions of networks. Under the context of global efforts to mitigate climate change impacts, comparative research on mitigation policy formulation and implementation between China and other countries is needed in order to share relevant experiences. In addition, more thorough research on comparing the outcomes of different policy arrangements deserves further attention.

Another interesting topic remaining for further research is the issue of climate change governance, which has been heatedly discussed in recent years. Governance 
addresses the "interrelated and increasingly integrated system of formal and informal rules, rule-making systems, and actor networks at all levels of human society (from local to global)" (Biermann et al. 2009). This study of China's climate change mitigation policy process has great relevance for the governance study. Among other things, one of the major difficulties in governance study is that, unlike many Western developed countries, China is a moving target, a state undertaking radical changes. Therefore, further research on governance is needed to reflect the dynamics of the political regime and the changes within the state and the society. 


\section{LIST OF REFERENCES}

Abele, C. (2007), CDM Market Brief: P. R. China. DEG-Bfai. February 2007.

Adam, S. and Kriesi, H. (2007), The Network Approach. In Sabatier, P. ed. Theories of Policy Process. Ashgate Publishing, pp. 129-154.

Aldy, J. and Stavins, R. (2007), Introduction: international policy architecture for global climate change, in Aldy, J. and Stavins, R. ed., Architecture for agreement: addressing global climate change in the post-Kyoto world, Cambridge University Press.

Andrews-Speed, C.P. (2004), Energy Policy and Regulation in the People's Republic of China, Hague: Kluwer Law International.

Andrews-Speed, C.P. (2009), China's ongoing energy efficiency drive: origins, progress and prospects, Energy Policy, 37(4): 1337-1344.

Asia-Pacific Partnership (APP) (2010), About the Asia-Pacific Partnership on Clean Development \& Climate. Available at: http://www.asiapacificpartnership.org/english/about.aspx.

Baumgartner, F. and Jones, B. (1993), Agendas and Instability in American Politics. Chicago: University of Chicago Press.

BBC (2009), China Seeks Export Carbon Relief. Available at: http://news.bbc.co.uk/2/hi/7947438.stm.

Berry, F., Brower, R., Choi, S., Gao, W., Jang, H., Kwon, M., and Word, J. (2004), Three traditions of network research: what the public management research agenda can learn from other research communities. Public Administration Review, 64 (5): $539-552$.

Bhandari P. (2003), Is the euphoria over CDM unwarranted? The Financial Express. Available at: http://www.financialexpress.com/news/story/73475/.

Biagiotti, I. (2002), Corporate Actors and Environment and Trade Governance: Challenging Alliances and Norms Setting Processes. Available at: http://www.ecologic-events.de/sustra/en/documents/IsabelleBiaggiotti.pdf.

Biermann, F., Betsill, M., Gupta, J., Kanie, N., Lebel, L., Lerman, D., Schroeder, H. and Siebenhuener, B. (2009), Earth System Governance: People, Places, and the Planet. Science and Implementation Plan of the Earth System Governance Project. Earth System Governance Report 1, IHDP Report 20. Bonn, IHDP: The Earth System Governance Project. 
Birkland, T. (2001), An Introduction to the Policy Process: Theories, Concepts, and Models of Public Policy Making. Armonk: M.E. Sharpe.

Bjørkum, I. (2005), China in the International Politics of Climate Change: A Foreign Policy Analysis. The Fridtjof Nansen Institute. Available at: www.fni.no/doc\&pdf/FNI-R1205.pdf.

Borzel, T. (1998), Organizing Babylon - on the different conceptions of policy networks, Public Administration, 76: 253- 273.

Brown, K. (2010), The Power Struggle among China's Elite. Foreign Policy. Available at: http://www.foreignpolicy.com/articles/2010/10/14/the power_struggle_among_c hinas elite?page $=0,1$.

Burtraw, D. and Toman, M. (2001), "Ancillary benefits" of greenhouse gas mitigation policies. In Toman M. ed. Climate Change Economics and Policy: An RFF Anthology. Washington D.C.: RFF Press.

CCChina (2002), Views on experience with the pilot phase of Activities Implemented Jointly submitted by China. Available at: http://www.ccchina.gov.cn/en/NewsInfo.asp?NewsId=5365.

CCPO (Climate Change Project Office) (2004), The Joint Implementation and Clean Development Mechanism Processes Explained, DTI, UK.

CD4CDM (2010), CDM/JI pipeline analysis and database, March 1, 2010. UNEP Riseo Center. Available at: http://cdmpipeline.org/publications/CDMpipeline.xls.

ChinaDaily (2010), Tackling climate change 'urgent,' Hu says. China Daily (February 24, 2010). Available at: http://www.chinadaily.com.cn/china/201002/24/content 9492163.htm.

China News (2010), The Standing Committee of the National People's Congress strengthens economic legislation work to Address Climate Change Challenge. Available at: http://www.china.com.cn/news/2010-03/09/content 19568000.htm.

China5e (2010), Hong Kong Enterprises Can enter Mainland to develop CDM projects. Available at: http://www.china5e.com/show.php?contentid=114651 (in Chinese).

Cochran, C., and Malone, E. (1995), Public policy: Perspectives and Choices. New York: McGraw Hill.

Cochran, C., Mayer, L., Carr, T., and Cayer, N. (1999), American Public Policy: An Introduction (7th ed.). Belmont, CA: Wadsworth. 
Coleman, W. and Perl, A. (1999), Internationalized policy environments and policy network analysis, Political Studies, 47(4): 691-709.

Coleman, W., Skogstad, G. and Atkinson, M. (1997), Paradigm shifts and policy networks: cumulative change in agriculture, Journal of Public Policy, 16 (3): 273301.

Compston, H. (2009), Policy Network and Policy Change: Putting Policy Network Theory to the Test. London: Palgrave Macmillan.

Constantin, C. (2007), Understanding China's Energy Security. World Political Science Review, 3(3): 1-30.

Corfee-Morlot, J., Kamal-Chaoui, L., Donovan, M., Cochran, I., Robert, A., and Teasdale, P. (2009), "Cities, Climate Change and Multilevel Governance", OECD Environmental Working Papers No.14, 2009, OECD publishing, OECD.

Cowles, M., Caporaso, J. and Risse, T. (2001), Transforming Europe: Europeanization and Domestic Change. Ithaca NY: Cornell University Press.

Creswell, J. (2007), Qualitative Inquiry and Research Design: Choosing Among Five Approaches (Second Edition). Thousand Oaks, CA: Sage Press.

Crotty, M. (1998), The Foundations of Social Research. Thousand Oaks, CA: Sage Press.

Dean, K. (1993), Taoist Ritual and Popular Cults in Southeast China. Princeton, NJ: Princeton University Press.

Dowding, K. (1995), Model of Metaphor? A Critical Review of the Policy Network Approach. Political Studies. 43(1): 136-158.

Dowding, K. (2001), There Must be End to Confusion: Policy Networks, Intellectual Fatigue, and the Need for Political Science Methods Courses in British universities. Political Studies. 49(1): 89-105.

Downie, D., Brash, K. and Vaughan, C. (2009), Climate Change: A Reference Handbook. Santa Barbara, California: ABC-CLIO.

Downs, E. (2008), China's "New" Energy Administration. China Business Review, November-December.

Downs, E. (2010), China's Energy Rise, in Womack, B. (eds.) China's Rise in Historical Perspective. New York: Rowman and Littlefield. 
Dreyer, J. (2006), China's Political System: Modernization and Tradition (Fifth Edition). New York: Pearson/Longman Press.

Duan, M. (2008), Assessment of experience and expectations for the future, in Olsen and Fenhann (eds.) A reformed CDM- including new mechanisms for sustainable development. UNEP Riseo Center.

Dye, T. (2002), Understanding Public Policy. Upper Saddle River: Prentice-Hall.

Dye, T. (2005), Understanding Public Policy (11th edition). Upper Saddle River: Prentice-Hall.

Earth Negotiations Bulletin (1995), "Summary of the First Conference of the Parties to the UN Framework Convention on Climate Change", Vol. 12, No. 21.

Earth Negotiations Bulletin (1996), "Summary of the Second Conference of the Parties to the UN Framework Convention on Climate Change", Vol. 12, No. 38.

Earth Negotiations Bulletin (1997), "Summary of the Third Conference of the Parties to the UN Framework Convention on Climate Change", Vol. 12, No. 76.

Easton, D. (1965), A System analysis of Political Life. New York: John Wiley Press.

Economy, E. (1997), "Chinese policy-making and global climate change: two-front diplomacy and the international community", in M. A. Schreurs and E. Economy (eds.): The Internationalization of Environmental Protection. Cambridge: Cambridge University Press, pp. 19-41.

EEA (2005), Greenhouse Gas Emission Trends and Projections, European Environmental Agency.

EIA (Energy Information Administration) (2010), Carbon Intensity Data. Available at: http://www.eia.doe.gov/emeu/international/carbondioxide.html.

Eichhorst, U. and Bongardt, D. (2009), Towards cooperative policy approaches in China - Drivers for voluntary agreements on industrial energy efficiency in Nanjing, Energy Policy, 37(2): 1855-1865.

Eisenhardt, K. (1989), Building theories from case study research, The Academy of Management Review, 14(4): 532-550.

ERI (Energy Research Institute) (2009), Improvement of CDM Policies in China, EUChina CDM Facilitation Project. Available at: http://www.euchinacdm.org/media/docs/Improvement\%20of\%20CDM\%20Policies\%20in\%20China EU\%20China\%20CDM\%20Facilitation\%20Project.pdf. 
European Union (2005), EU Emission Trading, An open scheme promoting global innovation to combat climate change, European Communities

Foster, K. (2008), Embedded within State Agencies: Business Associations in Yantai. in J. Unger ed., Associations and the Chinese State: Contested Spaces. Armonk, NY: M. E. Sharpe.

Fraenkel, J. and Wallen, N. (2009), How to Design and Evaluate Research in Education (Seventh Edition). Boston: McGraw-Hill Higher Education.

Frolic, B. M. (1997), State-Led Civil Society, in T. Brook and B.M. Frolic (eds). Civil Society in China, Armonk, NY: M. E. Sharpe.

Gallagher, K. (2007), China needs help with climate change. Belfer Center for Science and International Affairs. Cambridge: Harvard University.

Ganapati, S. and Liu, L. (2008), "The clean development mechanism in China and India: A comparative institutional analysis", Public Administration and Development, 28 (5): 351-362.

George, A. and Bennett, A. (2005), Case Studies and Theory Development in the Social Sciences. Cambridge: MIT Press.

Gerring, J. (2004), What is a case study and what is it good for? American Political Science Review, 98 (2): 341-354.

Gerson, (2004), Public Policy Making: Process and Principles. Armonk, N.Y.: M. E. Sharpe.

Glaser, B. and Strauss, A. (1967), The Discovery of Grounded Theory: Strategies for Qualitative Research. Chicago: Aldine Publishing.

Gupta, D. (2001), Analyzing Public Policy: Concepts, Tools, and Techniques. Washington D.C.: CQ Press.

Hall, D. (2007), Offsets: Incentivizing Reductions While Managing Uncertainty and Ensuring Integrity, in Assessing U.S. climate policy potions, Washington D.C.: RFF Press.

Harris, P. G. and Yu, H. (2005), "Environmental change and the Asia Pacific: China responds to global warming". Global Change, Peace \& Security: formerly Pacifica Review: Peace, Security \& Global Change, 17(1): 45-58. 
He, J., Liu, B., Chen, Y. et al. (2007), "China's National Assessment Report on Climate Change (III): integrated evaluation on policies of China responding to climate change", Advances in Climate Change Research. 3 (Suppl.): 12-18.

Heggelund, G. (2007), China's Climate Change Policy: Domestic and International Developments. Asian perspective, 31 (2): 155-191.

Heggelund, G. and Beacker, E. (2007), China and UN Environmental Policy: Institutional Growth, Learning and Implementation. International Environmental Agreements, 7 (4): 415-438.

Hochman, G. and Zilberman, D. (2010), Trade and the Environment. Available at: http://www.wto.org/english/res_e/publications_e/wtr10_forum_e/wtr10_21july10 e.htm.

Hu, J. (2007), Hold high the great banner of Socialism with Chinese characteristics and strive for new victories in building a moderately prosperous Society, Report to the Seventeenth National Congress of the Communist Party of China on Oct. 15, 2007. Available at: http://www.china.org.cn/english/congress/229611.htm.

Hu, J. (2009), Chinese president calls for int'l efforts to address climate change. Available at: http://za.china-embassy.org/eng/zt/cc/t605841.htm.

Hu, Y. (2007), Implementation of voluntary agreements for energy efficiency in China, Energy Policy, 35 (11): 5541-5548.

Hudson, J. and Lowe, S. (2004), Understanding the Policy Process: Analyzing Welfare Policy and Practice. The Policy Press.

IEA (International Energy Agency) (2010), Climate change policies and measures in China. Available at: http://www.iea.org/textbase/pm/?mode=cc\&action=view\&country=China.

Institute for Global Environmental Strategies (IGES) (2005), China chapter. Asian Perspective on Climate Regime Beyond 2012: Concerns, Interests and Priorities. Hayama: IGES Publication.

IPCC (Intergovernmental Panel on Climate Change) (2001), The Third Assessment Report (TAR). Available at: http://www.ipcc.ch/publications and data/ar4/wg2/en/tssts-1.html.

IPCC (Intergovernmental Panel on Climate Change) (2007), Climate Change 2007. The Physical Science Basis. Cambridge: Cambridge University Press. 
Johnson, K. (2009), Export Duties: Chinese Factories, Greenhouse-Gas Emissions, and the West, May 28, 2009, The Wall Street Journal. Available at:

http://blogs.wsj.com/environmentalcapital/2009/05/28/export-duties-chinesefactories-greenhouse-gas-emissions-and-the-west/.

Jones, C. (1970), An Introduction to the Study of Public Policy. Belmont, CA: Wadsworth.

Jost, G. and Jacob, K. (2004), The climate change policy network in Germany, European Environment, 14 (1): 1-15.

Kan, F. (2008), Top-1000 Enterprises Energy Saving Project in China, UN Energy Conference presentation. Available at: https://www.unido.org/fileadmin/user_media/Services/Energy_and_Climate_Cha nge/EPU/TOP1000_UN_Energy_FloraKan.pdf.

Katzenstein, P. (1978), Conclusion: Domestic structures and strategies of foreign economic policy. In Katzenstein, P. ed., Between Power and Plenty: Foreign Economic Policies of Advanced Industrial States. Madison, WI: University of Wisconsin Press, pp. 295-336.

Kaupp, A., H. Liptow, and A. Michaelowa. (2002), CDM is not about subsidies - it is about additionality, Energise, 1(3): 8-9.

Kenis, P. (1991), The preconditions for policy networks: Some findings from a threecountry study on industrial restructuring, In Bernd Martin and Renate Mayntz, eds., Policy Networks: Empirical Evidence and theoretical considerations, Frankfurt/Boulder, CO: Campus/Westview Press. pp. 297-330.

Kennedy, S. (2008), The Price of Competition: The Failed Government Effort to Use Associations to Organize China's Market Economy. in J. Unger ed., Associations and the Chinese State: Contested Spaces. Armonk, NY: M.E.Sharpe.

Kingdon, J. (1995), Agendas, Alternatives and Public Policies (Second Edition). New York: Harper Collins.

Knoke, D. (1990), Political Networks: The Structural Perspective. New York: Cambridge University Press.

Knoke, D., Broadbent, F. and Tsujinaka, Y. (1996), Comparing Policy Networks: Labour Politics in the US, Germany and Japan, Cambridge: Cambridge University Press.

Leggett, J., Logan, R. and Mackey, A. (2008), China's Greenhouse Gas Emissions and Mitigation Policies, Congressional Research Service. 
Lema, A. and ruby, K., (2007), Between fragmented authoritarianism and policy coordination: creating a Chinese market for wind energy, Energy Policy, 35 (7): 3879-3890.

Levine, M. and Aden, N. (2008), Global Carbon Emission in the Coming Decades: The Case of China, Lawrence Berkeley National Laboratory.

Lewis, J., Logan, J., and Cummings, M. (2010), Understanding the Climate Challenge in China. In Schneider, S., Rosencranz, A., Mastrandrea, M. and Kuntz-Duriseti. (ED.) Climate Change Science and Policy. Island Press.

Li, C. (2005), One Party, Two Factions: Chinese Bipartisanship in the Making? Paper Presented at the Conference on "Chinese Leadership, Politics, and Policy", Carnegie Endowment for International Peace, November 2, 2005.

Li, L. (2007), Interview. In Chong W. China Rejects Emissions Caps in Climate Plan. Available at: http://www.scidev.net/en/climate-change-and-energy/news/chinarejects-emissions-caps-in-climate-plan.html.

Lieberthal, K., and Oksenberg, M. (1988), Policy Making in China: Leaders, Structures, and Processes. Princeton: Princeton University Press.

Lieberthal, K. (1992), The "fragmented authoritarianism" model and its limitations. In K. Lieberthal and D. Lampton (eds.) Bureaucracy, Politics, and Decision Making in Post-Mao China, Berkley: University of California Press, pp. 1-30.

Lieberthal. K. (2004), Governing China: From Revolution through Reform (Second Edition). New York/London: W.W. Norton \& Company.

Liefferink, D., Andersen, M. and Enevoldsen, M. (2000), Interpreting joint environmental policy-making: between deregulation and political modernization, in Mol, A., Lauber, V. and Liefferink, D. (Ed.), The Voluntary Approach to Environmental Policy: Joint Environmental Policy-making in Europe. Oxford: Oxford University Press, pp.1-9.

Liu, J. and Yi, S. (2009), Interview with Hu Angang about how China's climate-change policy is formed, and how it can change, China Dialogue. Available at: http://www.chinadialogue.net/article/show/single/en/3210.

Liu, L. (2010), Exploring the voluntary approach in China: the case of the Top-1000 Industrial Energy Conservation Program. Journal of Knowledge-based Innovation in China, 2(3): 283-298. 
Lloyd, B. and Subbarao, S. (2009), Development challenges under the clean development mechanism (CDM) - can renewable energy initiatives be put in place before peak oil? Energy Policy, 37(1): 237-245.

Long, N. and Long, A. (1992), Battlefields of knowledge: the interlocking of theory and practice in social research and development. New York: Routledge.

Lynn, L., Heinrich, C. and Hill, C. (2000), Studying governance and public management: why? how?, in Heinrich, C. and Lynn, L. (Eds), Governance and Performance: New Perspectives, Georgetown University Press, Washington, DC., pp.1-33.

Marsh, D. and Rhodes, R. A. W. (1992), Policy Networks in British Government. Oxford: Clarendon Press.

Marsh, D. and Smith, M. (2000), "Understanding policy networks: towards a dialectical approach”, Political Studies, 48(1): 4-21.

Mertha, A. (2008), “'Fragmented Authoritarianism 2.0': Political Pluralization in the Chinese Policy Process. Available at: http://falcon.arts.cornell.edu/am847/pdf/FA_2.0.1.pdf.

Metz, B., Davidson, O., Bosch, P., Dave, R., and Meyer, L. (2007), Contribution of Working Group III to the Fourth Assessment Report of the Intergovernmental Panel on Climate change, 2007. Cambridge: Cambridge University Press.

Michaelowa, A. (2002), The AIJ pilot phase as laboratory for CDM and JI. International Journal of Global Environmental Issues, 2 (3): 260-287.

Michaelowa, A. (2007), Graduation and deepening. in Aldy, J. and Stavins, R. ed., Architecture for agreement: addressing global climate change in the post-Kyoto world, Cambridge University Press.

MOFA (Ministry of Foreign Affairs) (2002), Views on Experience with the Pilot Phase of Activities Implemented Jointly Submitted by China. Available at: http://www.ccchina.gov.cn/en/NewsInfo.asp?NewsId=5365.

Mol, A., Liefferink, D. and Lauber, V. (2000), Introduction, in Mol, A., Lauber, V. and Liefferink, D. (Ed.), The Voluntary Approach to Environmental Policy: Joint Environmental Policy-making in Europe. Oxford University Press, Oxford, pp.1-9.

Morgenstern, R. and Pizer, W. (2007), "Concluding observations: what can we learn from the case studies?" in Morgenstern, R. and Pizer, W. (Ed.), Reality Check: The Nature and Performance of Environmental Programs in the United States, Europe and Japan, Resources For the Future (RFF)Press, Washington D.C. pp166-186. 
National Development and Reform Commission (NDRC) (2006), "Notice of implementing the Top-1000 Enterprises Energy Conservation Program Action Plan". Available at: http://hzs.ndrc.gov.cn/newzwxx/t20060413 66111.htm (in Chinese).

NBS (National Bureau of Statistics) (2010), Chinese Statistical Yearbook. Available at: http://www.stats.gov.cn/english/statisticaldata/yearlydata/.

NDRC (National Development and Reform Commission) (2004), The People's Republic of China initial national communication on climate change. Available at: http://www.ccchina.gov.cn/file/en source/da/da2004110901.pdf.

NDRC (2004b), Interim Measures for Operation and Management of CDM Projects in China.

NDRC, 2005. Measures for Operation and Management of CDM Projects in China.

NDRC (National Development and Reform Commission) (2007), National climate change program. Available at:

www.ccchina.gov.cn/WebSite/CCChina/UpFile/File188.pdf.

NDRC and NBS (2007), Report on the state of the energy use of the Top-1000 Enterprises. Available at: http://www.eri.org.cn/manage/englishfile/80-2007-1011-804695.pdf (in Chinese).

NDRC (2009), Notice of Evaluation Result of the Top-1000 Program. Available at: http://www.sdpc.gov.cn/zcfb/zcfbgg/2009gg/t20091124 315017.htm (in Chinese).

Nordhaus, W. and J. Boyer (2000), Warming the World: Economic Models of Global Warming. Cambridge, MA: MIT press.

Nordqvist, J. (2007), Reining China's industrial energy - challenges of promoting expedient measures in a Chinese actor environment, Energy Policy, 35 (6): 32703279.

NPC (National People's Congress) (2009), Resolution of the Standing Committee of the National People's Congress on Making Active Responses to Climate Change. $A$ vailable at: www.npc.gov.cn.

Ostrom, E. (1990), Governing the Commons: The Evolution of Institutions for Collective Actions. Cambridge: Cambridge University Press.

Pang, J. and Zou, J. (2008), China: Climate change policy-making process. In Kameyama, Y., Sari, A. Soejachmoen, M. and Kanie, N. ed., Climate Change in Asia: 
Perspectives on the Future Climate Regime. Tokyo: United Nations University Press.

Peng, B. (2003), The policy process in contemporary China: mechanisms of politics and government, in Finer, C. (Ed.), Social Policy Reform in China: Views from Home and Abroad, Aldershot: Ashgate, pp. 37-50.

Perry, E. and Selden, M. (2000), China Society: Change, Conflict, and Resistance (Second Edition), New York, NY: RoutledgeCurzon.

Peters, B. G. (1999), American Public Policy: Promise and Performance. New York, NY: Chatham House/Seven Rivers.

Pew Center. (2007), Climate Change Mitigation Measures in the People's Republic of China. Available at: http://www.pewclimate.org/international/brief/chinamitigation/042007.

Price, L. (2005), Voluntary agreements for energy Efficiency or GHG emissions reduction in industry: an assessment of programs around the world, in Proceedings of the 2005 ACEEE Summer Study on Energy Efficiency in Industry, New York. Available at: http://ies.lbl.gov/iespubs/58138.pdf.

Price, L. and Wang, X. (2007), Constraining energy consumption of China's largest industrial enterprises through the Top-1000 Energy-Consuming Enterprise Program, 2007 ACEEE Summer Study on Energy Efficiency in Industry, New York. Available at: http://ies.lbl.gov/iespubs/LBNL-62874.pdf.

Price, L., Wang, X. and Jiang, Y. (2008), China's Top-1000 Energy-Consuming Enterprises Program: reducing energy consumption of the 1000 largest industrial enterprises in China. Available at: http://ies.lbl.gov/iespubs/LBNL-519E.pdf.

Price, L., Wang, X. and Jiang, Y. (2010), The challenge of reducing energy consumption of the top-1000 largest industrial enterprises in China, Energy Policy, 38 (11): 6485-6498.

Pye, L. (1992), The Spirit of Chinese Politics, Cambridge: Harvard University Press.

Qi, Y., Ma, L. and Zhang, H, and Li, H. (2008), Translating a global issue into local priority, The Journal of Environment \& Development, 17 (4): 379-400.

Qi, Y., Ma, L. and Zhang, L. (2007), Climate change governance in China: a case study, China Population, Resources and Environment, 17(2): 8-12. 
Ragin, C. (2005), Turning the Tables: How Case-Oriented Research Challenges VariableOriented Research. In Brady, H. and Collier D. ed. Rethinking Social Inquiry: Diverse Tools, Shared Standards. Rowman \& Littlefield Publishers, Inc.

Raustiala, K. (2001), Nonsate actors in the global climate regime, in Luterbacher, U. and Sprinz, D. (Ed.), International relations and Global Climate Change, Cambridge: The MIT Press, pp. 95-117.

Richardson, J. (2000), Government, Interest Groups and Policy Change. Political Studies, 48 (5): 1006-1025.

Richerzhagen, C. and Scholz, I. (2007), China's capacities for mitigating climate change. World Development, 36 (2): 308-324.

Sabatier, P. (1988), An advocacy coalition framework of policy change and the role of policy-oriented learning therein. Policy Science, 21: 129-168.

Sabatier, P. (2007a), The need for better theories. In Sabatier, P. ed. Theories of Policy Process. Boulder: Westview Press, pp 3-17.

Sabatier, P. (2007b), Fostering the development of policy theory. In Sabatier, P. ed. Theories of Policy Process. Boulder: Westview Press, pp. 321-336.

Saich, T. (2004), Governance and Politics of China (Second Edition). New York: Palgrave Macmillan.

Salamon, L, and Lund, M. (1989), The Tools Approach: Basic Analytics. In Salamon, L. ed. Beyond Privatization: The Tools of Government Action. Washington D.C.: Urban Institute Press.

Saner, R. (2005), Hype or Reality: Can the CDM Trigger FDI? ECP Background Paper.

Schlager, E. (2007), A comparison of frameworks, theories and models of policy process. In Sabatier, P. ed. Theories of Policy Process. Boulder: Westview Press, pp 293319.

Schroeder, M. (2009), Varieties of carbon governance: utilizing the Clean Development Mechanism for Chinese priorities, The Journal of Environment Development, 18 (4): 371-394.

Seligsohn, D. (2010), China's System for Measuring, Monitoring, and Reporting Energy and Climate Data. Available at: http://www.chinafaqs.org/library/testimonydeborah-seligsohn-congressional-executive-commission-china-april-1-2010. 
Seres, S. (2007), Analysis of technology transfer in CDM projects. Report prepared for the UNFCCC Registration \& Issuance Unit CDM/SDM. Final Report.

Simon, H. (1955), A behavior model of rational choice, Quarterly Journal of Economics, 69 (1): 53-67.

Sinton, J.E. (2006), China's quest for energy efficiency: its Top-1000 Enterprises Program. Available at: http:/www.iea.org/work/2006/gb/papers/ChinaQuest.pdf.

Stake, R. (1995). The Art of Case Study Research. Thousand Oaks, CA: Sage Press.

State Council (2008), China's Policies and Actions for Addressing Climate Change. Available at: http://www.gov.cn/english/2008-10/29/content 1134544.htm.

State Council (2010), Notice of strengthening efforts to ensure the achievements of the 11th Five Year Plan targets. Available at: http://www.gov.cn/zwgk/201005/05/content_1599897.htm (in Chinese).

Szymanski, T. (2002), Clean Development Mechanism in China. China Business Review, November-December 2002.

Thacher, M. (1998), The development of policy network analysis. Journal of Theoretical Politics, 10 (4): 389-416.

Tiempo (1997), Climate change activities in China, Issue 25. Available at: http://www.tiempocyberclimate.org/portal/archive/issue25/index.htm\#RETURN.

Tu J. (2009), Future prospects of China's policy on climate change, China Brief, 9 (1).

UNEP (2004), CDM Information and Guidebook (Second edition), UNEP Riseo Center, 2004.

Unger, J. and Chan, A. (2008), Associations in a bind: the emergence of political corporatism, in J. Unger ed., Associations and the Chinese State: Contested Spaces, Armonk, NY: M. E. Sharpe.

Van Warrden, F. (1992), Dimensions and types of policy networks. European Journal of Political Research, 21(1): 29-52.

Victor, D. (2004), Climate Change: Debating America's Policy Options, Council on Foreign Relations.

Walder, A. (1986), Communist Neo-Traditionalism: Work and Authority in Chinese Industry. Berkley and Los Angeles: University of California Press. 
Wang, S. (2006), Agenda setting modes in China's public policy process. Social Sciences in China, Issue 5.

Wang, X. (2006), Top-1000 Enterprises Energy Conservation Action in China: An Introduction. Available at: http://www.iea.org/work/2006/indicators apr26/Wang China.pdf.

Wang, T. (2008), Who Owns China's Carbon Emission? Some Thoughts on Consumption Based Accounting, Presentation at the International Roundtable on Consumptionbased Nation-State Carbon Accounting.

Watson, A. (2008), Civil society in a transitional state. In J. Unger ed., Associations and the Chinese State: Contested Spaces. Armonk, NY: M. E. Sharpe.

Weber, C., Peters, G., Guan, D. and Hubacek, K. (2008), The contribution of Chinese exports to climate change, Energy Policy, 36(9): 3572-3577.

Wiener, J. (2007), Climate change policy and policy change in China, UCLA Law Review, 55(6): 1805-1826.

Willems, S. and Baumert, K. (2003), Institutional Capacity and Climate Actions, Available at: http://www.oecd.org/dataoecd/46/46/21018790.pdf.

Williams, T. (2007), International Cooperation on Climate Change Outside of the Kyoto Protocol. Available at: http://www.parl.gc.ca/information/library/PRBpubs/prb0730-e.htm.

World Bank (2004), Clean Development Mechanism in China - Taking Proactive and Sustainable Approach, World Bank.

World Resources Institute (WRI) (2006), Top-1000 Enterprises Energy Conservation Action in China. Available at: http://projects.wri.org/sd-pams-database/china/top1000-enterprises-energy-conservation-action-china.

Wu, F. (2003), Environmental GONGO autonomy: unintended consequences of state strategies in China. The Good Society, 12 (1): 34-45.

WWF (World Wildlife Fund) (2008), The Value of Carbon in China: Carbon Finance and China's Sustainable Energy Transition. Washington D.C.

Xie, Z. (2010), Emissions reduction goal will be decomposed in the 12th Five Year Plan. Available at: http://www.022net.com/2010/9-30/475436403066673.html (in Chinese). 
Yang, H. (2010), Personal Interview at the CDM Capacity Development Workshop in Beijing. January 30, 2010.

Yu, H. (2008), Global Warming and China's Environmental Diplomacy. New York: Nova Science Publishers.

Zhang, Z. (2005), Towards an effective implementation of CDM projects in China. Energy Policy, 34 (18): 3691-3701.

Zhao, H. (2002), Political Regime of Contemporary China. Lanham, Maryland: University Press of America.

Zheng, H., Jong, M. and Koppenjan, J. (2010), Applying policy network theory to policymaking in China: the case of urban health insurance reform, Public Administration, Vol. 88 (2): 398-417.

Zhou, X. and Mori, H. (2008), Institutional change in Asia in response to climate change, in IGES Whitepaper Climate Change Policies in the Asia-Pacific: Re-Uniting Climate Change and Sustainable Development, IGES, pp. 185-219. 


\section{VITA}

\section{LIGUANG LIU}

1995

2001

1995-2001

1999-2001

$2002-2004$

2006

2008

2011
B.S., Applied Mathematics

Liaoning University

Shenyang, China

MBA, General Management

Northeastern University

Shenyang, China

Researcher

Institute of Economic Research

Liaoning Provincial Development and Reform Commission

Shenyang, China

Research Associate

Project Coordinator

Energy Management Office

EU-China Liaoning Integrated Environmental Program (LIEP)

Shenyang, China

Economy and Information Institute

Chinese Academy of Coal Sciences (CACS)

Beijing, China

M.S., Environmental Policy

Roskilde University

Roskilde, Denmark

Spofford Summer Intern

Resources for the Future

Washington, D.C., USA

Candidate, Public Administration

Florida International University, Miami, USA.

Major: Public Affairs. 


\section{PUBLICATIONS AND PRESENTATIONS}

Liguang Liu. "Network Development in China's Climate Change Governance". Capacity Building Workshop on Carbon Governance in Asia: Bridging Scales and Disciplines. Yokohama, Japan, November 1-3, 2010.

Liguang Liu. (2010). Exploring the voluntary approach in China: the case of the Top1000 Industrial Energy Conservation Program. Journal of Knowledge-based Innovation in China. 2(3). 283-298.

Liguang Liu. (2010). Developing Climate Policy in Coastal Cities: Lessons Learned from Miami-Dade County in the USA. In Dutta, D. and Wright, W. (eds.) Proceedings of the International Symposium on Coastal Zones and Climate Change: Assessing the Impacts and Developing Adaptation Strategies, April 12 - 13, 2010, Monash University, Australia. [CD Disk]. 315-322.

Liguang Liu. "Clean Development Mechanism (CDM) in China: Building an Action Network". Midwest Political Science Association (MPSA) Annual National Conference. Panel 49-10. Chicago, USA. April 22-25, 2010.

Liguang Liu. "Climate Change and Public Health in Miami Metropolitan Area". Scientific Workshop on Environmental Change and Health Security in Beijing-Tianjin Urban Area- Vulnerability and Vulnerable Groups. Ministry of Science and Technology. Beijing, China. November 19-26, 2009.

Sukumar Ganapati and Liguang Liu. (2009) Sustainable development in the Clean Development Mechanism: the role of Designated National Authority in China and India. Journal of Environmental Planning and Management. 52(1).43-60.

Sukumar Ganapati and Liguang Liu. (2008). Clean Development Mechanism in China and India: A comparative institutional analysis. Public Administration and Development. 28(5). 351-362.

Liguang Liu. "Potential and Prospects of Clean Development Mechanism (CDM) in China." The 17th Global Warming International Conference and Expo (GW17), Miami, USA. April 20-22, 2006

Liguang Liu and Yong Liu. (2003). Energy policies for sustainable development in China. Proceedings of the EnerEnv' 2003 Conference. Science Press New York Ltd. 19-24. 